\title{
Synthesis and Cytotoxicity Studies of Bioactive
}

\author{
Benzofurans from Lavandula agustifolia and
}

\section{Modified Synthesis of Ailanthoidol, Homoegonol,}

\section{and Egonol}

Aneesh Sivaraman, ${ }^{\dagger}$ Jin Sook Kim, ${ }^{\ddagger}$ Dipesh S. Harmalkar, ${ }^{\dagger}, \S$ Kyoung ho Min, ${ }^{\dagger}$ Joong-Won Park, ${ }^{\neq}$Yongseok Choi, ${ }^{\S}$ Kyungtae Kim, ${ }^{*, ~}$ " and Kyeong Lee*, ${ }^{\dagger}$

${ }^{\dagger}$ College of Pharmacy, Dongguk University-Seoul, Goyang, 10326, Republic of Korea.

${ }^{\ddagger}$ Division of Clinical Research, Research Institute, National Cancer Center, Goyang 10408,

Republic of Korea

${ }^{\S}$ College of Life Sciences and Biotechnology, Korea University, Seoul, 02841, Korea Republic of Korea.

"Division of cancer research, Research institute, National Cancer Center, Goyang 10408, Republic of Korea 


\section{Supporting Information}

\section{Table of Contents}

Cell viability assay.

${ }^{1} \mathrm{H}$ NMR and ${ }^{13} \mathrm{C}$ NMR spectra of compounds.

S6-S65

HR-ESIMS of compounds 1-8

S66-S73

HPLC of compounds 1-8

S74-S77 
Figure S1

\section{A}

MCF-7
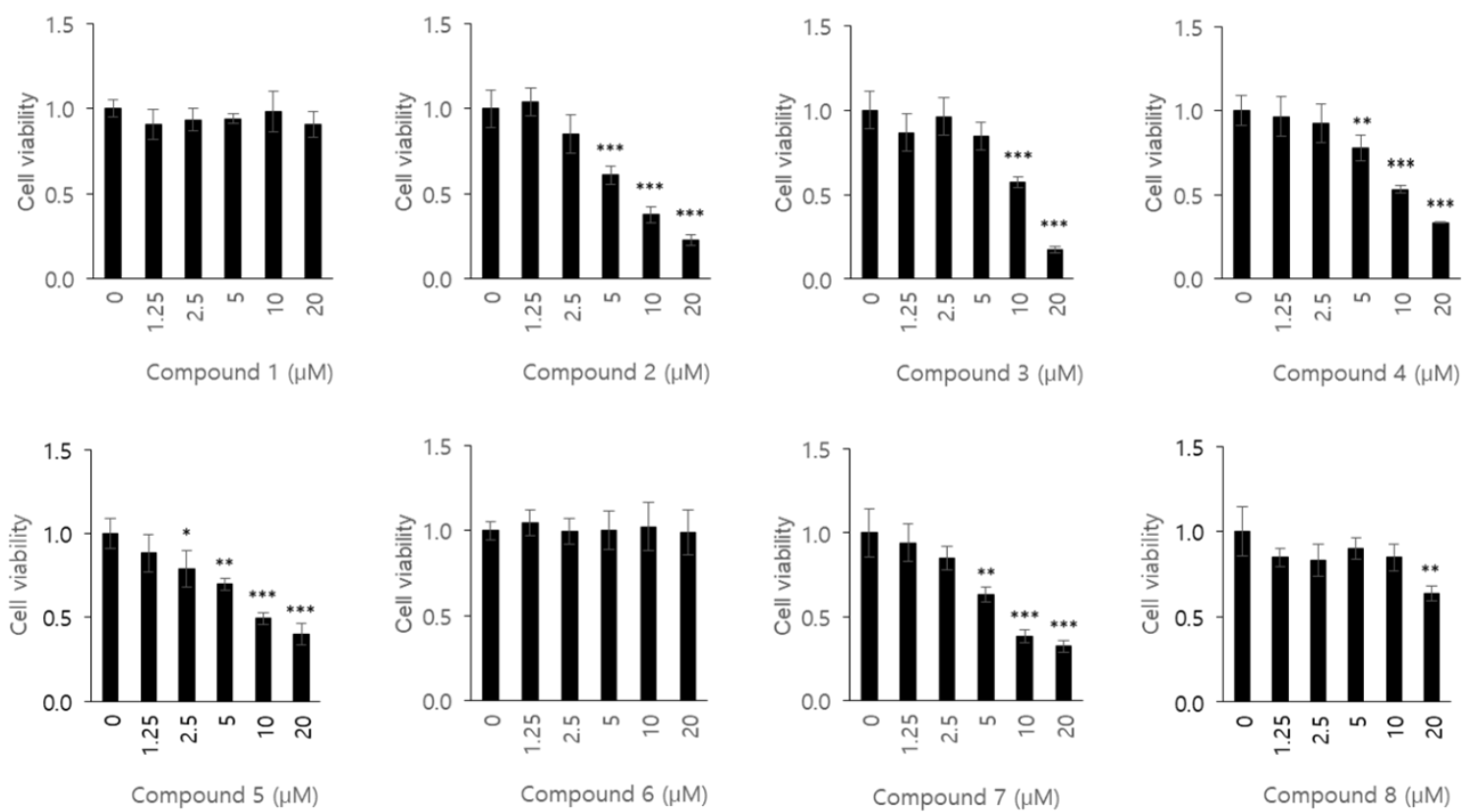

\section{B}

A549

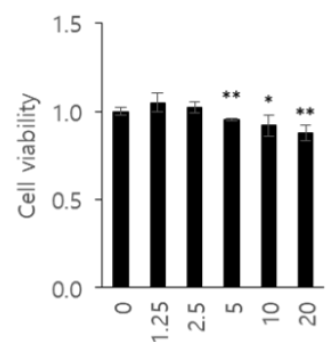

Compound $1(\mu \mathrm{M})$

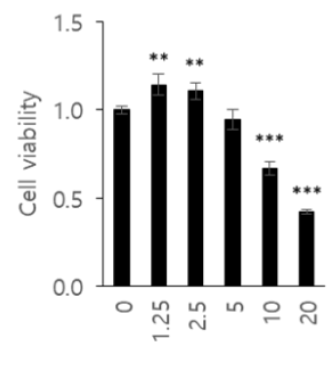

Compound $5(\mu \mathrm{M})$

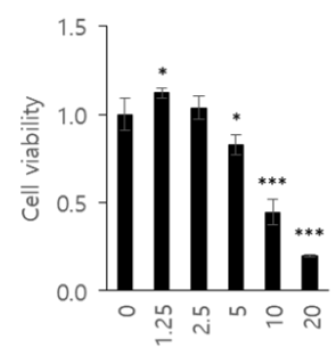

Compound $2(\mu \mathrm{M})$

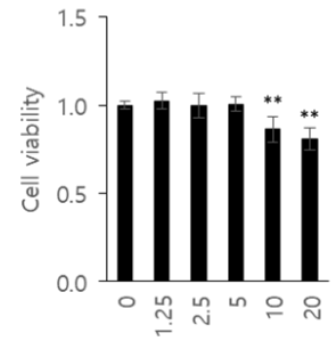

Compound $6(\mu \mathrm{M})$

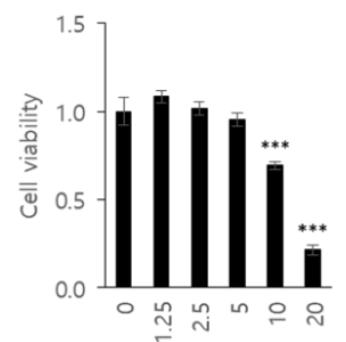

Compound $3(\mu \mathrm{M})$

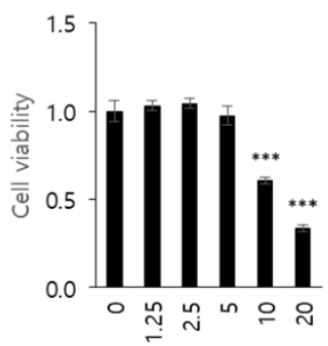

Compound 7 ( $\mu \mathrm{M})$

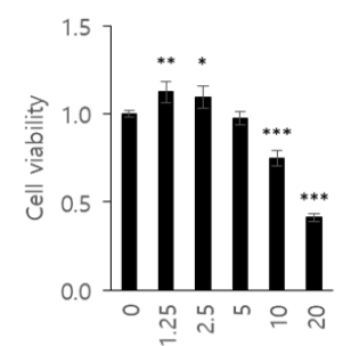

Compound $4(\mu \mathrm{M})$

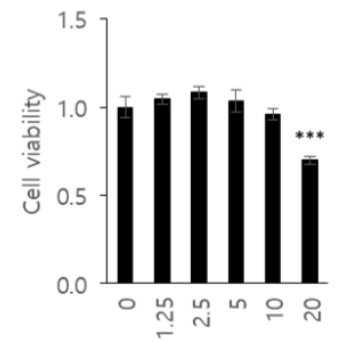

Compound $8(\mu \mathrm{M})$ 
C

PC-3
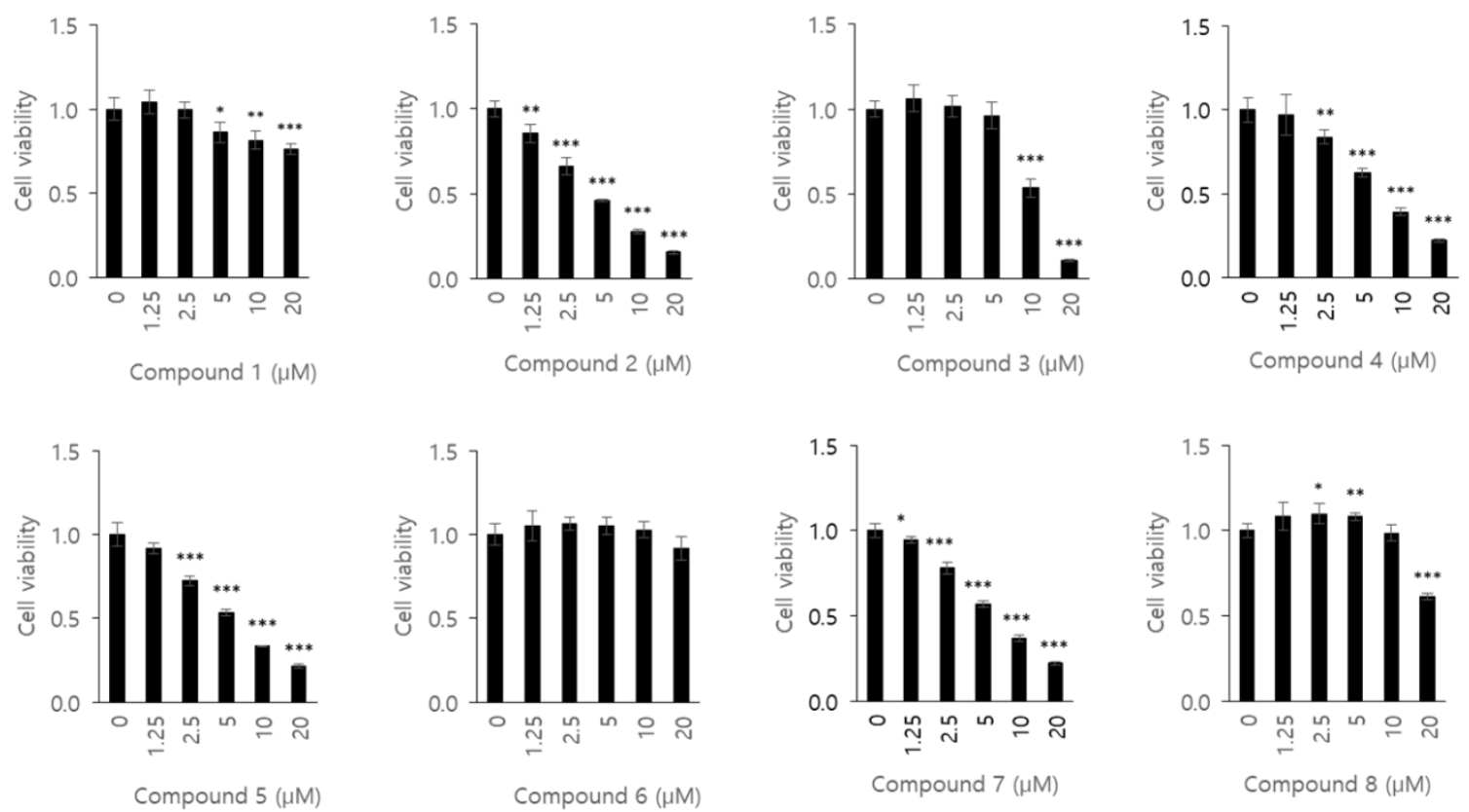

D

HepG2
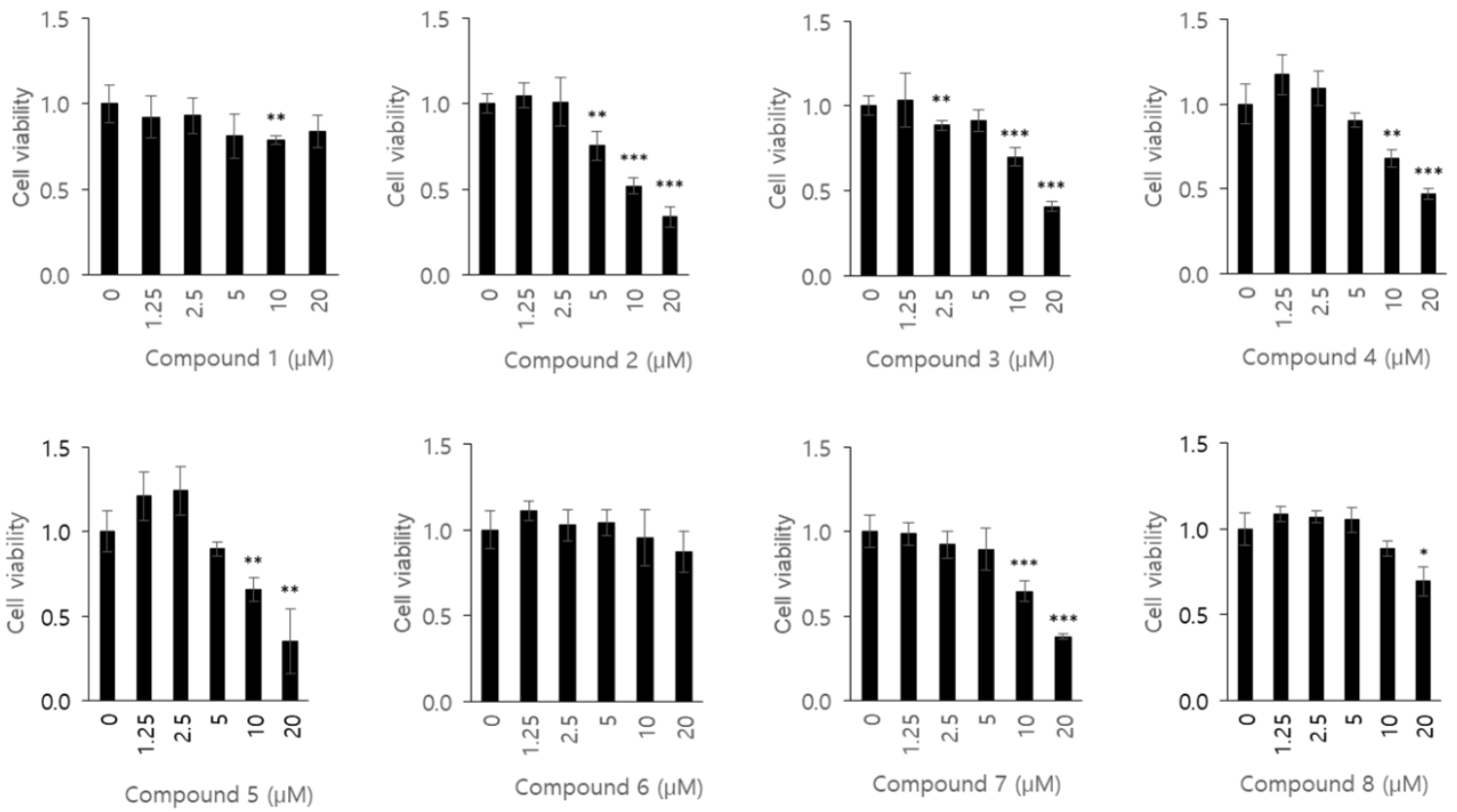
Нер3в
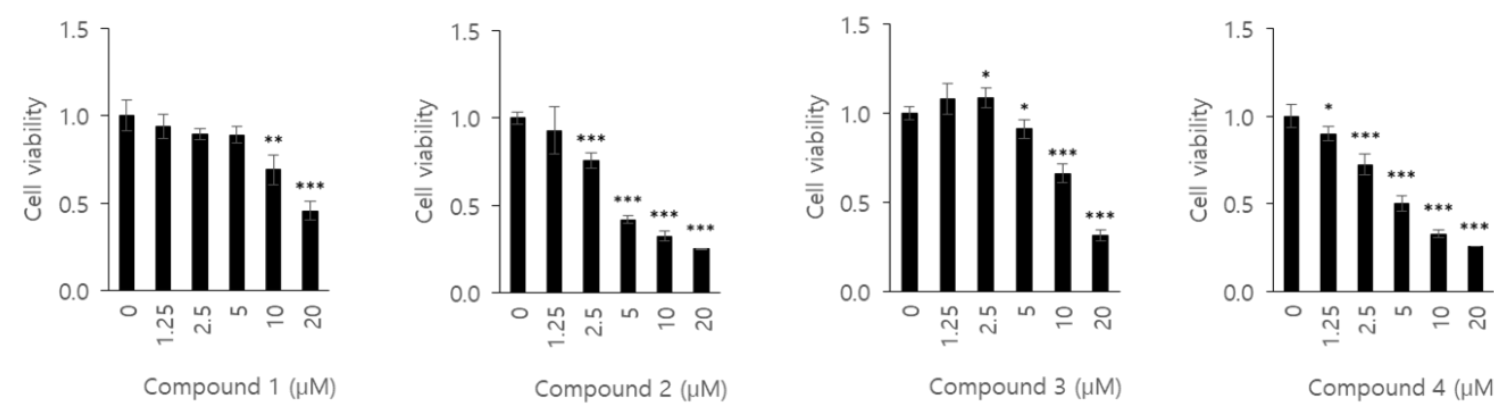

Compound $4(\mu \mathrm{M})$
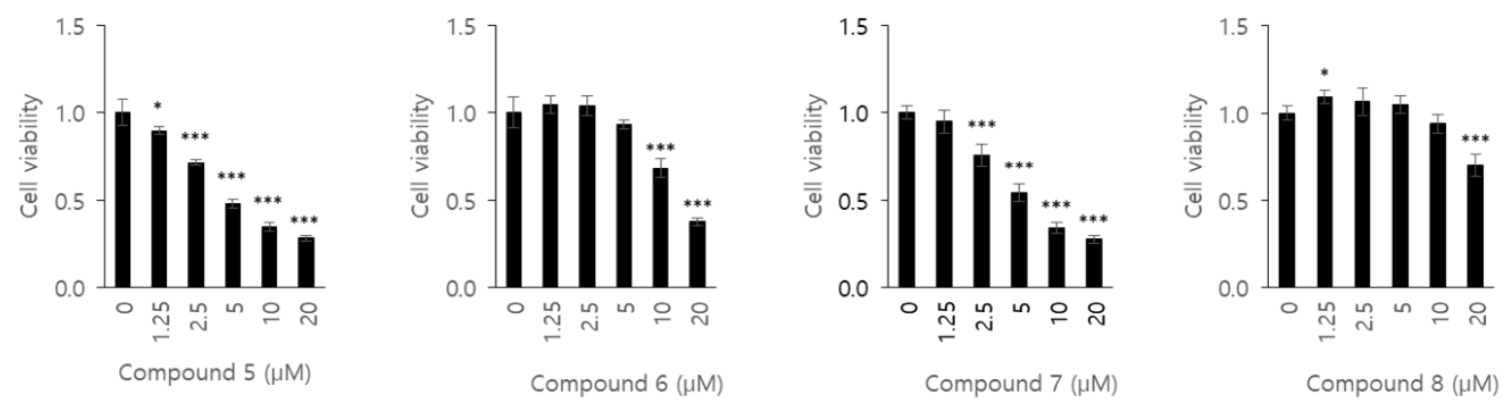

Figure S1. Cell viability assay. (A-E) Each cell lines were treated with $0-20 \mu \mathrm{M}$ of compounds (1-8) for $72 \mathrm{~h}$. Cell viability was measured by Hoechst 33342 stained cell nuclei and calculated as the ratio of treated cells relative to that of untreated cells. All values are presented as mean \pm SD. ${ }^{*} \mathrm{p}<0.05,{ }^{* *} \mathrm{p}<0.01$, and ${ }^{* * *} \mathrm{p}<0.001$ versus the untreated cell. 
${ }^{1} \mathrm{H}$ NMR (400 MHz, $\mathrm{CDCl}_{3}$ ) spectrum of compound $\mathbf{1}$

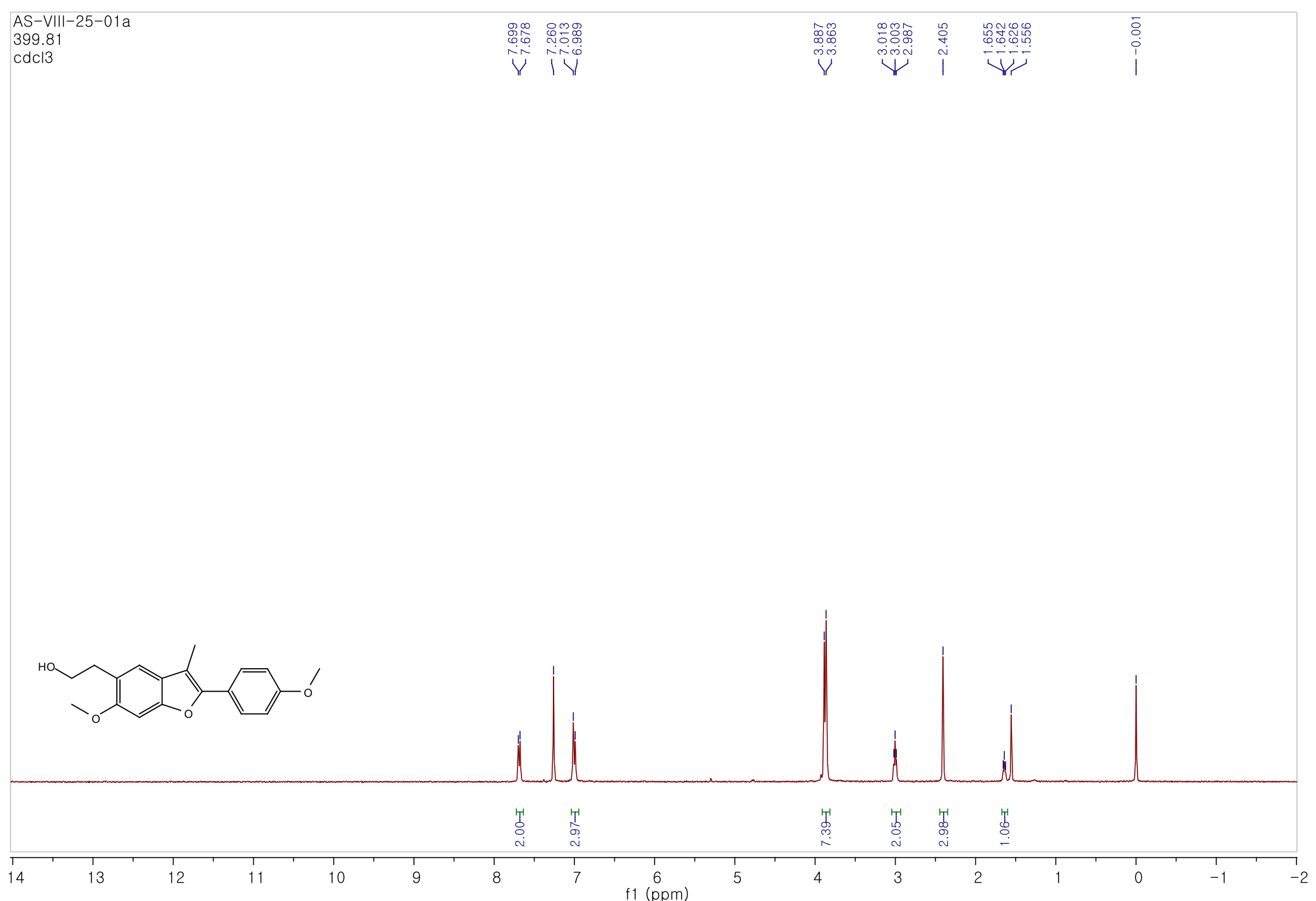


${ }^{13} \mathrm{C}$ NMR (100 MHz, $\mathrm{CDCl}_{3}$ ) spectrum of compound $\mathbf{1}$

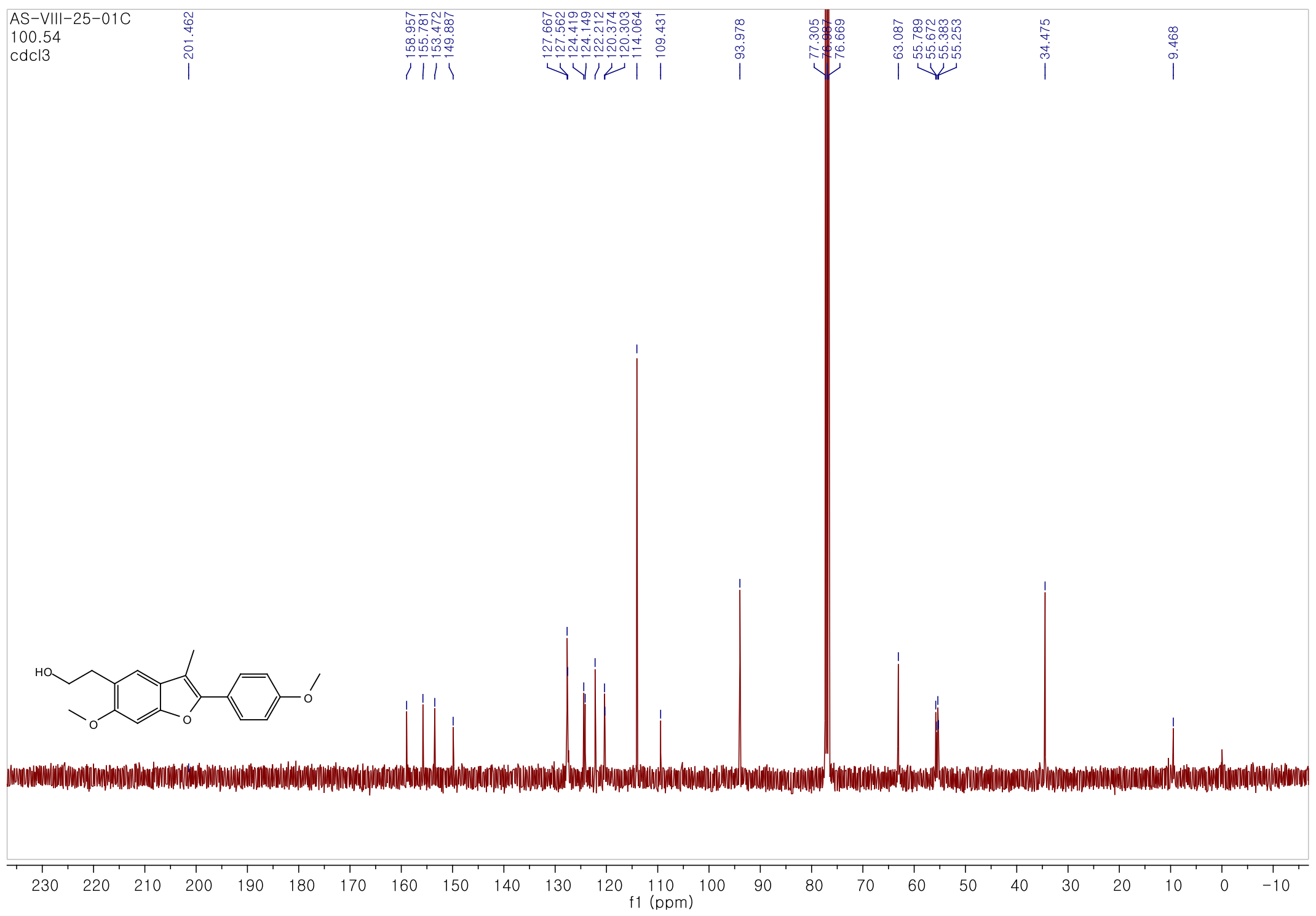

ST 
${ }^{1} \mathrm{H}$ NMR (400 MHz, methanol- $d_{4}$ ) spectrum of compound 2

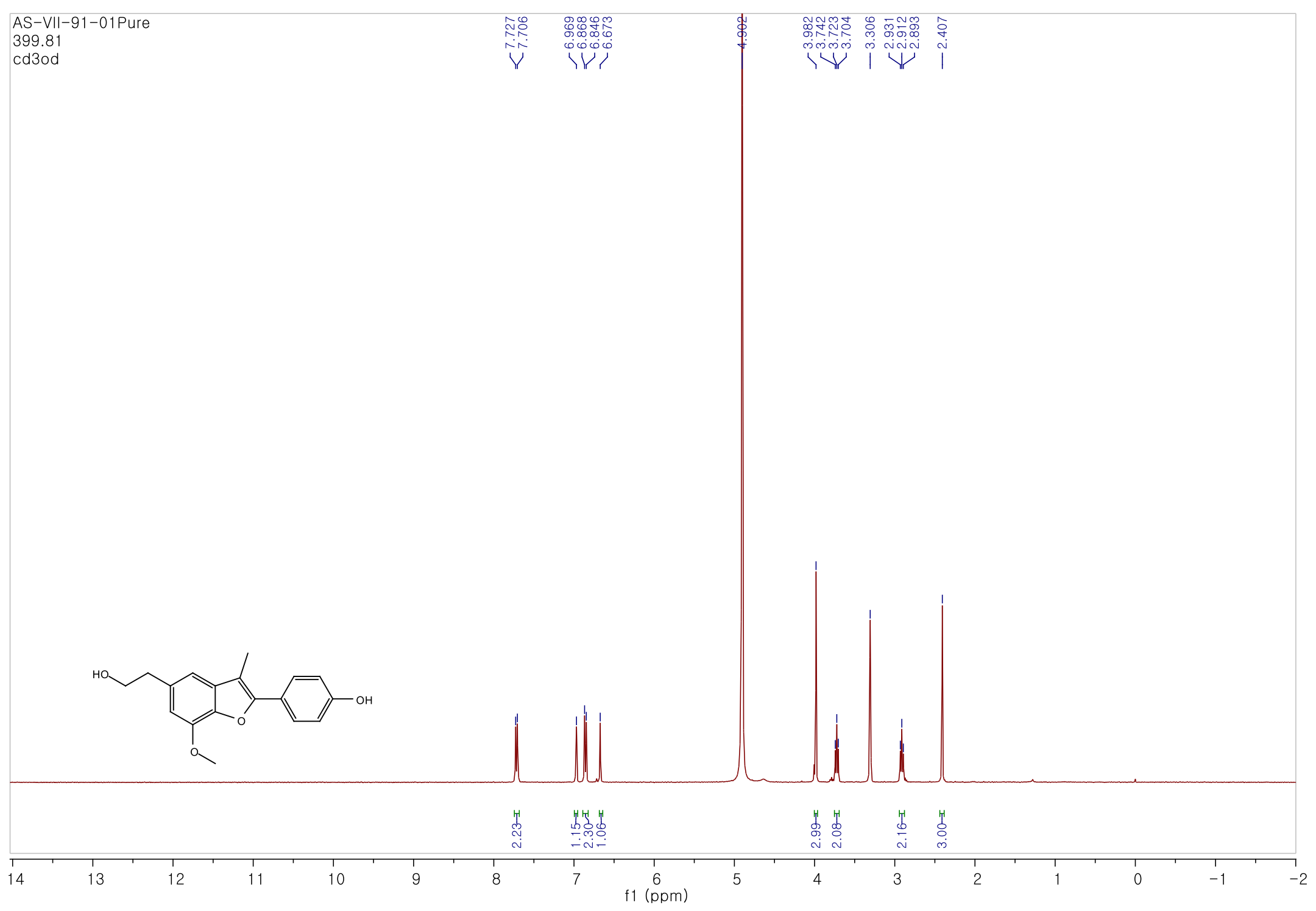




$$
\mathrm{III}
$$


${ }^{1} \mathrm{H}$ NMR (400 MHz, methanol- $d_{4}$ ) spectrum of compound 3

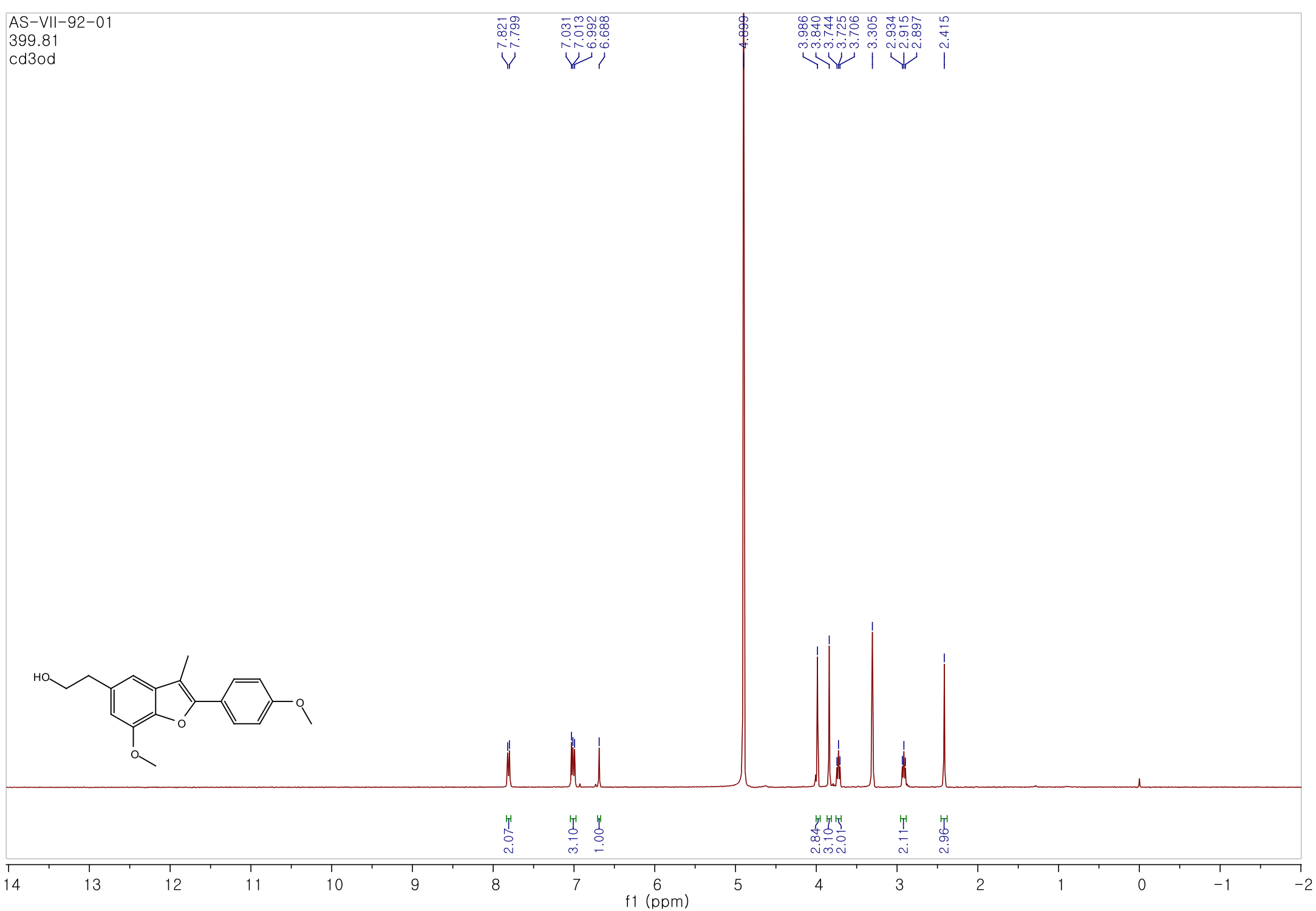


${ }^{13} \mathrm{C}$ NMR (100 MHz, methanol- $d_{4}$ ) spectrum of compound 3

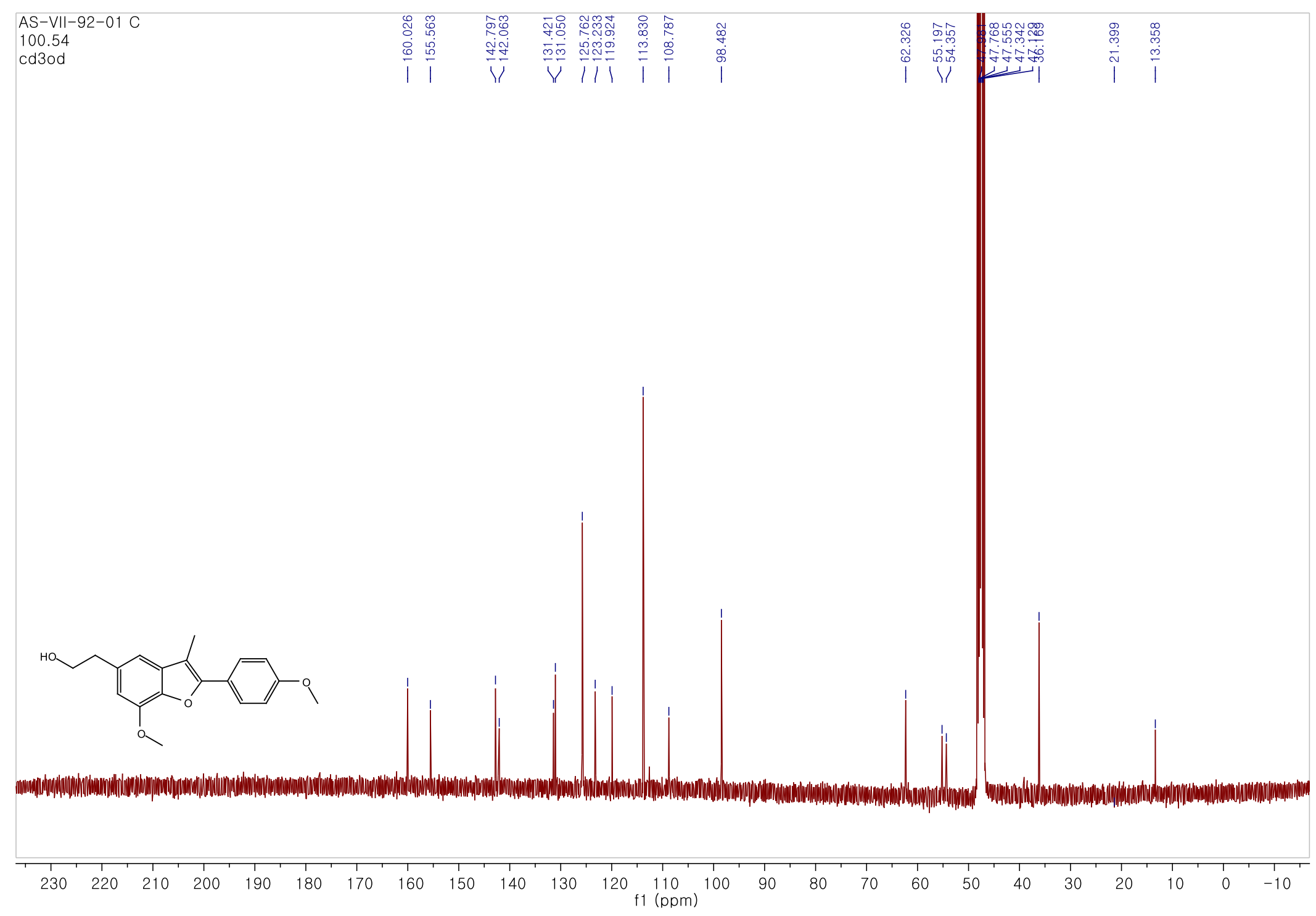


${ }^{1} \mathrm{H}$ NMR (400 MHz, methanol- $d_{4}$ ) spectrum of compound 4

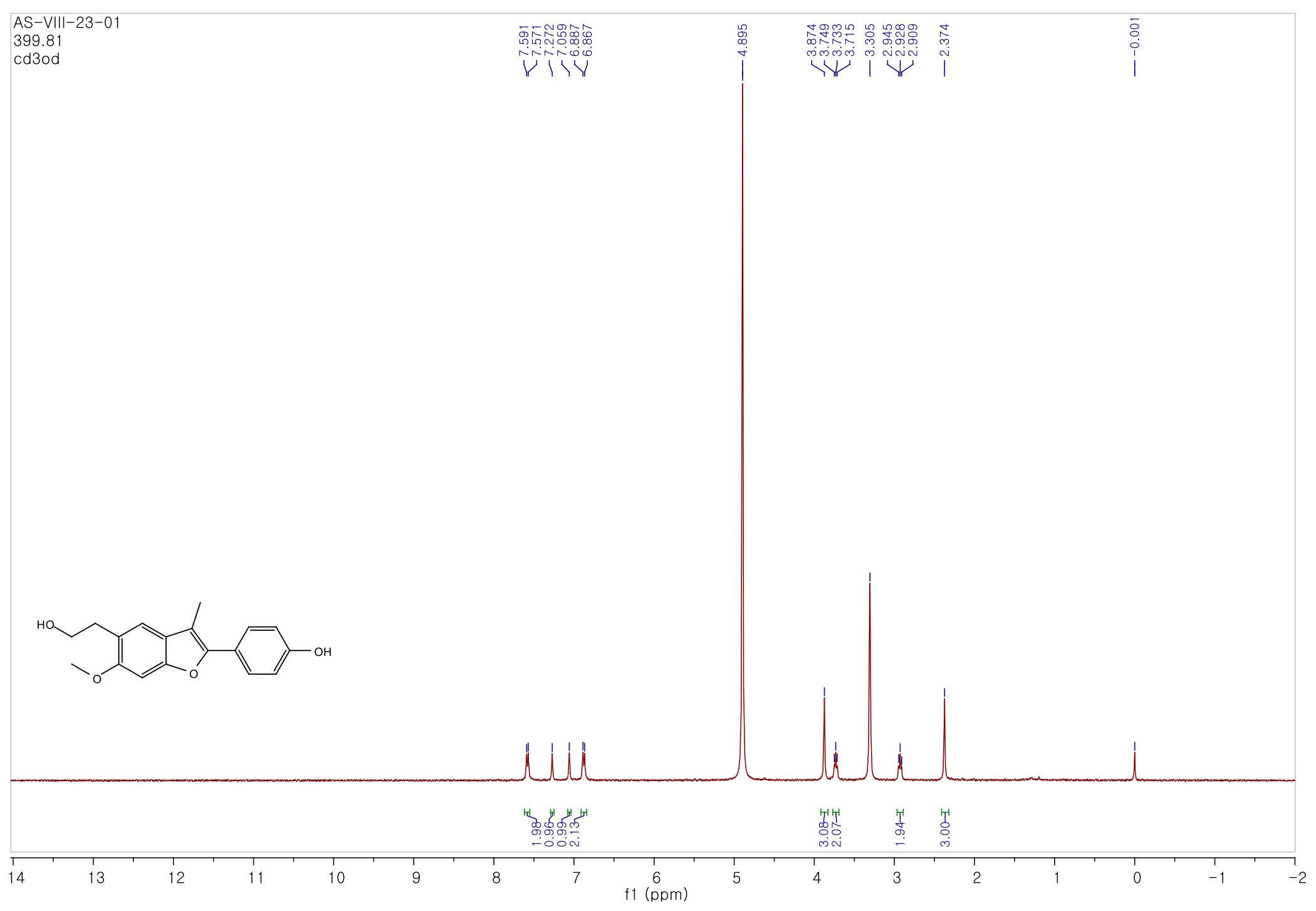


${ }^{13} \mathrm{C}$ NMR (100 MHz, methanol- $\left.d_{4}\right)$ spectrum of compound 4

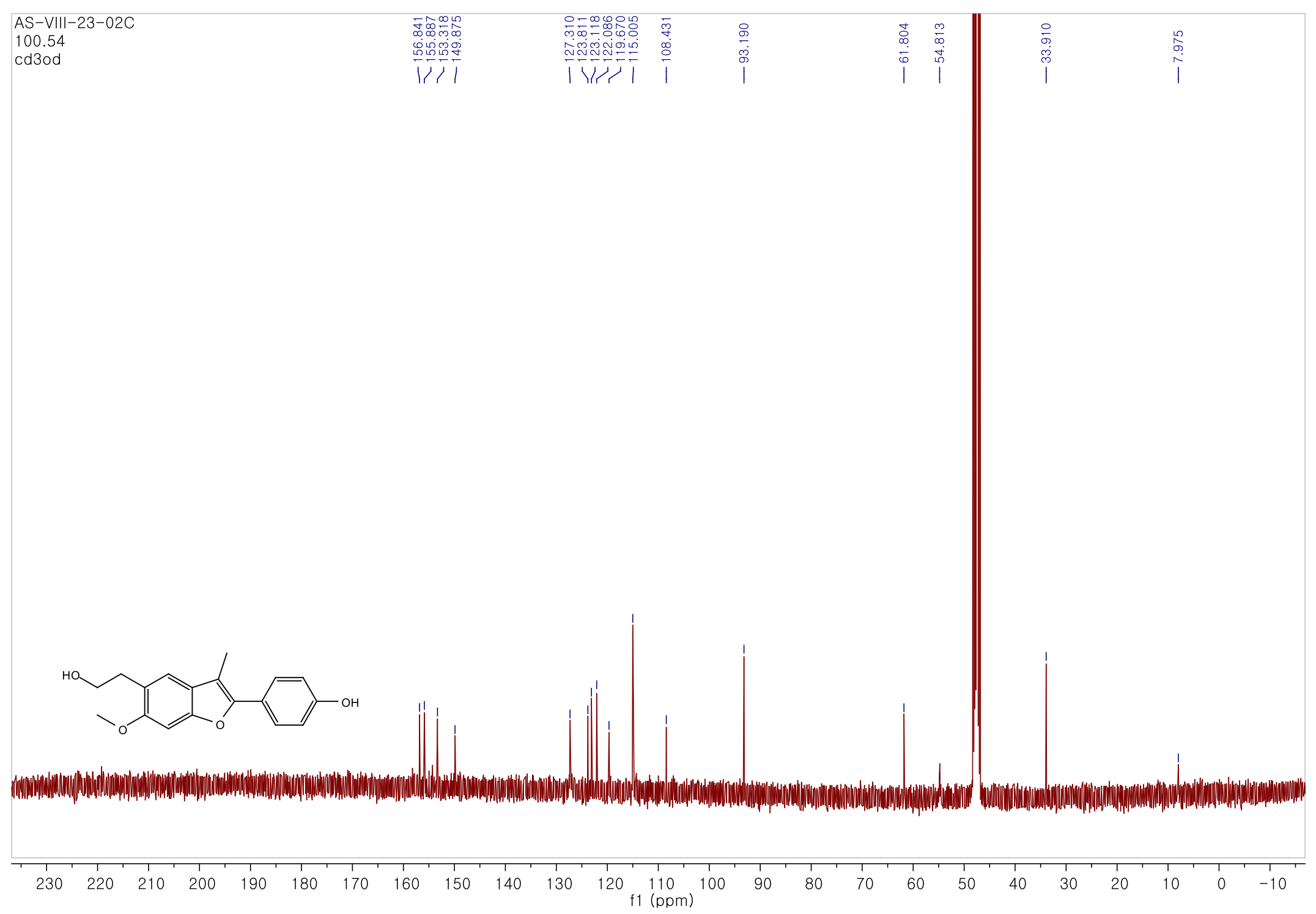


${ }^{1} \mathrm{H}$ NMR (400 MHz, methanol- $d_{4}$ ) spectrum of compound 5

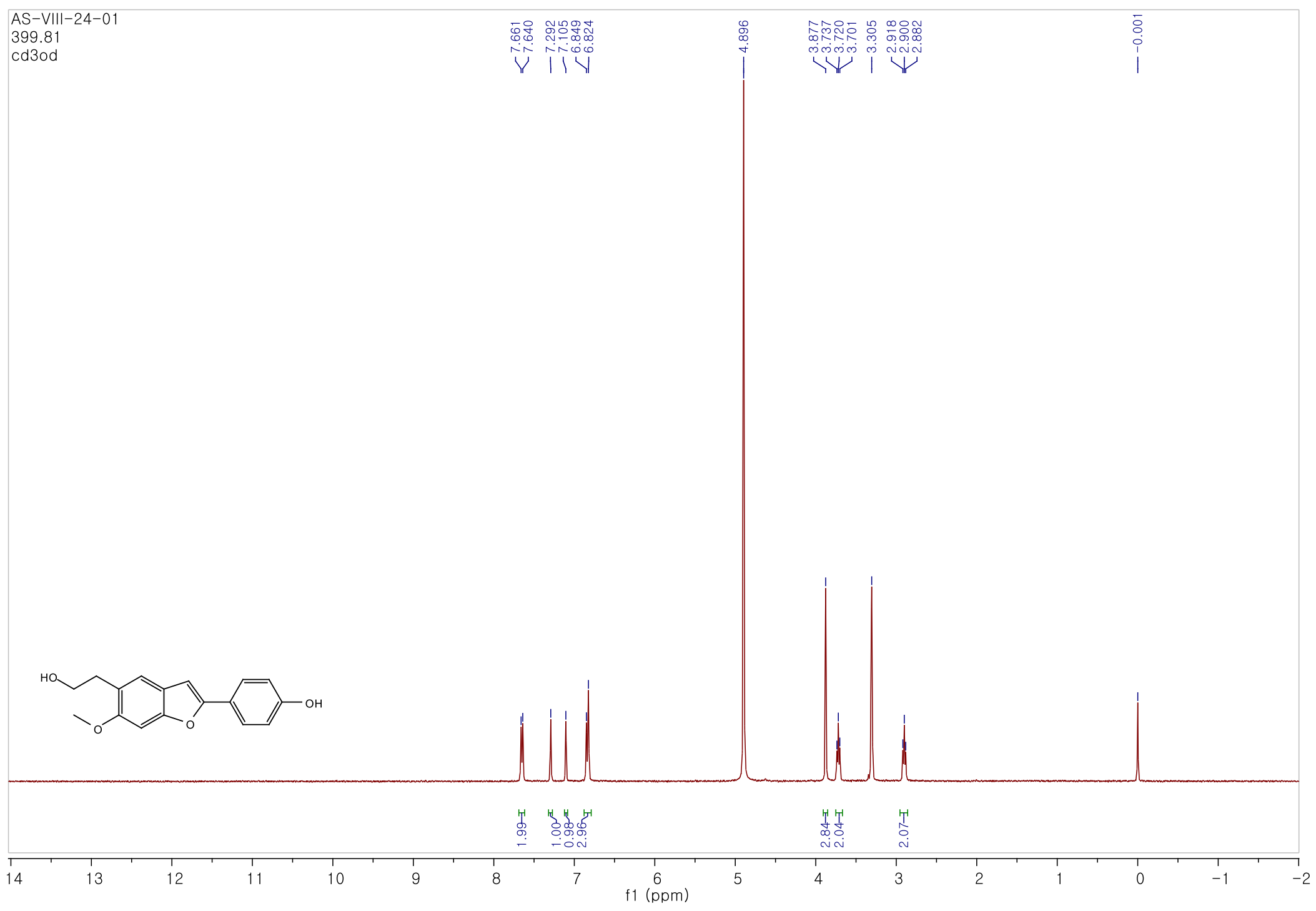




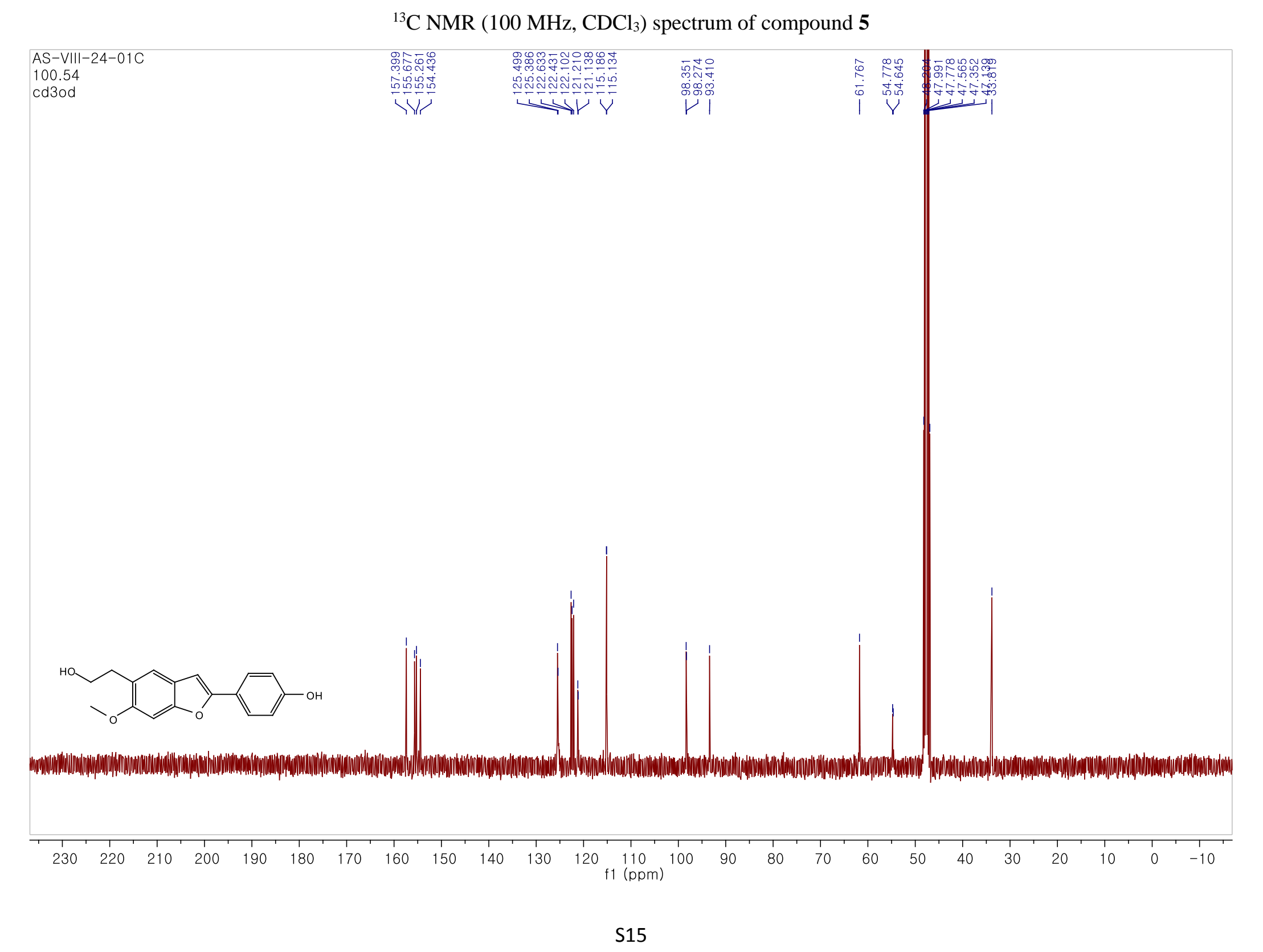


${ }^{1} \mathrm{H}$ NMR (400 MHz, $\mathrm{CDCl}_{3}$ ) spectrum of compound 6

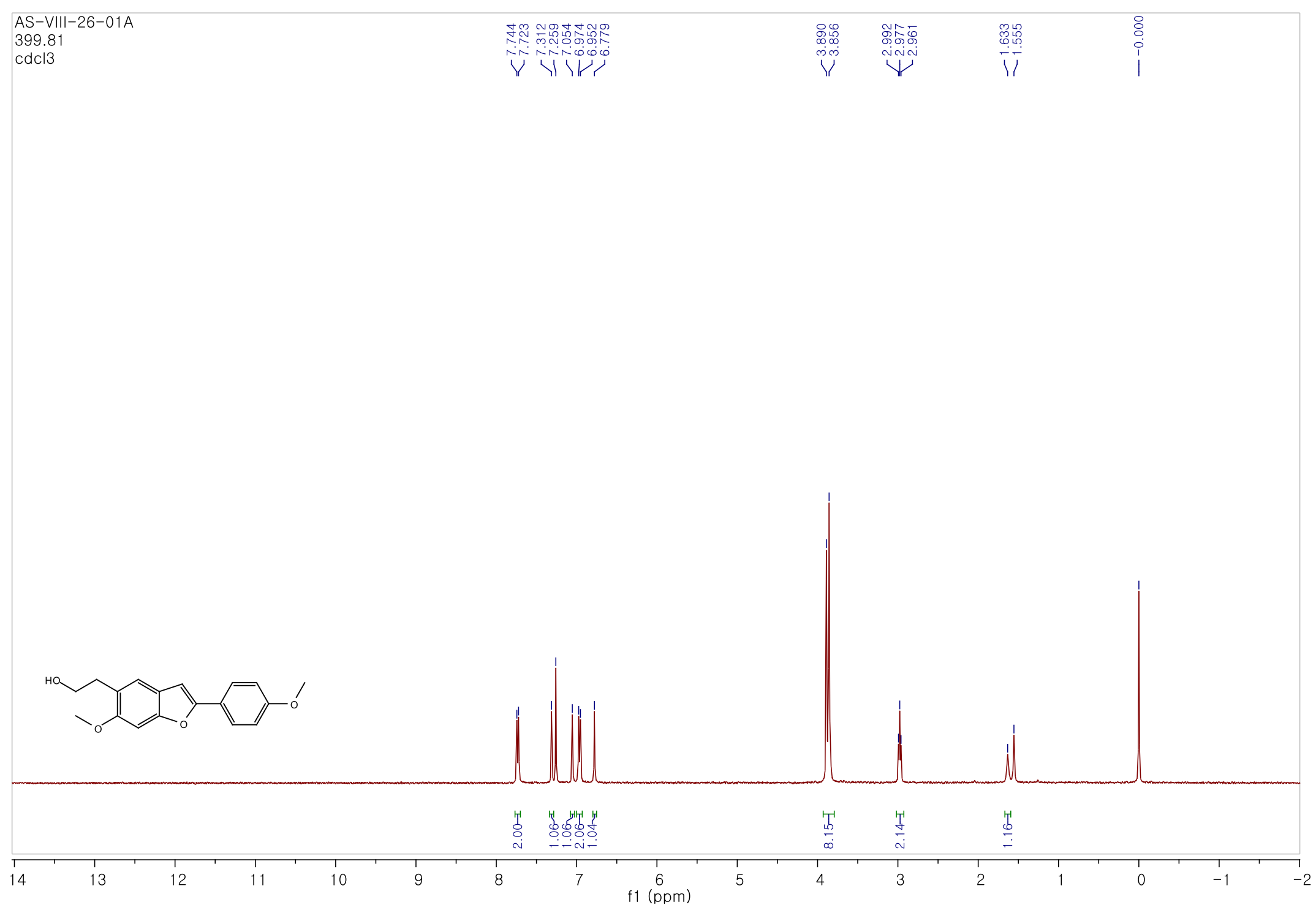


${ }^{13} \mathrm{C}$ NMR $\left(100 \mathrm{MHz}, \mathrm{CDCl}_{3}\right)$ spectrum of compound $\mathbf{6}$

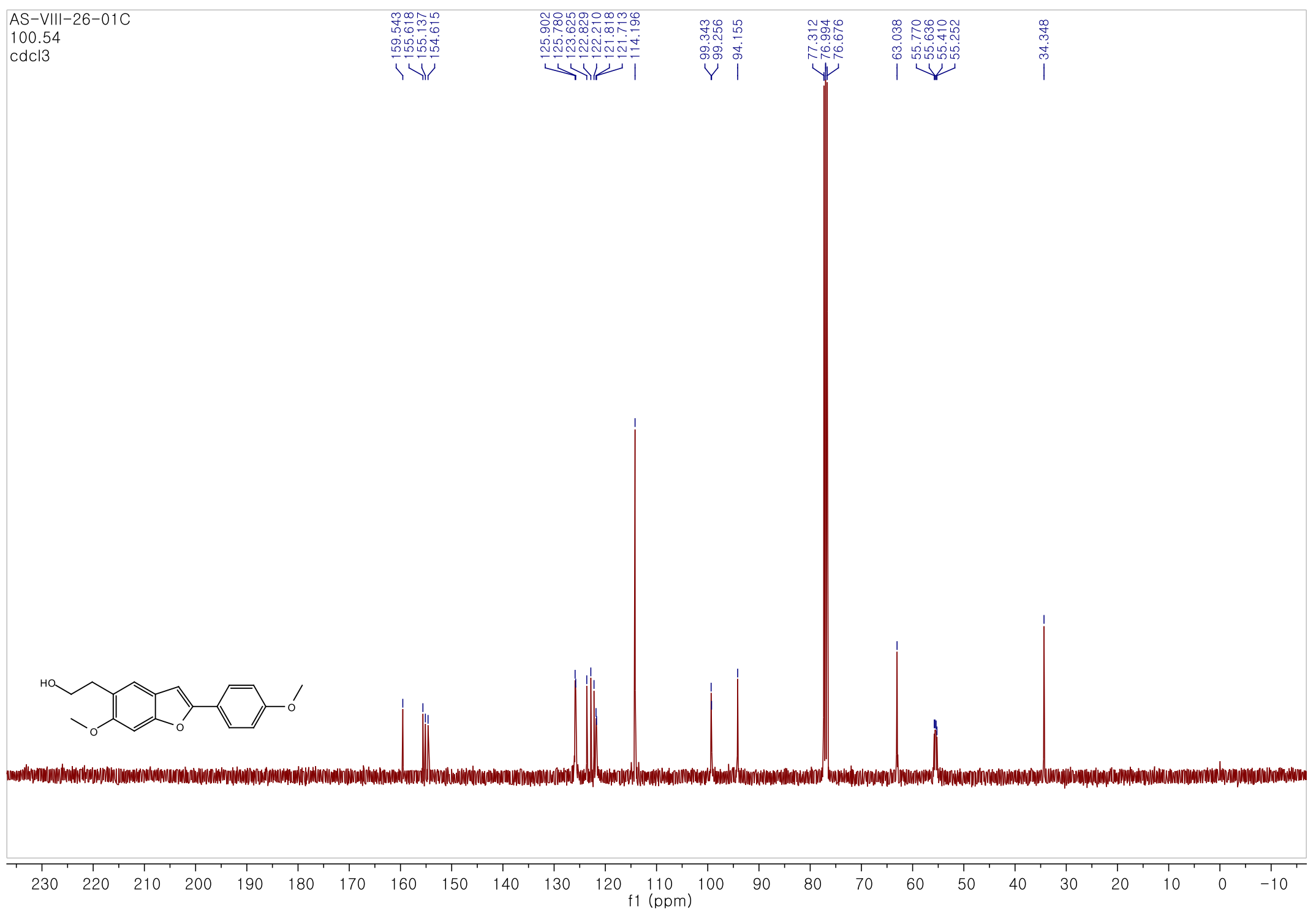

S17 
${ }^{1} \mathrm{H}$ NMR (400 MHz, methanol- $d_{4}$ ) spectrum of compound 7

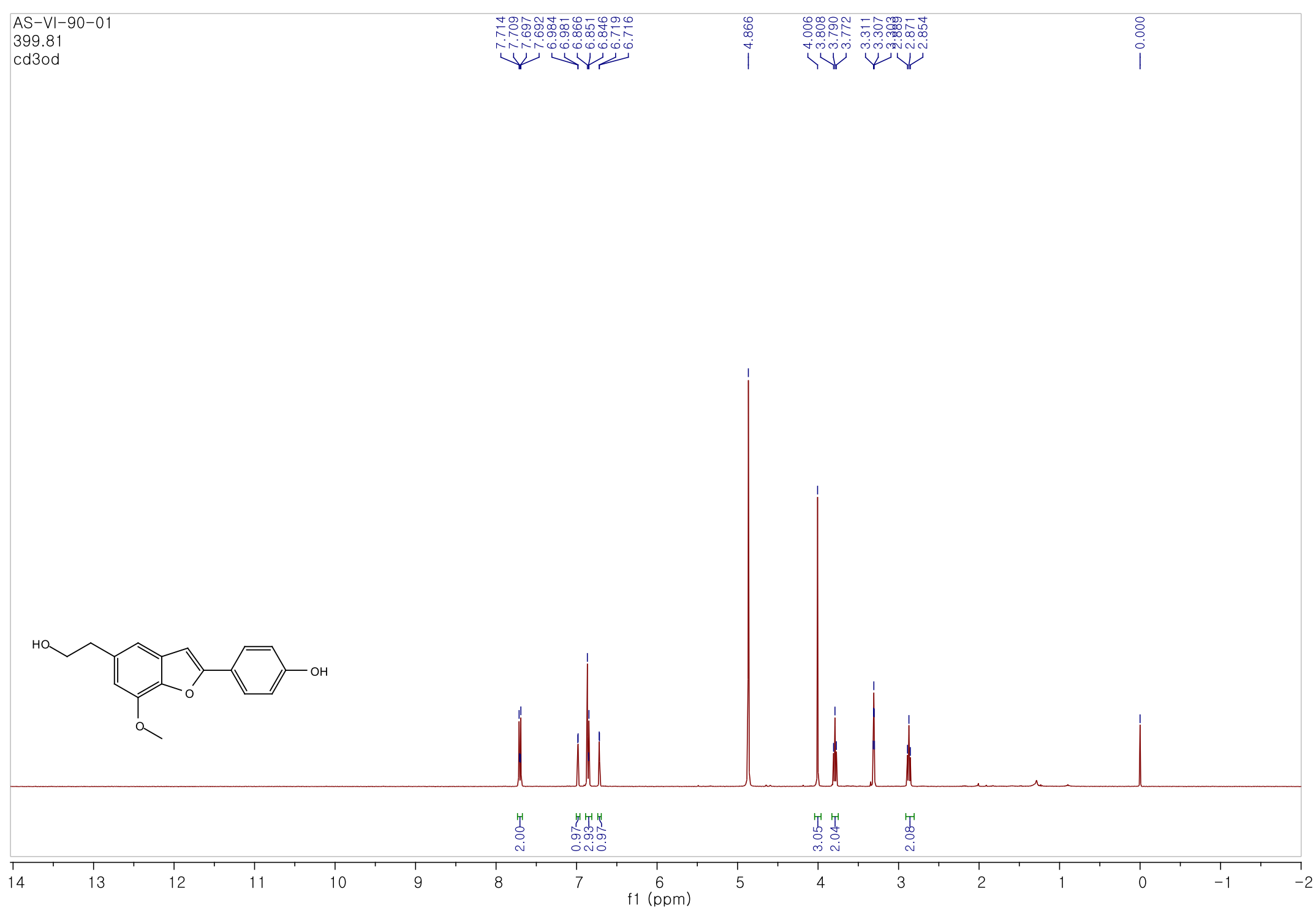


${ }^{13} \mathrm{C}$ NMR (100 MHz, methanol- $d_{4}$ ) spectrum of compound 7

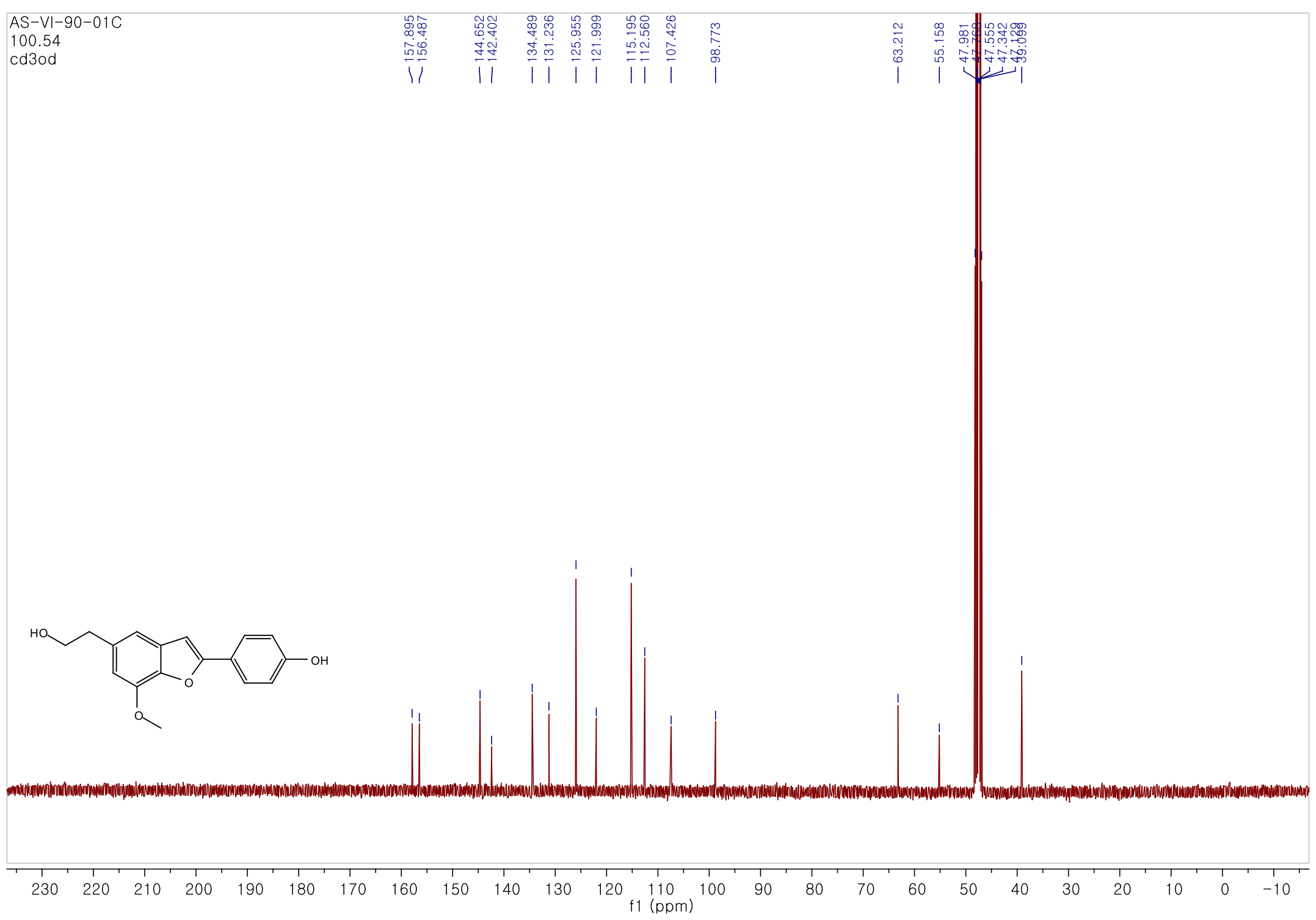


${ }^{1} \mathrm{H}$ NMR (400 MHz, $\mathrm{CDCl}_{3}$ ) spctrum of compound 8

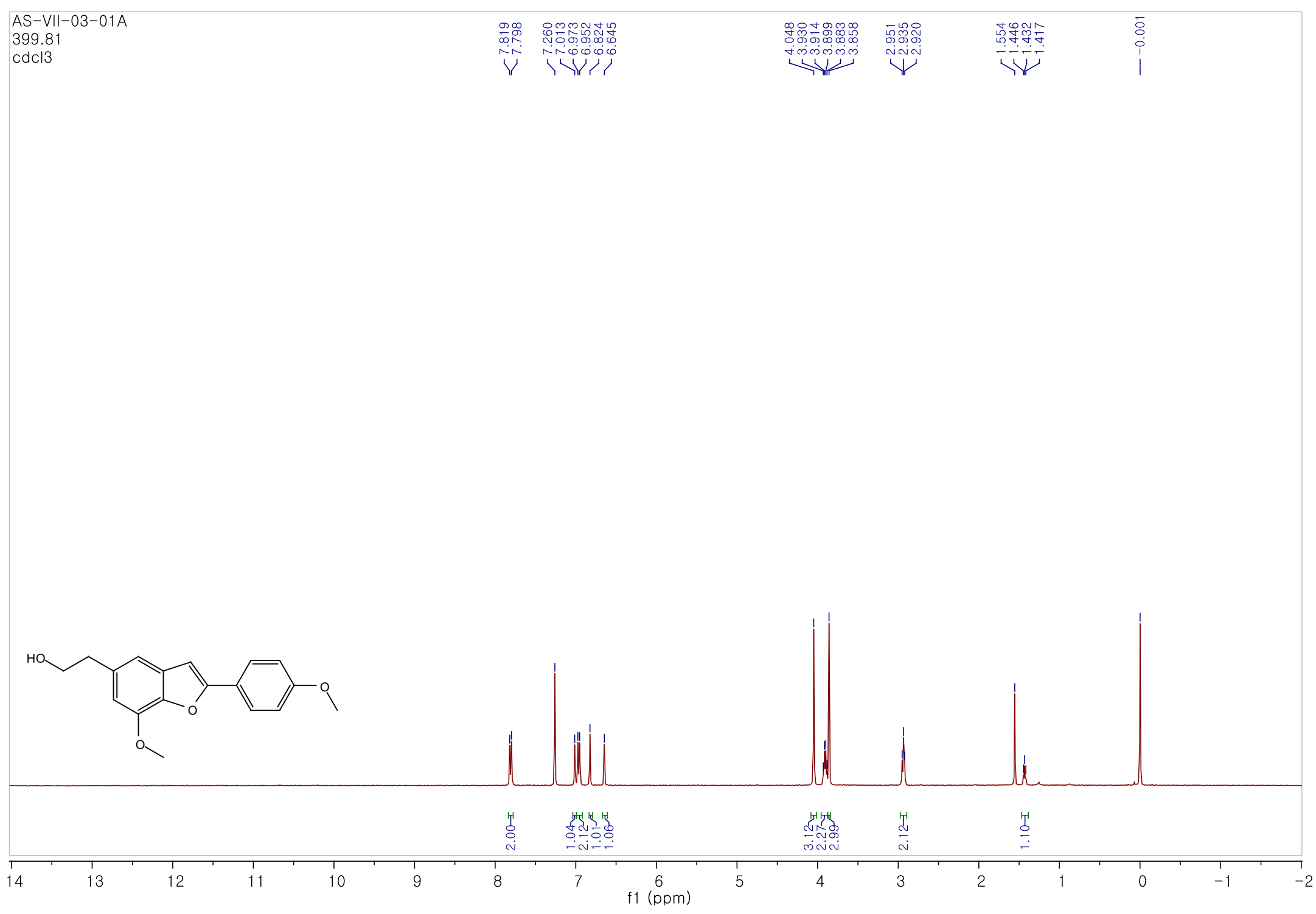


${ }^{13} \mathrm{C}$ NMR (100 MHz, $\mathrm{CDCl}_{3}$ ) spctrum of compound 8

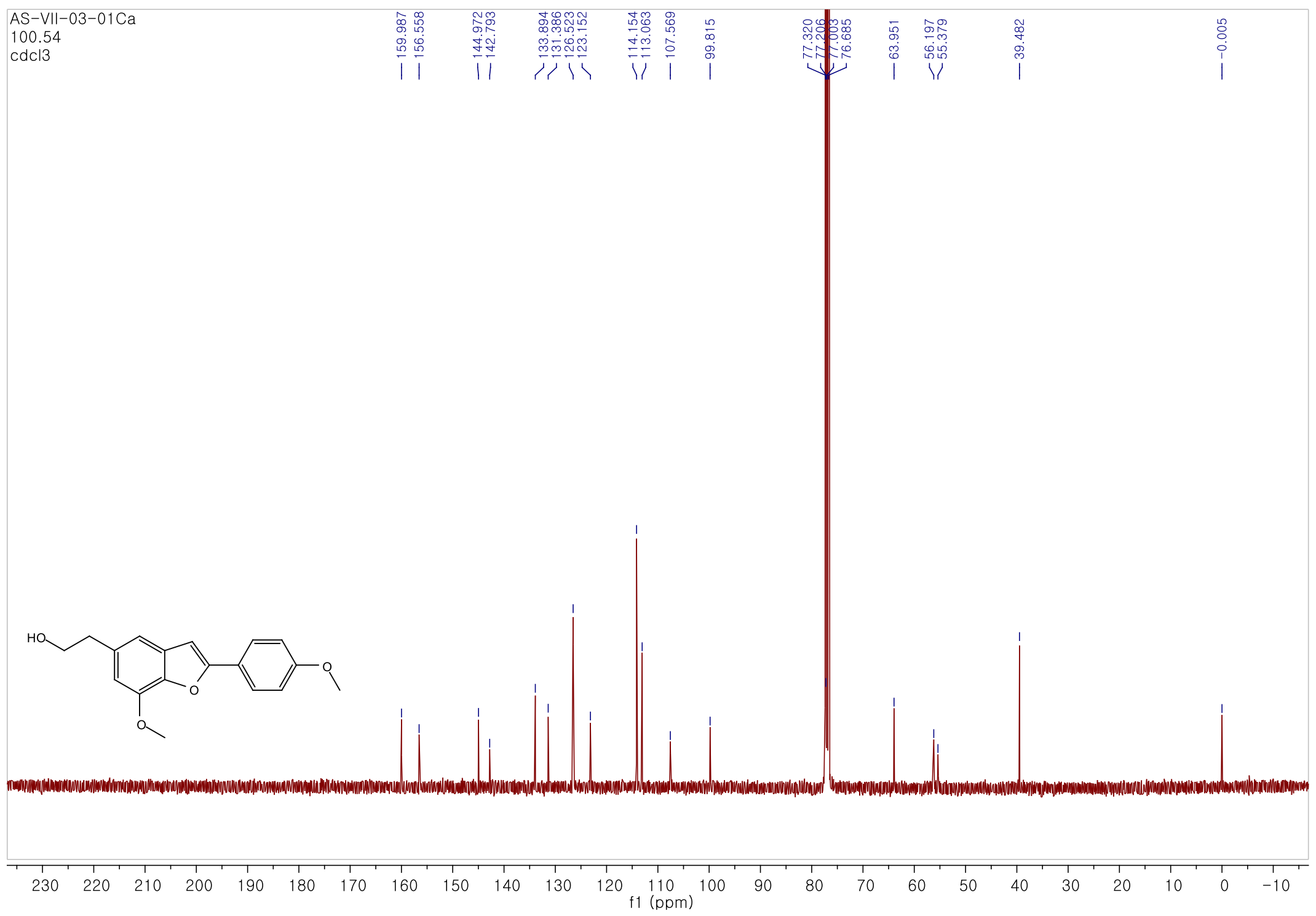

S21 
${ }^{1} \mathrm{H}$ NMR (400 MHz, DMSO-d $d_{6}$ ) spctrum of compound 9

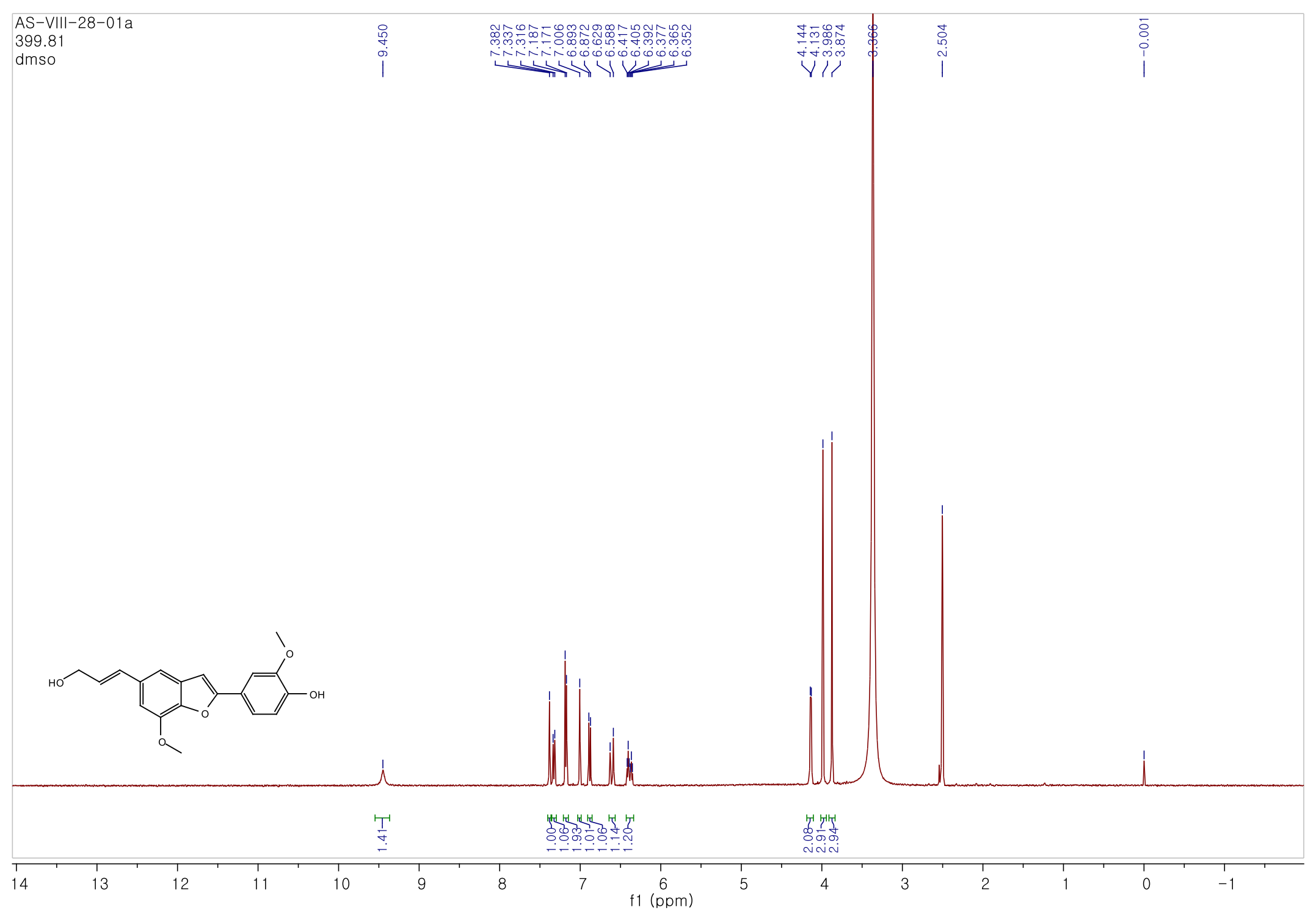


${ }^{13} \mathrm{C}$ NMR (100 MHz, DMSO- $\left.d_{6}\right)$ spctrum of compound 9

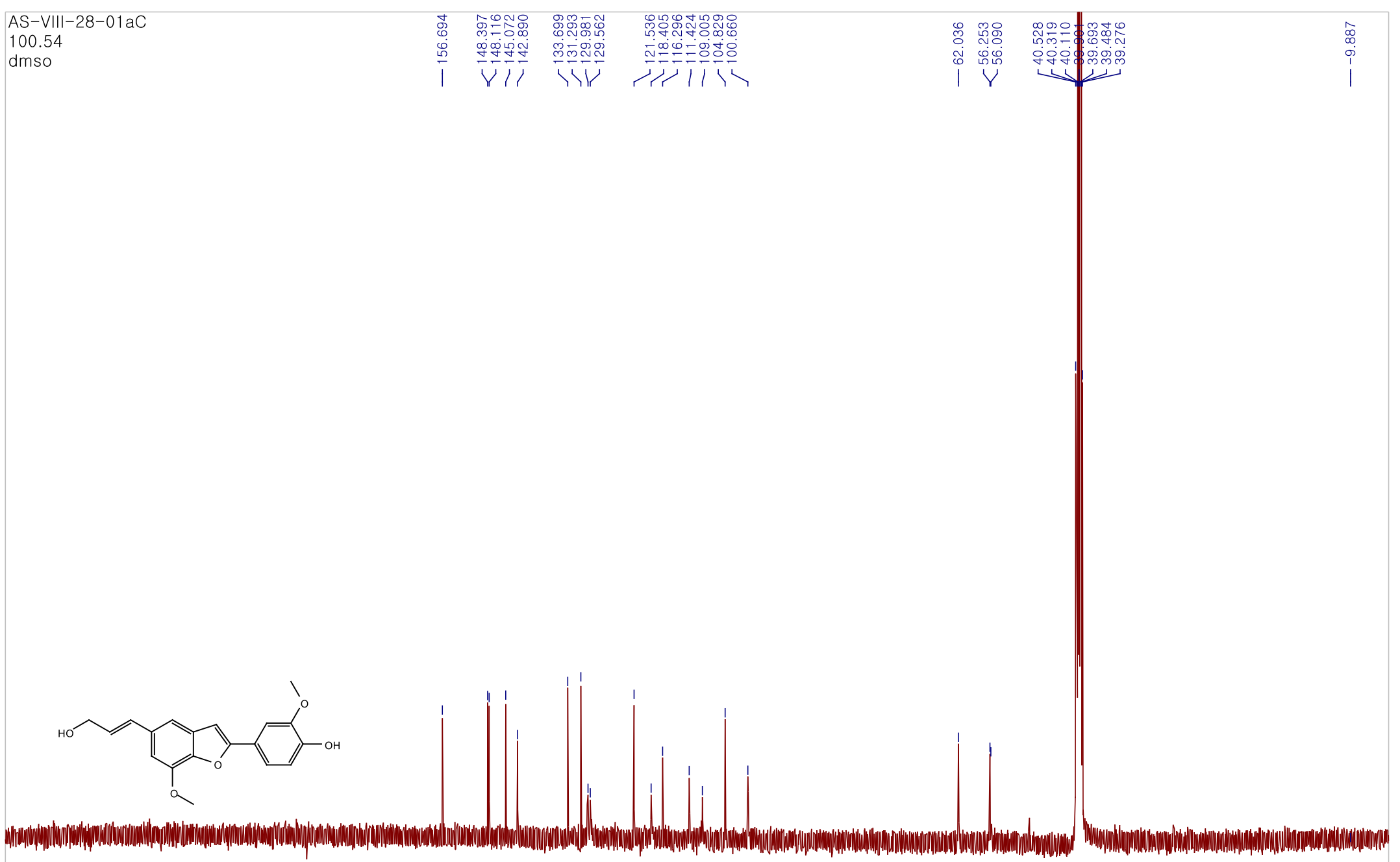

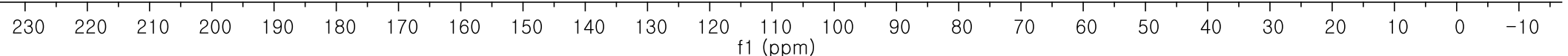


${ }^{1} \mathrm{H}$ NMR (400 MHz, $\mathrm{CDCl}_{3}$ ) spctrum of compound $\mathbf{1 0}$

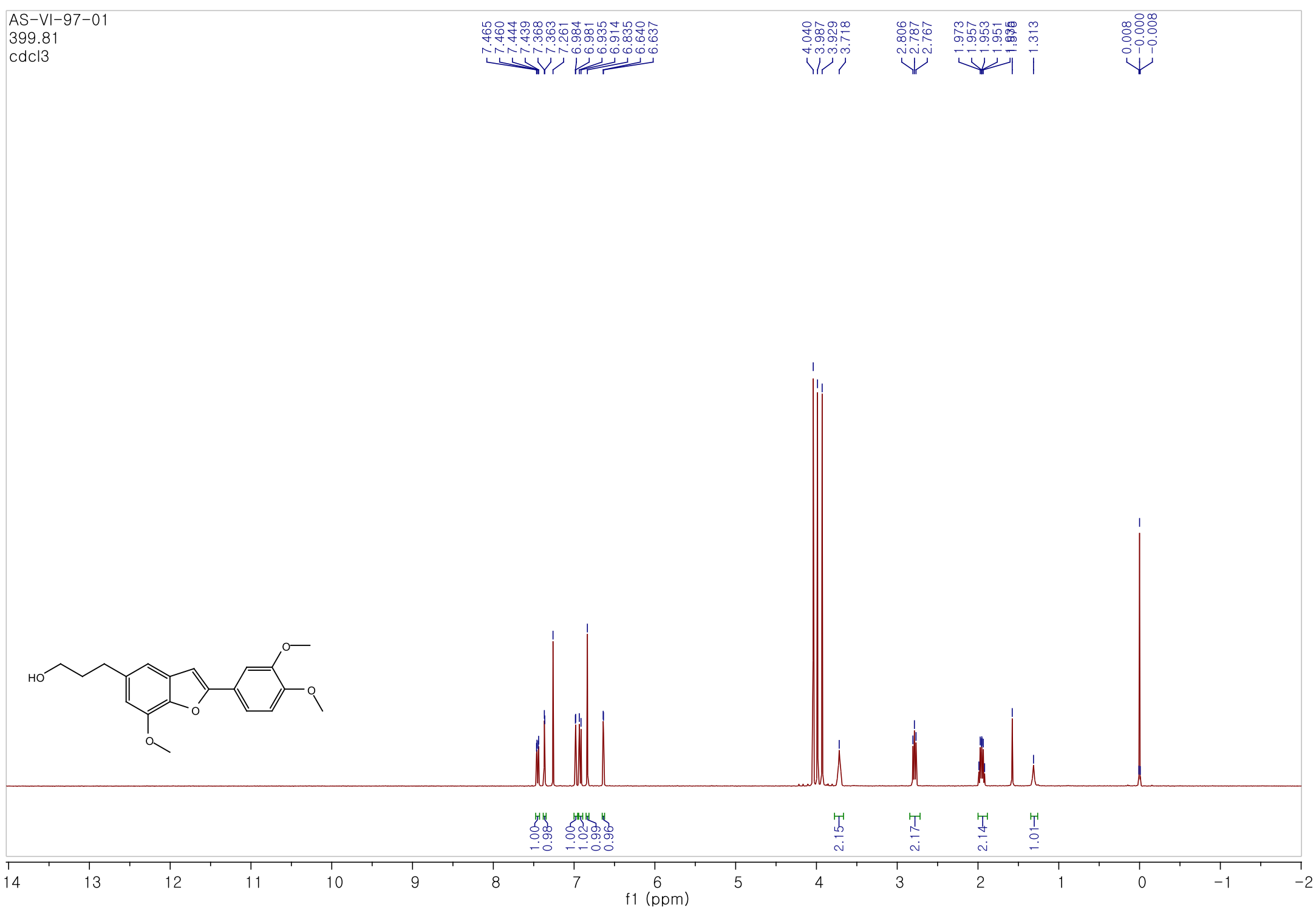




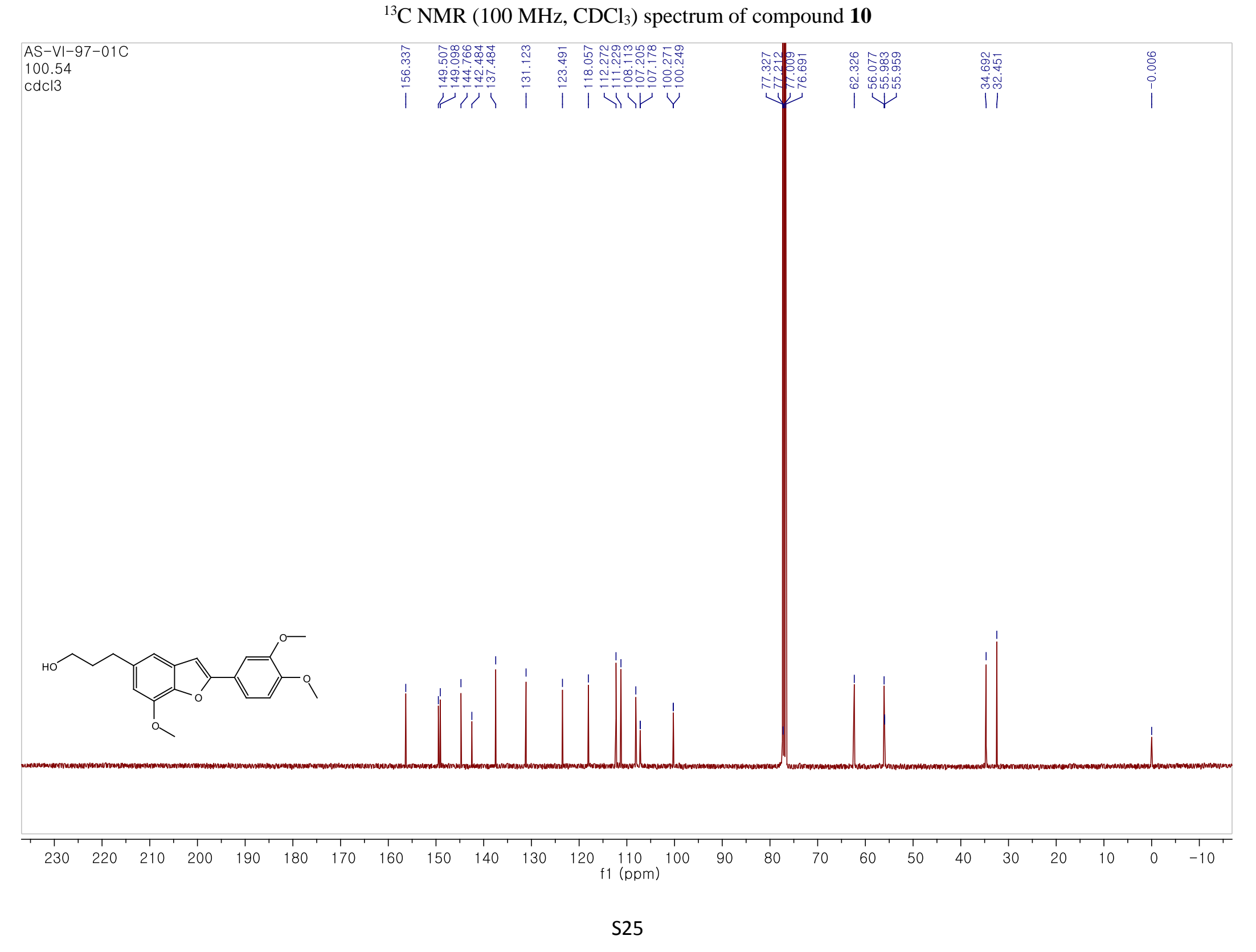


${ }^{1} \mathrm{H}$ NMR (400 MHz, $\mathrm{CDCl}_{3}$ ) spctrum of compound $\mathbf{1 1}$

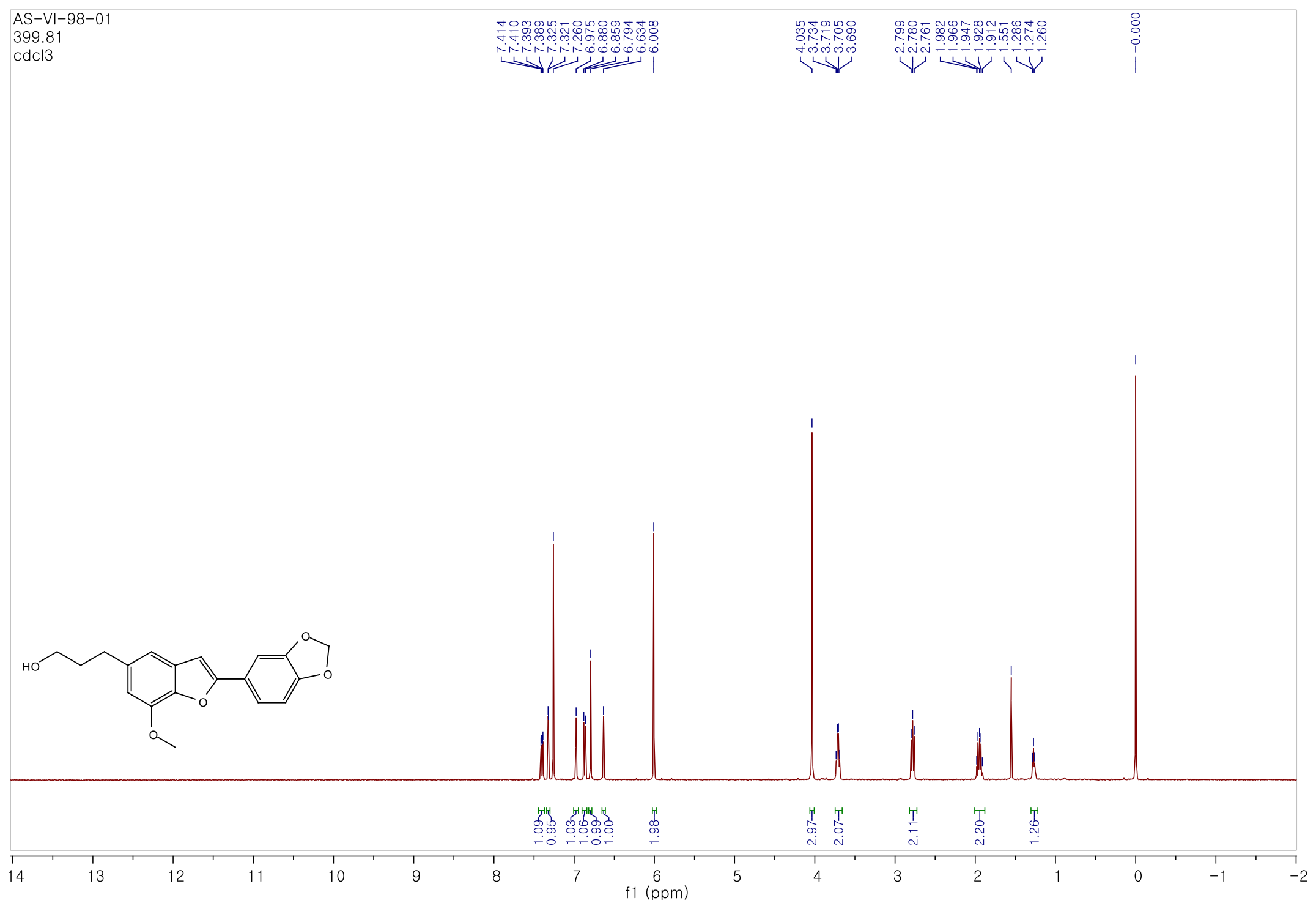


${ }^{13} \mathrm{C}$ NMR (100 MHz, $\mathrm{CDCl}_{3}$ ) spectrum of compound $\mathbf{1 1}$
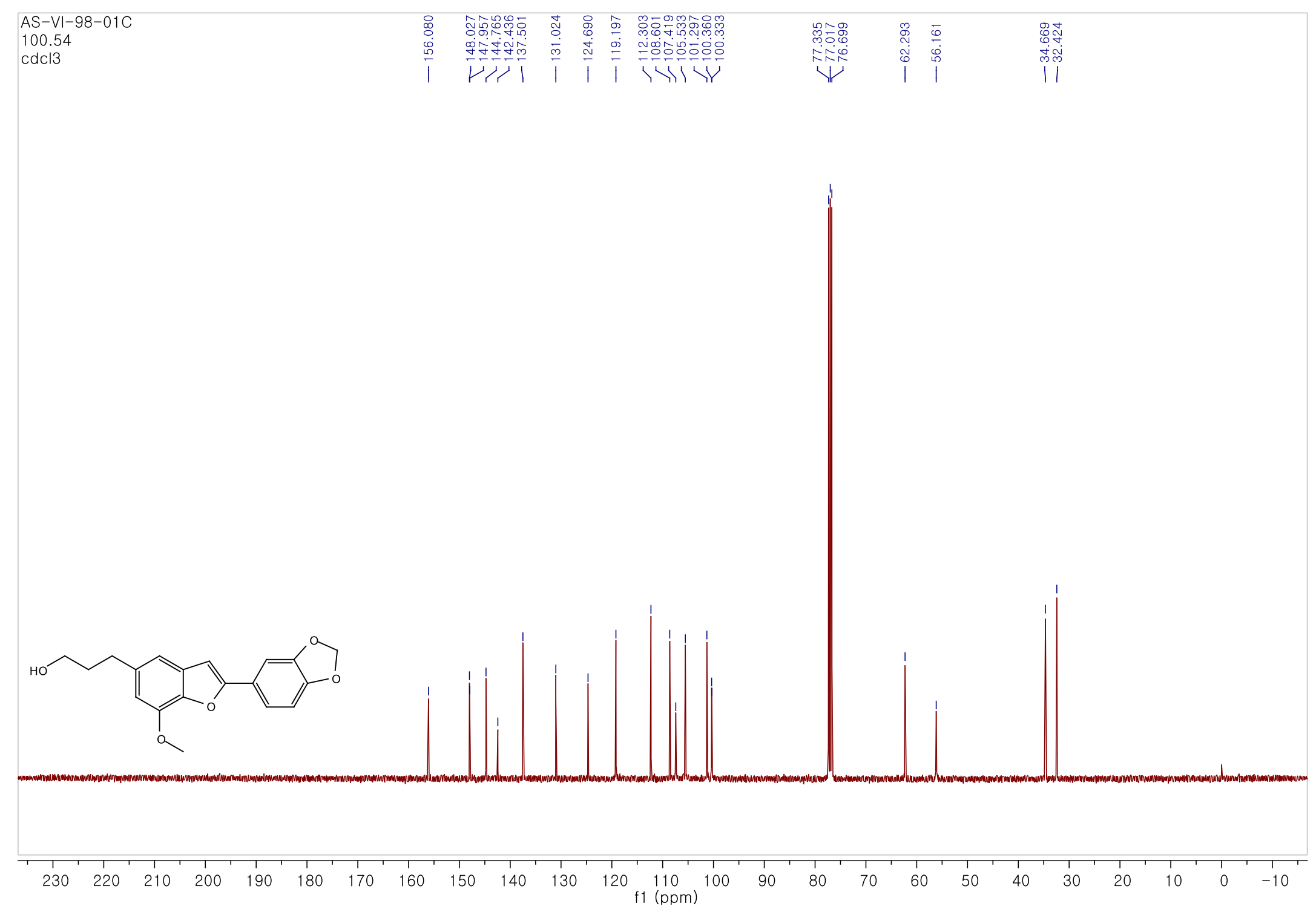
${ }^{1} \mathrm{H}$ NMR (400 MHz, $\mathrm{CDCl}_{3}$ ) spctrum of compound 13a

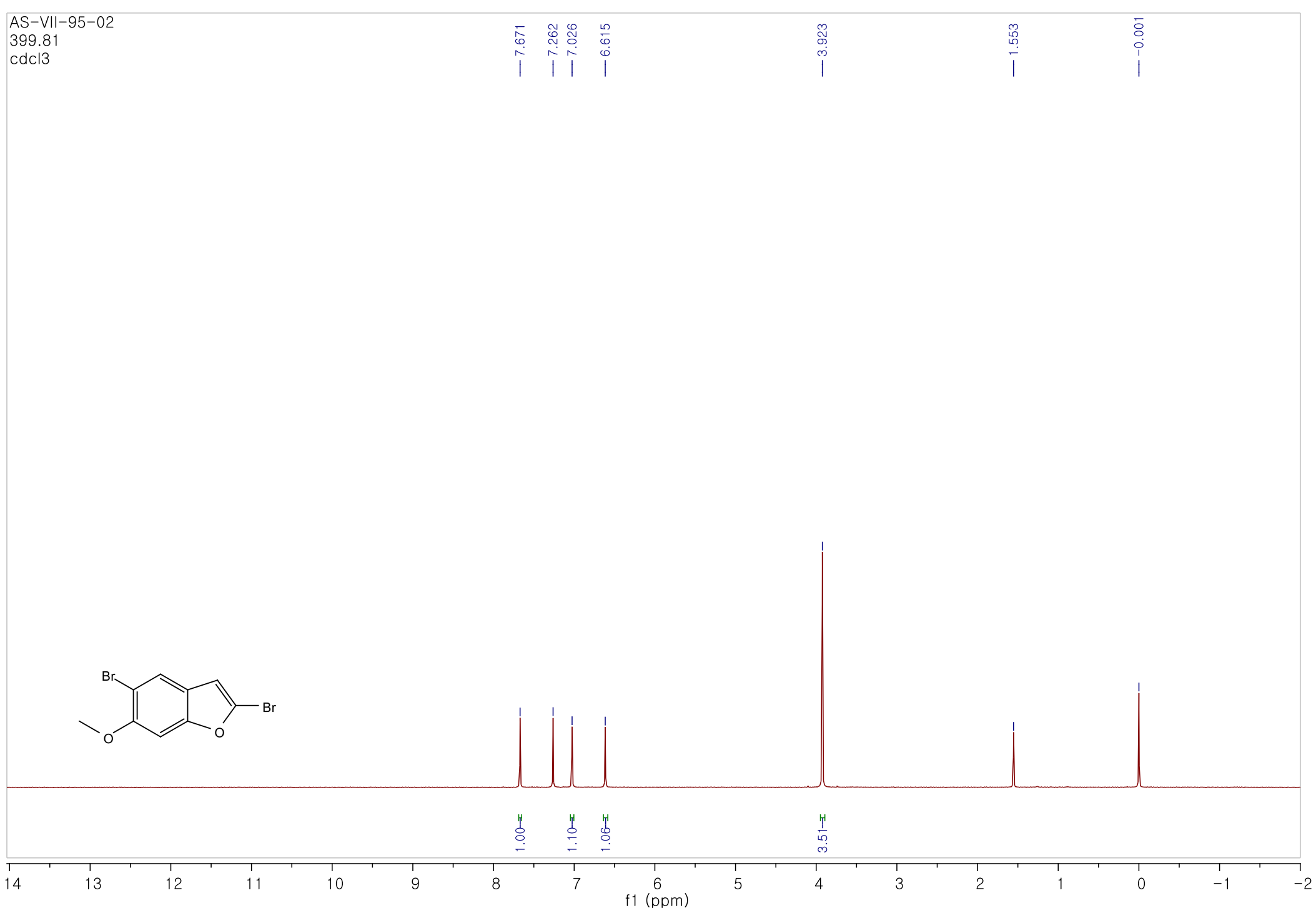


${ }^{13} \mathrm{C}$ NMR $\left(100 \mathrm{MHz}, \mathrm{CDCl}_{3}\right)$ spectrum of compound $\mathbf{1 3 a}$

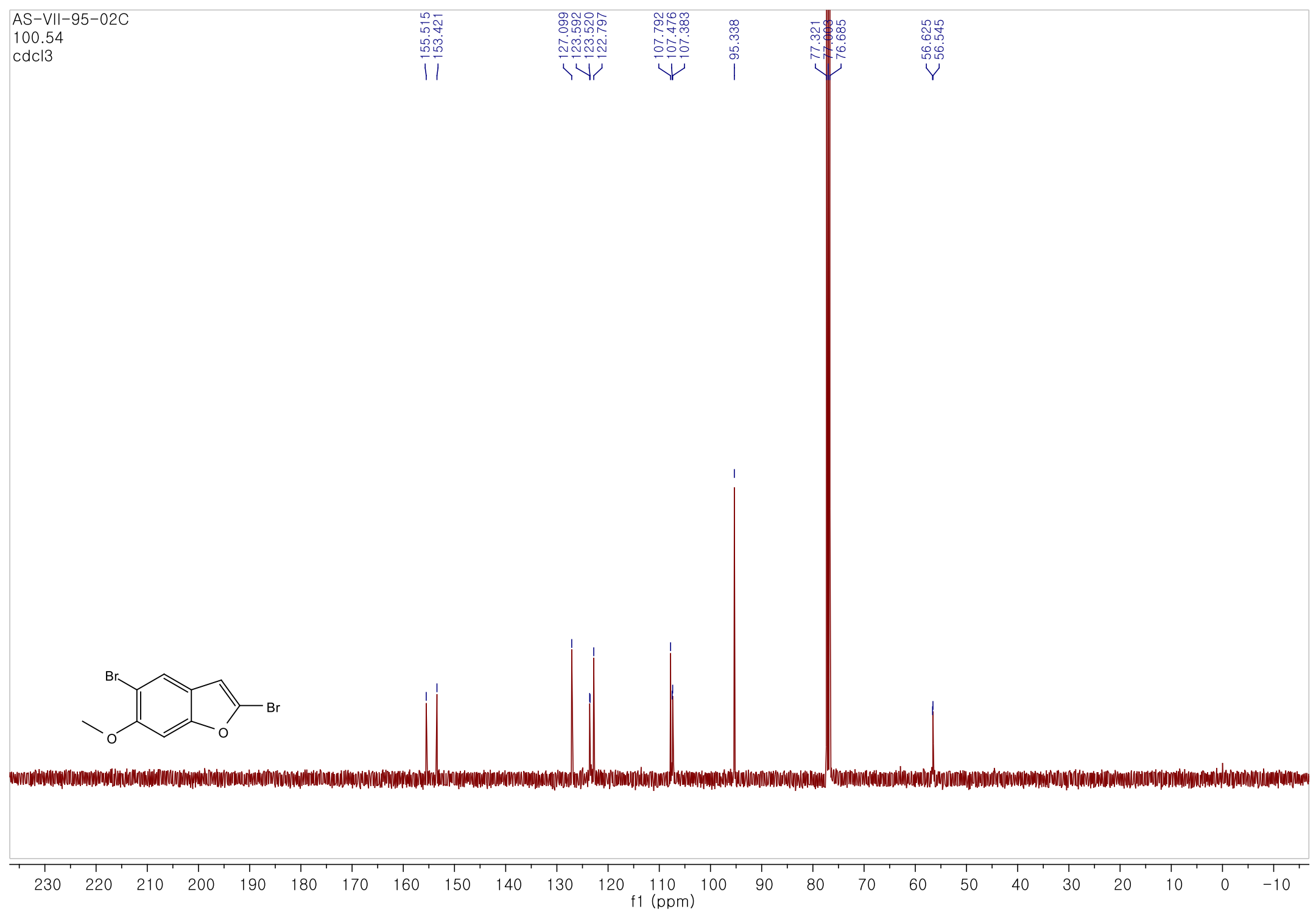

S29 
${ }^{1} \mathrm{H}$ NMR (400 MHz, $\mathrm{CDCl}_{3}$ ) spctrum of compound 13b

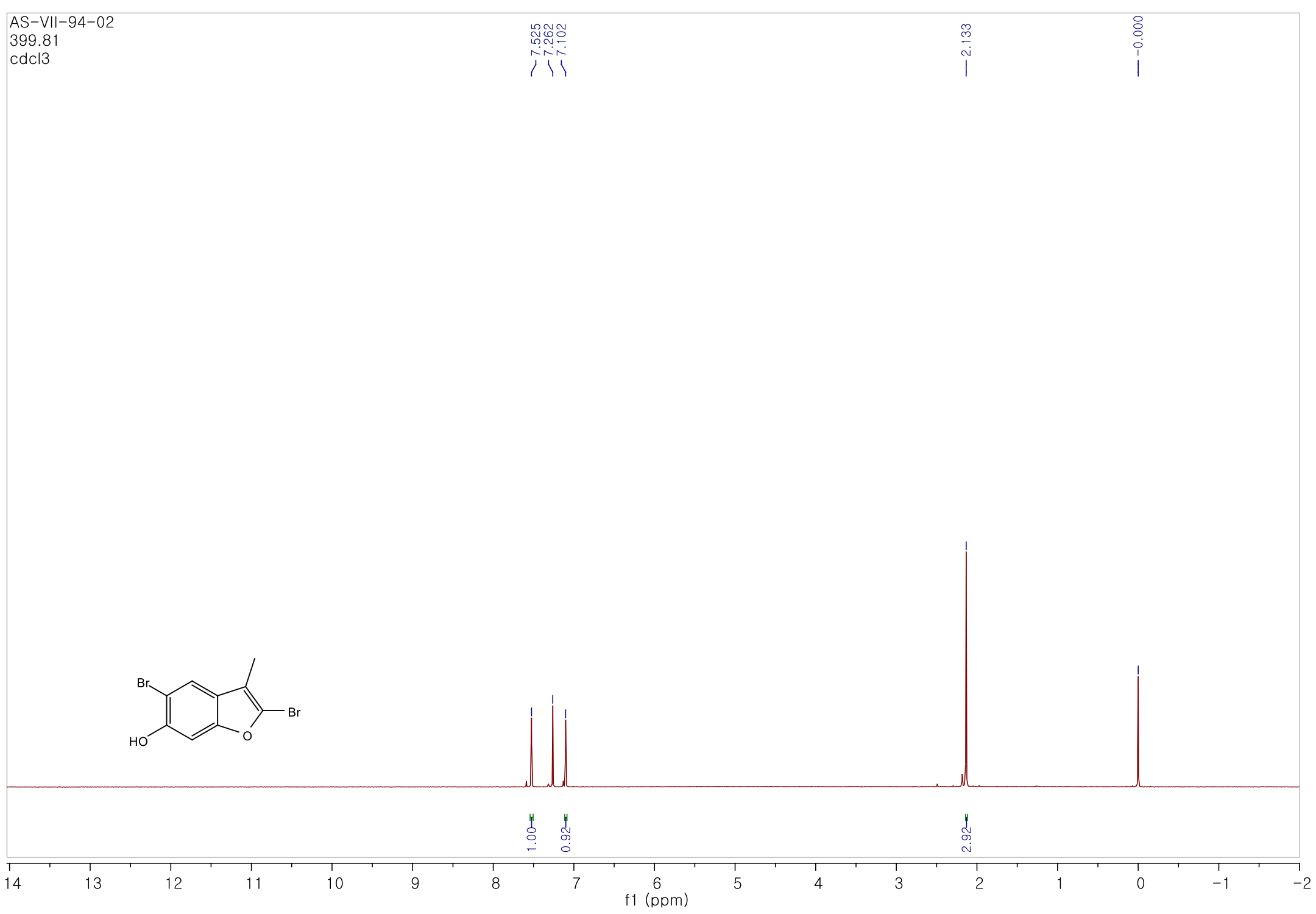


${ }^{13} \mathrm{C}$ NMR (100 MHz, $\mathrm{CDCl}_{3}$ ) spectrum of compound 13b

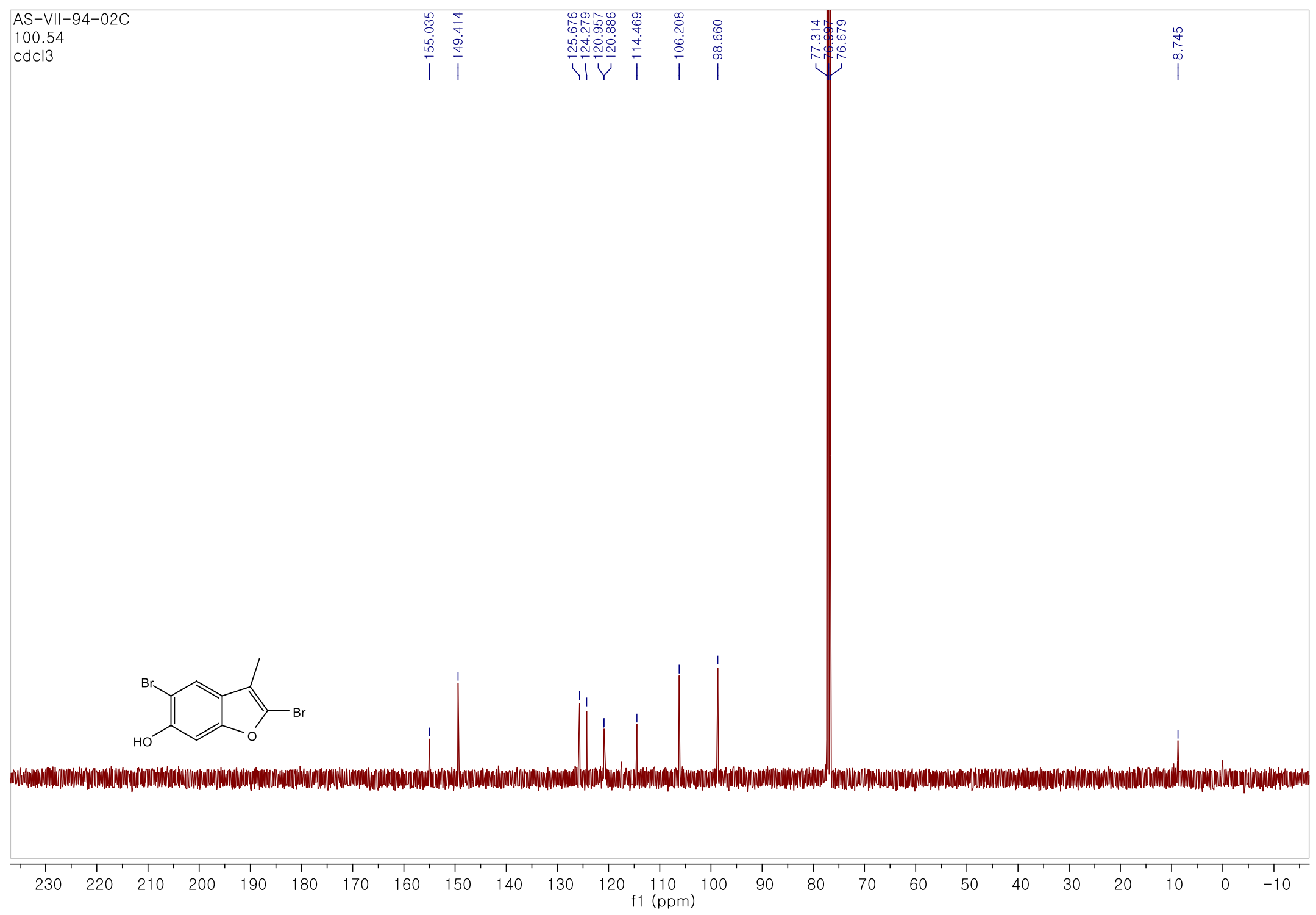

S31 
${ }^{1} \mathrm{H}$ NMR (400 MHz, $\mathrm{CDCl}_{3}$ ) spctrum of compound 13c

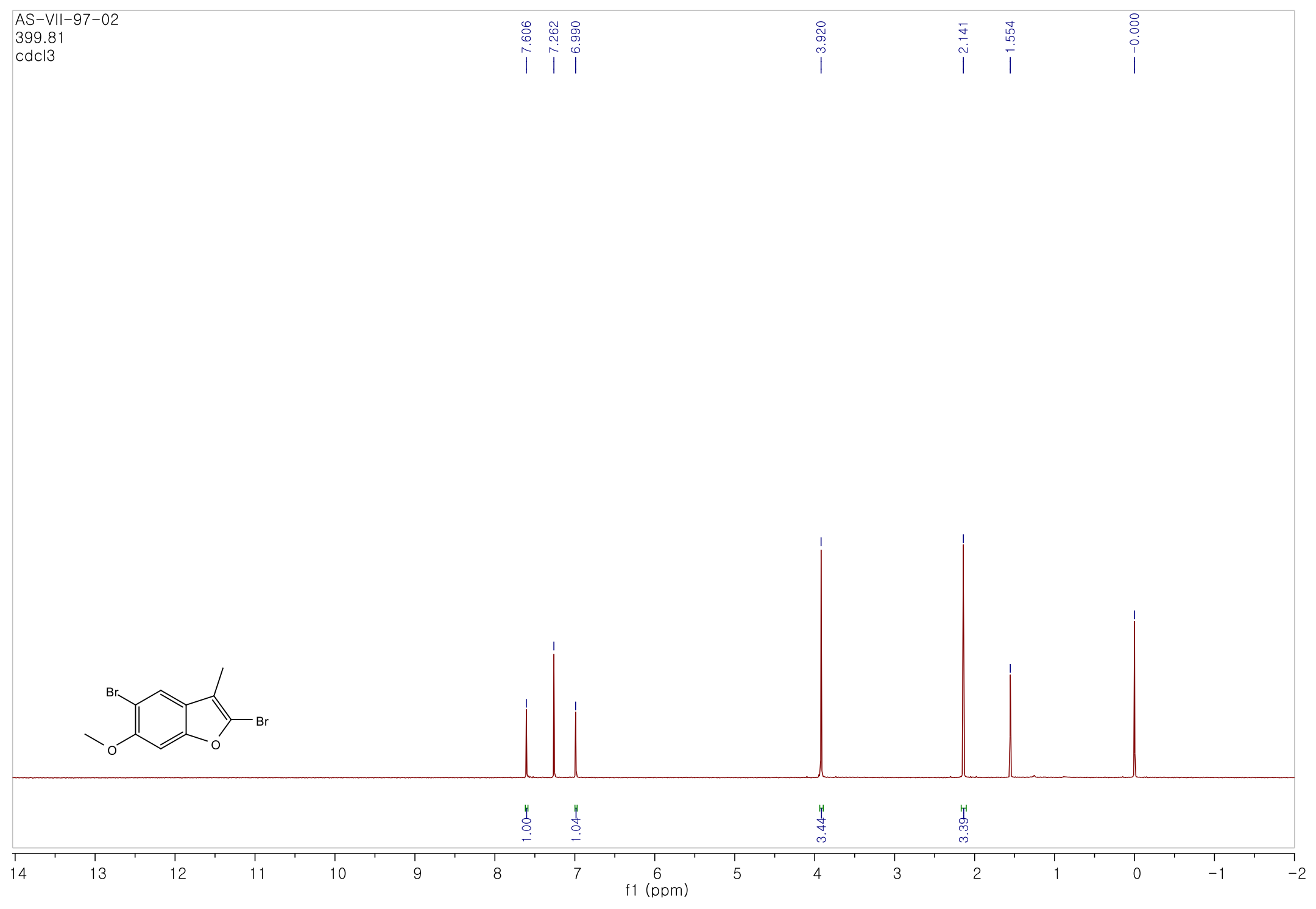


${ }^{13} \mathrm{C}$ NMR (100 MHz, $\mathrm{CDCl}_{3}$ ) spectrum of compound $\mathbf{1 3 c}$

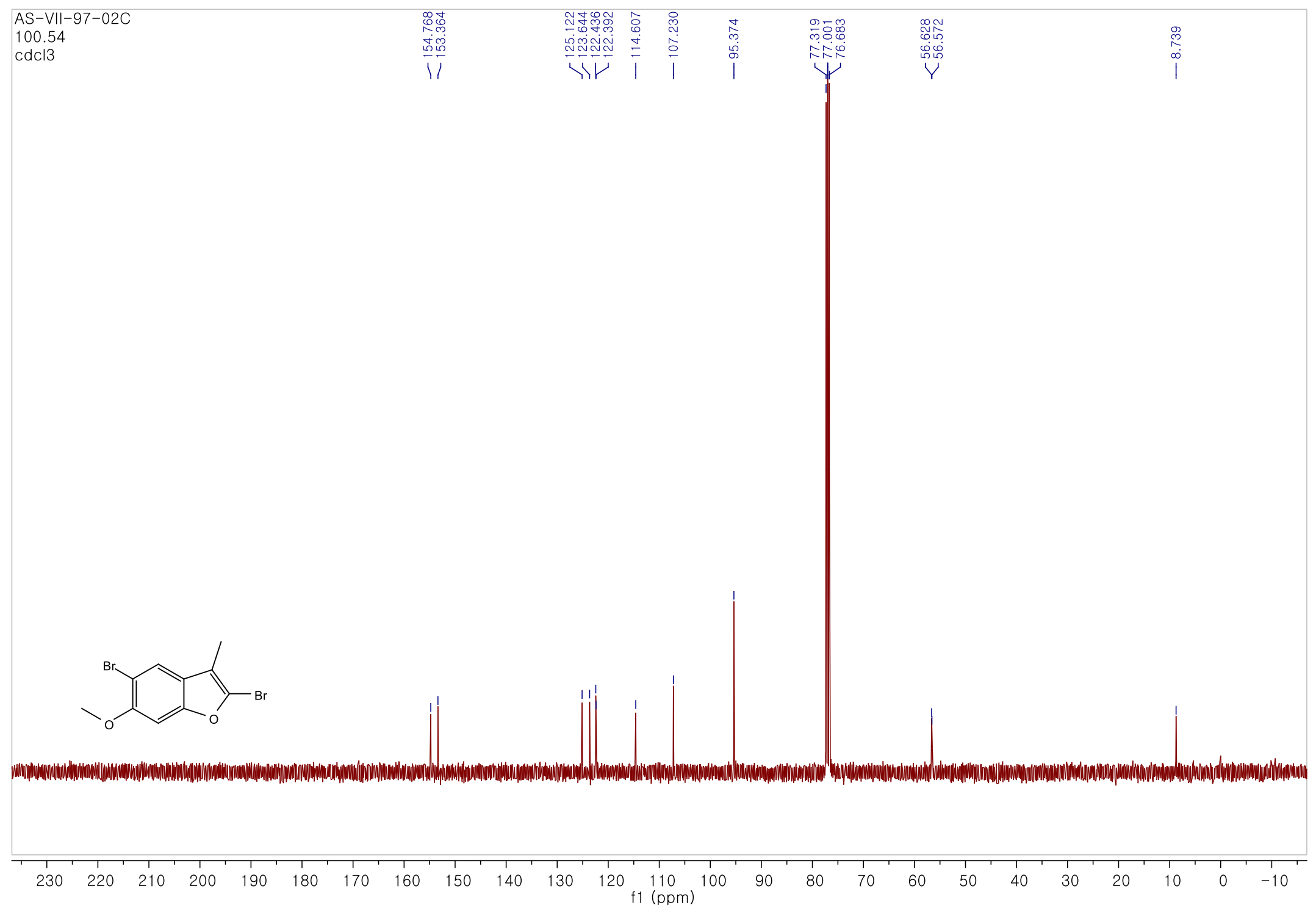

S33 
${ }^{1} \mathrm{H}$ NMR (400 MHz, DMSO- $d_{6}$ ) spctrum of compound 14a

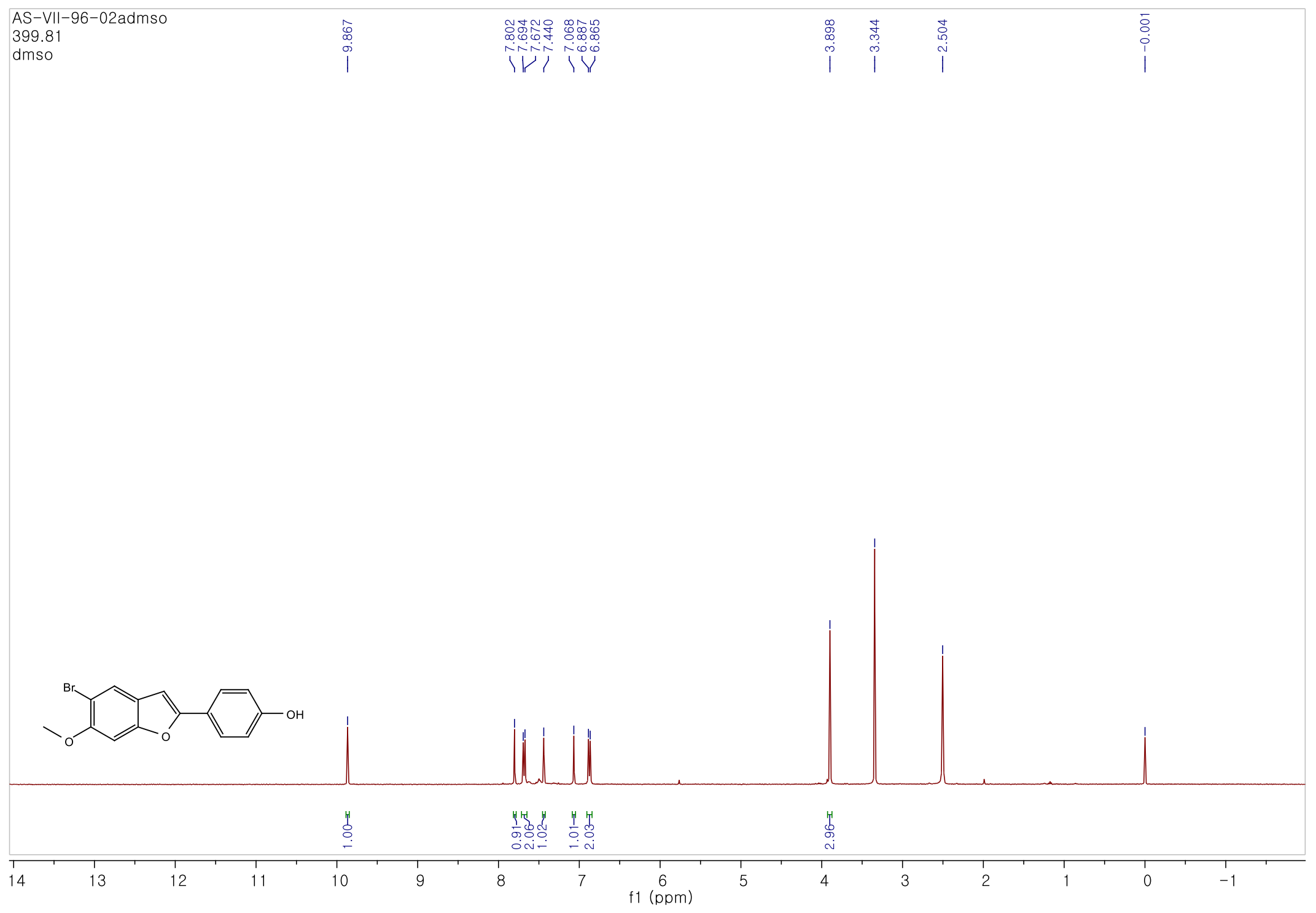

S34 
${ }^{13} \mathrm{C}$ NMR (100 MHz, DMSO- $d_{6}$ ) spctrum of compound 14a

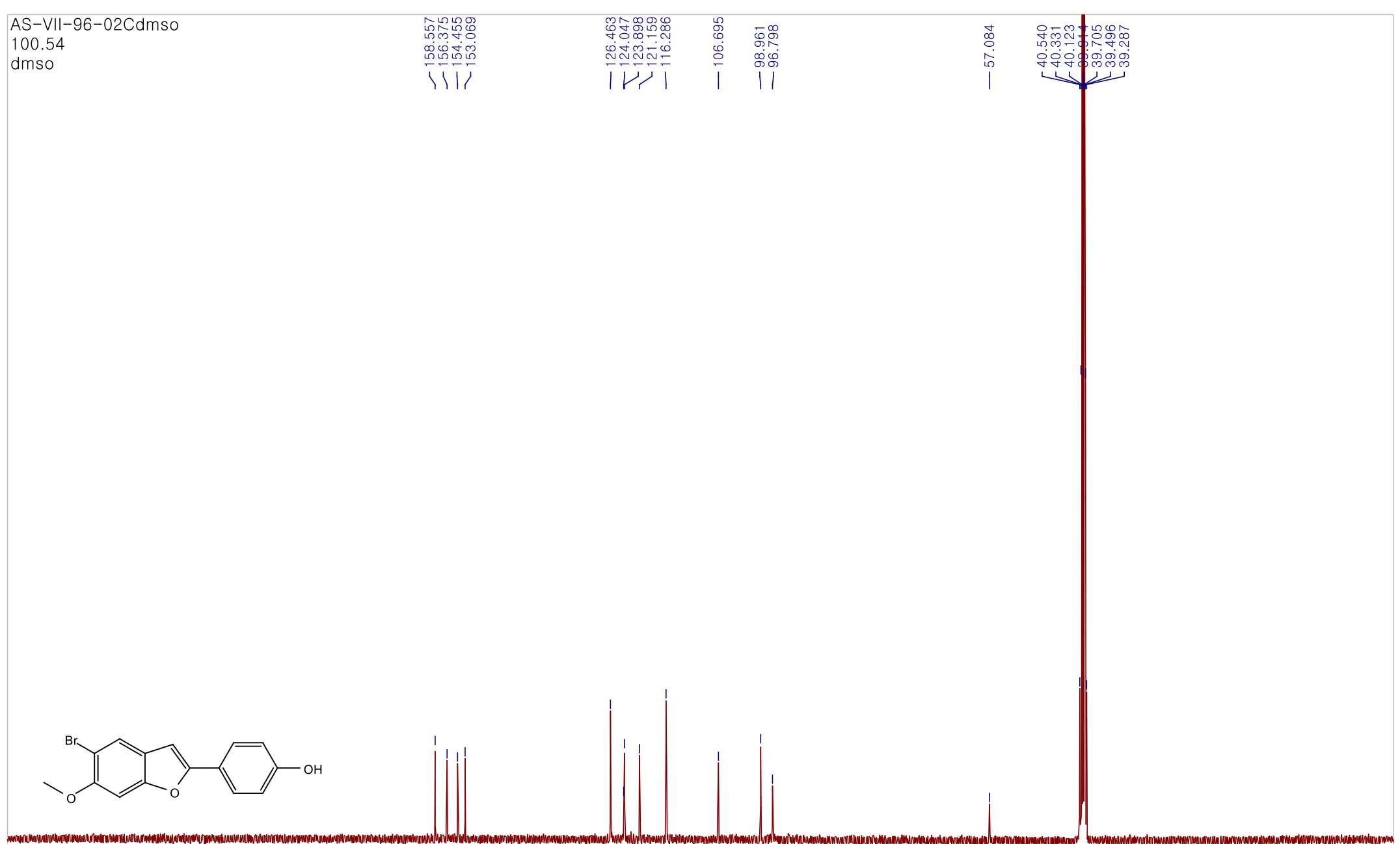

mim wow

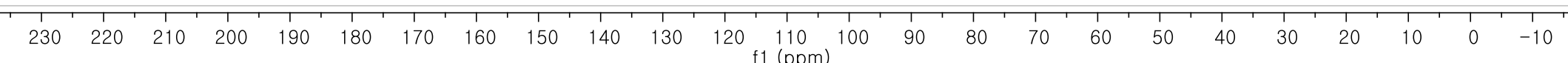


${ }^{1} \mathrm{H}$ NMR (400 MHz, DMSO- $d_{6}$ ) spctrum of compound 14b

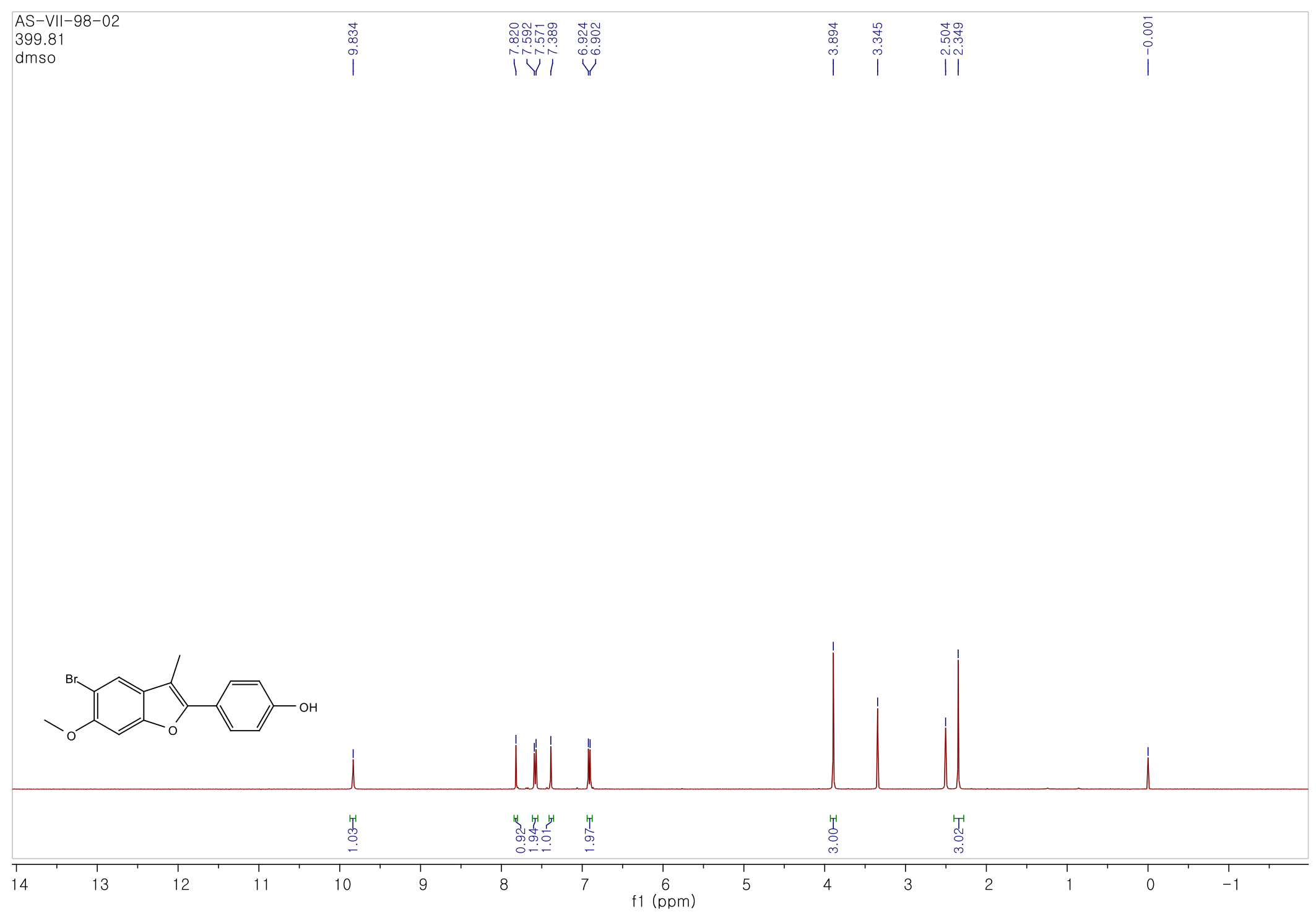


${ }^{13} \mathrm{C}$ NMR (100 MHz, DMSO- $d_{6}$ ) spctrum of compound 14b

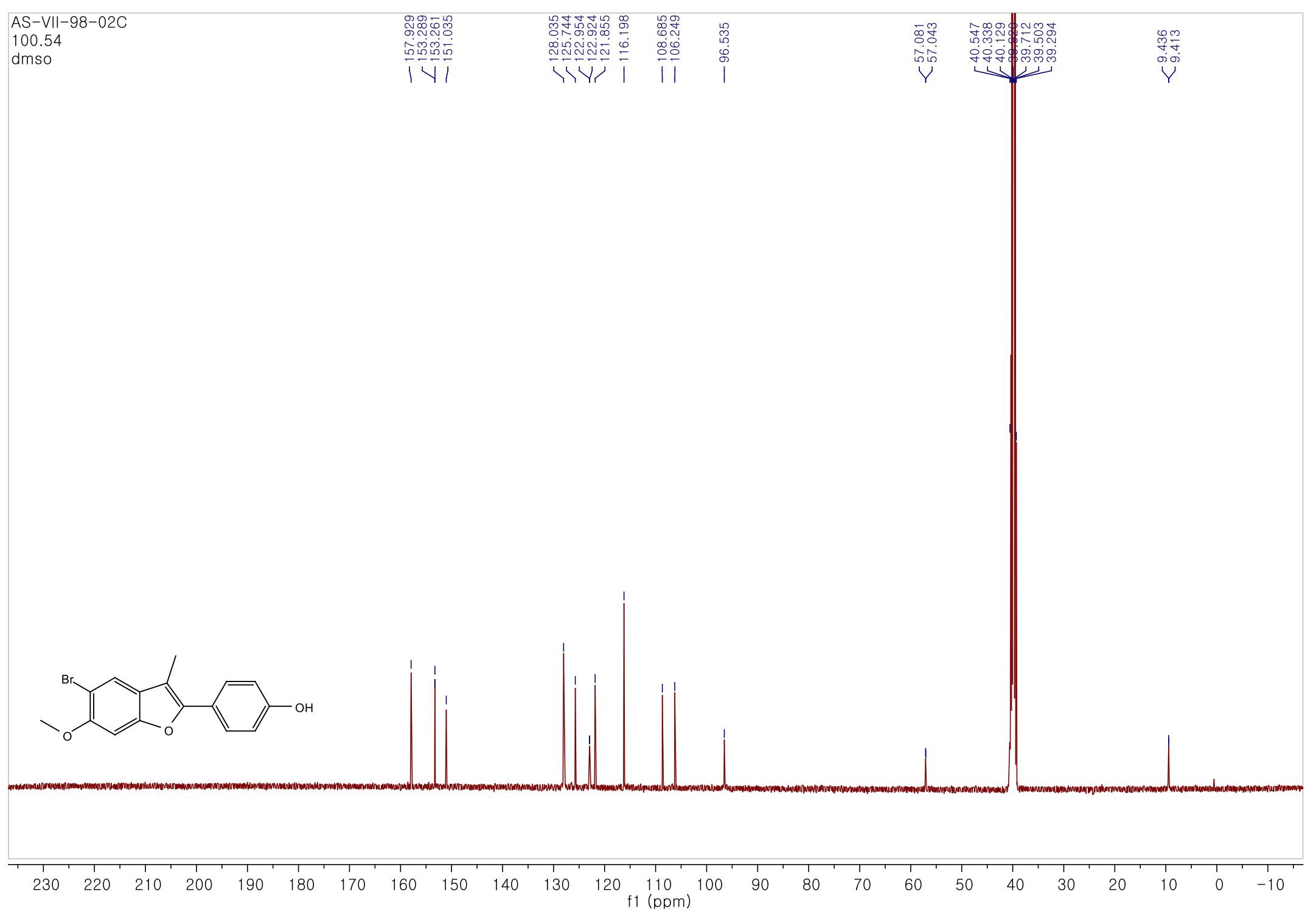


${ }^{1} \mathrm{H}$ NMR (400 MHz, methanol- $d_{4}$ ) spctrum of compound 15a

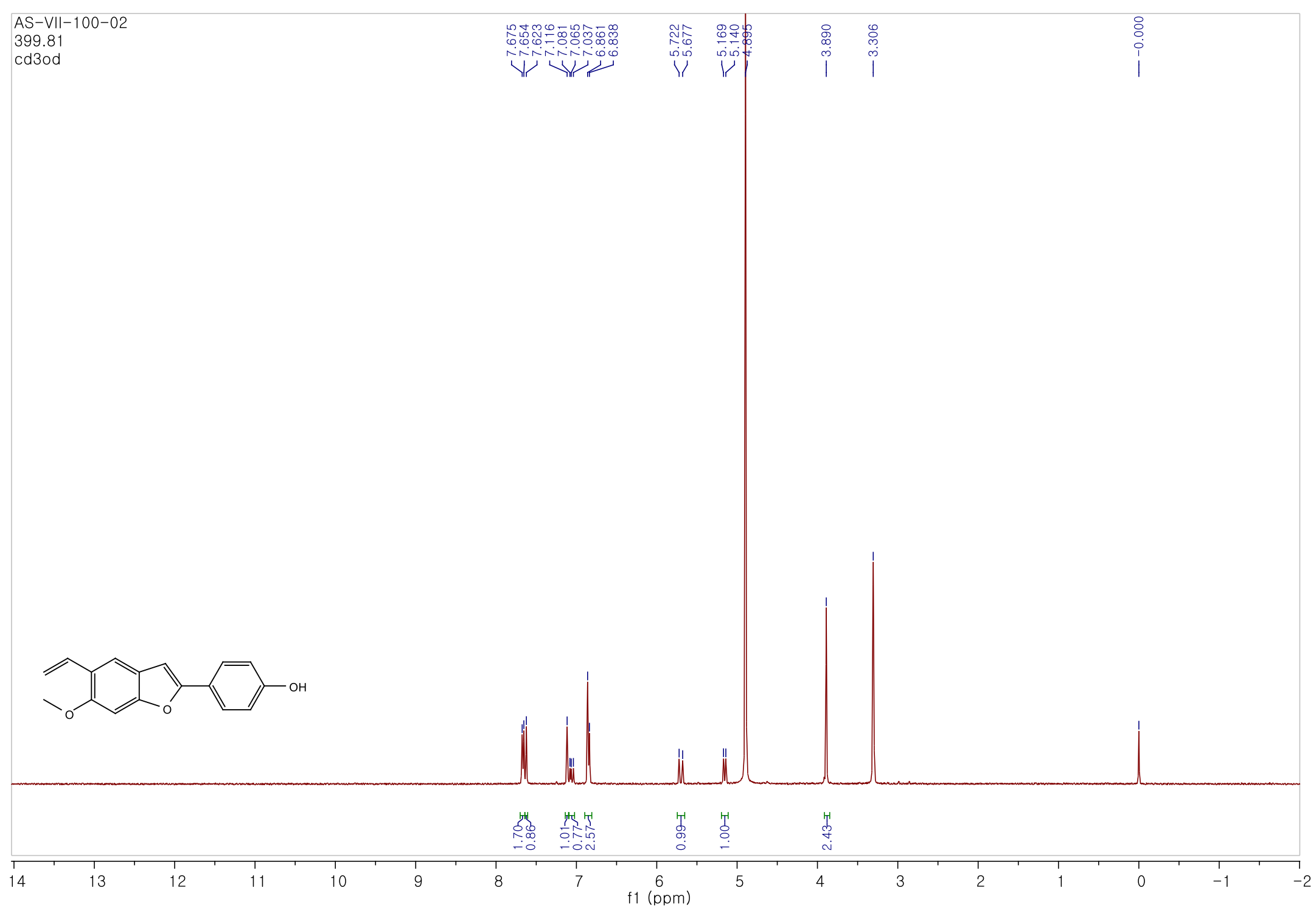


${ }^{13} \mathrm{C}$ NMR (100 MHz, methanol- $d_{4}$ ) spctrum of compound 15a

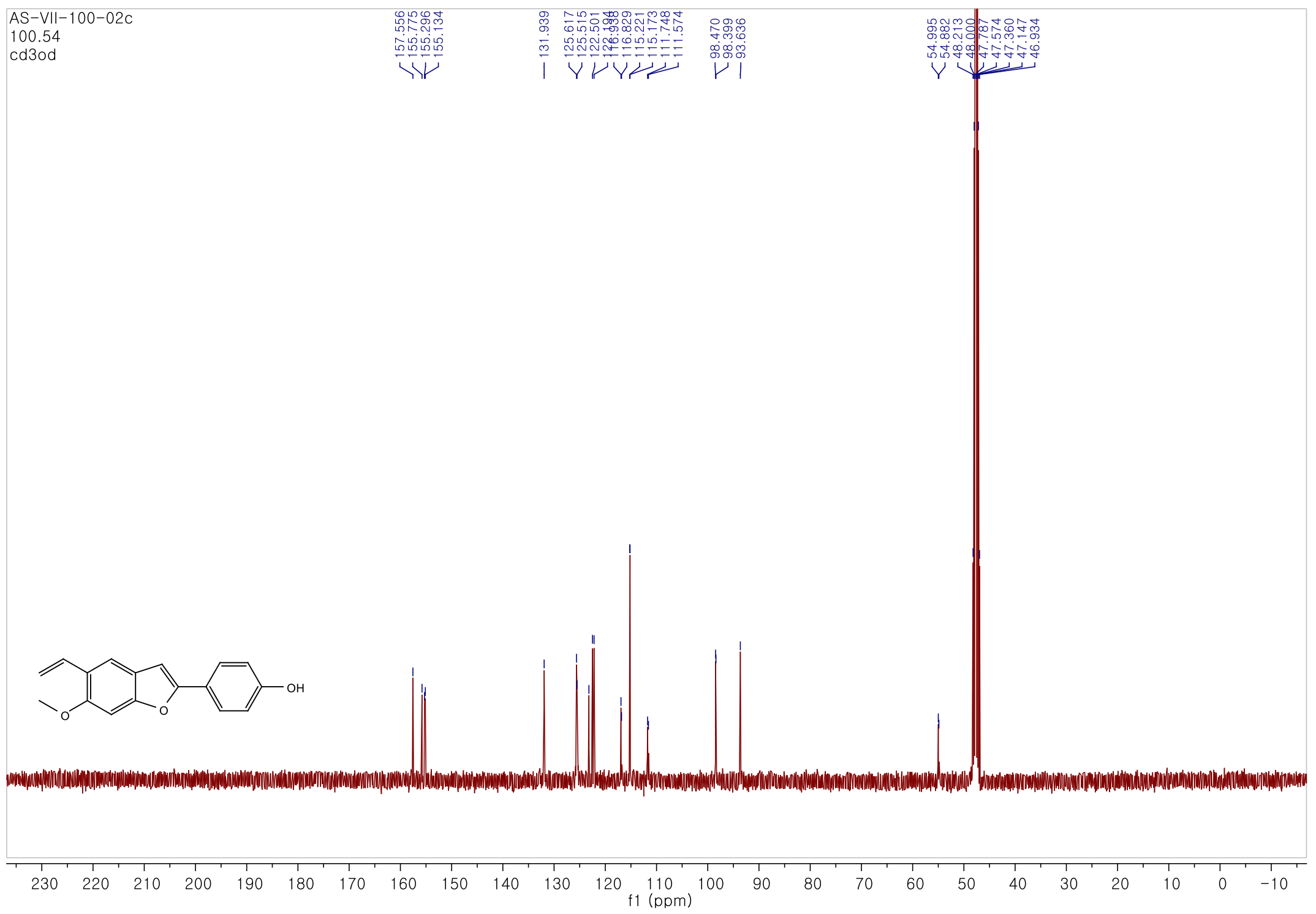

S39 
${ }^{1} \mathrm{H}$ NMR (400 MHz, methanol- $d_{4}$ ) spctrum of compound $\mathbf{1 5 b}$

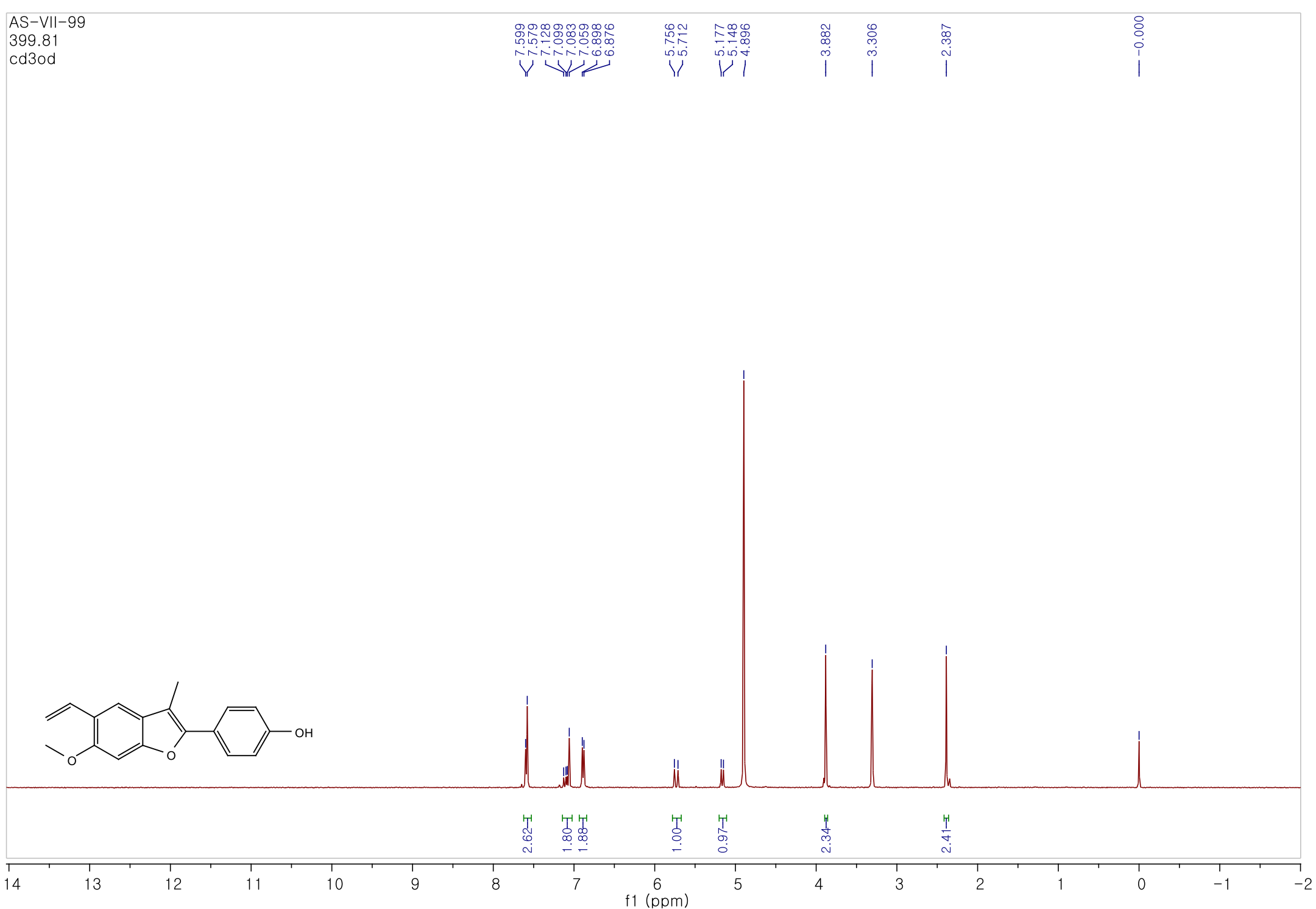


${ }^{13} \mathrm{C}$ NMR (100 MHz, methanol- $d_{4}$ ) spctrum of compound $\mathbf{1 5 b}$

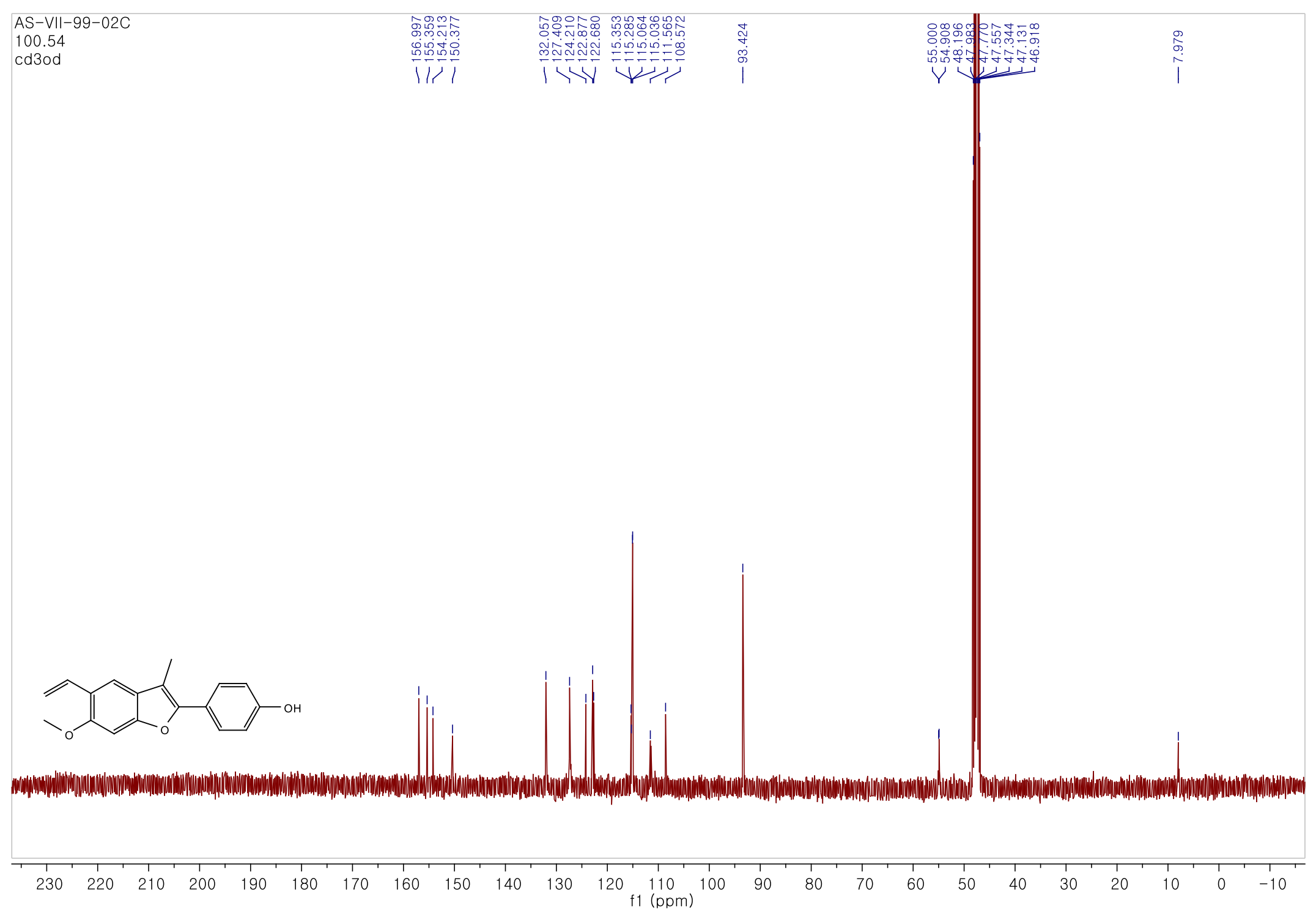


${ }^{1} \mathrm{H}$ NMR (400 MHz, $\mathrm{CDCl}_{3}$ ) spctrum of compound $\mathbf{1 7}$

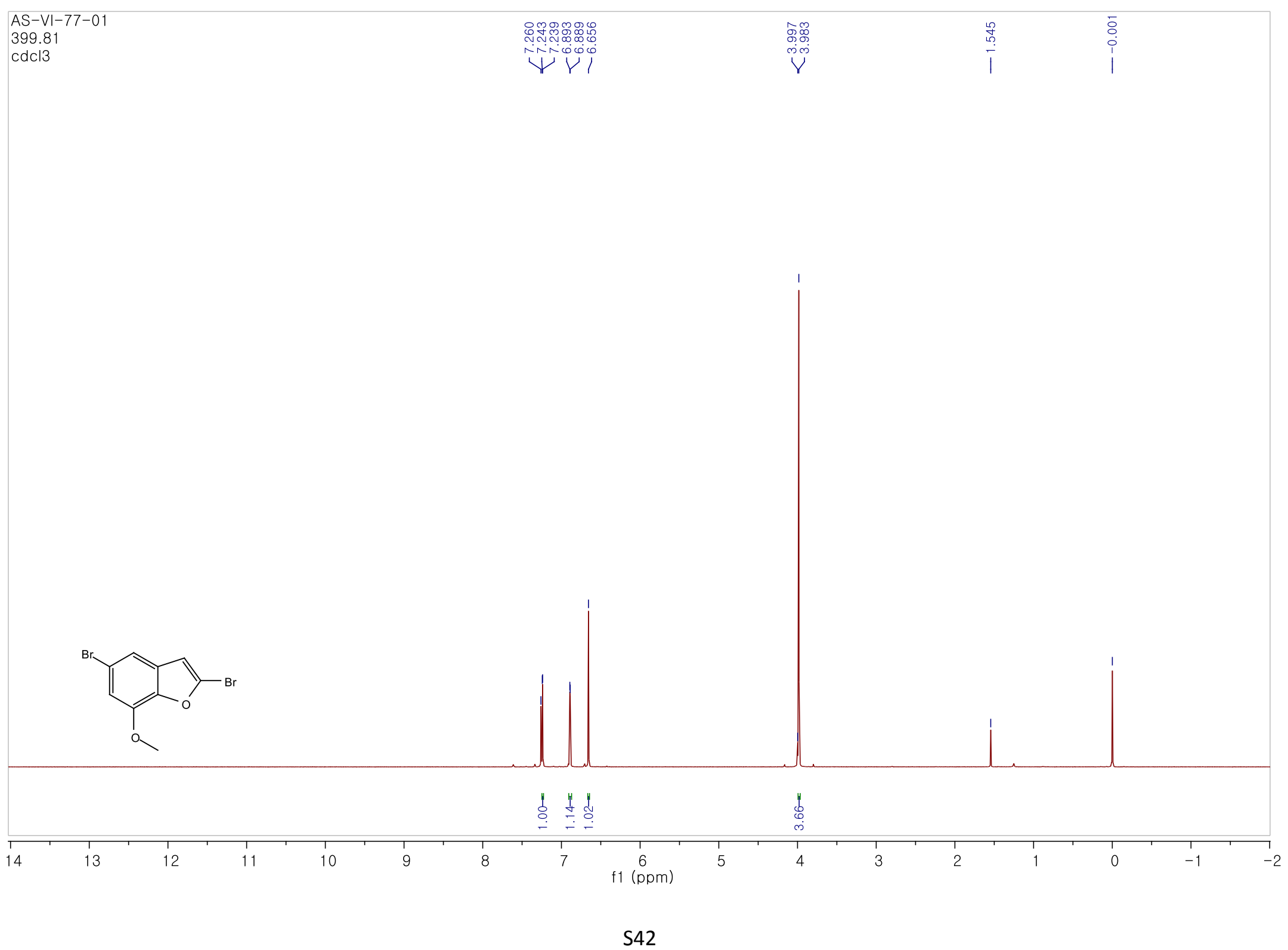


${ }^{13} \mathrm{C}$ NMR (100 MHz, $\mathrm{CDCl}_{3}$ ) spctrum of compound 17

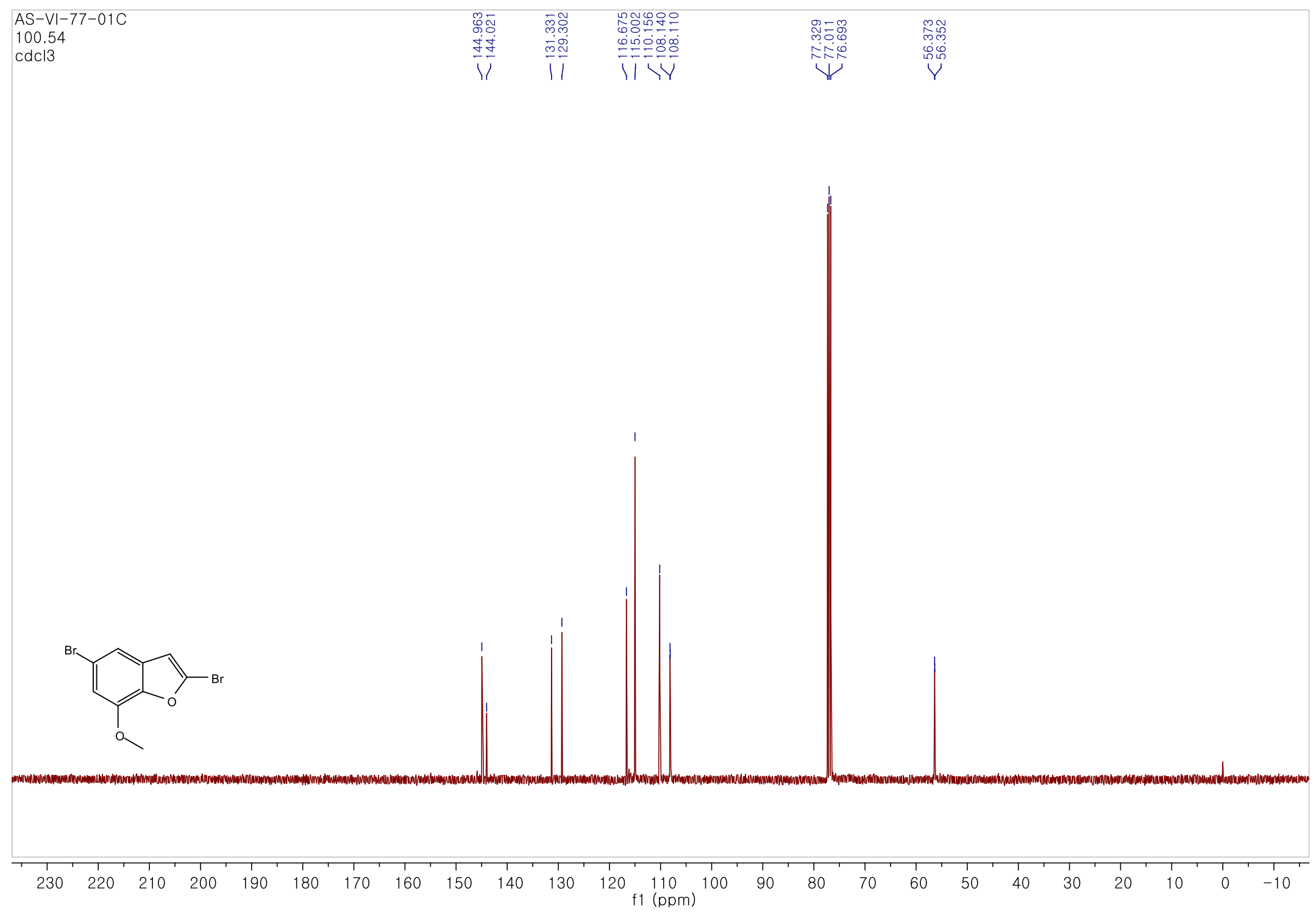

S43 
${ }^{1} \mathrm{H}$ NMR (400 MHz, $\mathrm{CDCl}_{3}$ ) spctrum of compound $\mathbf{1 8}$

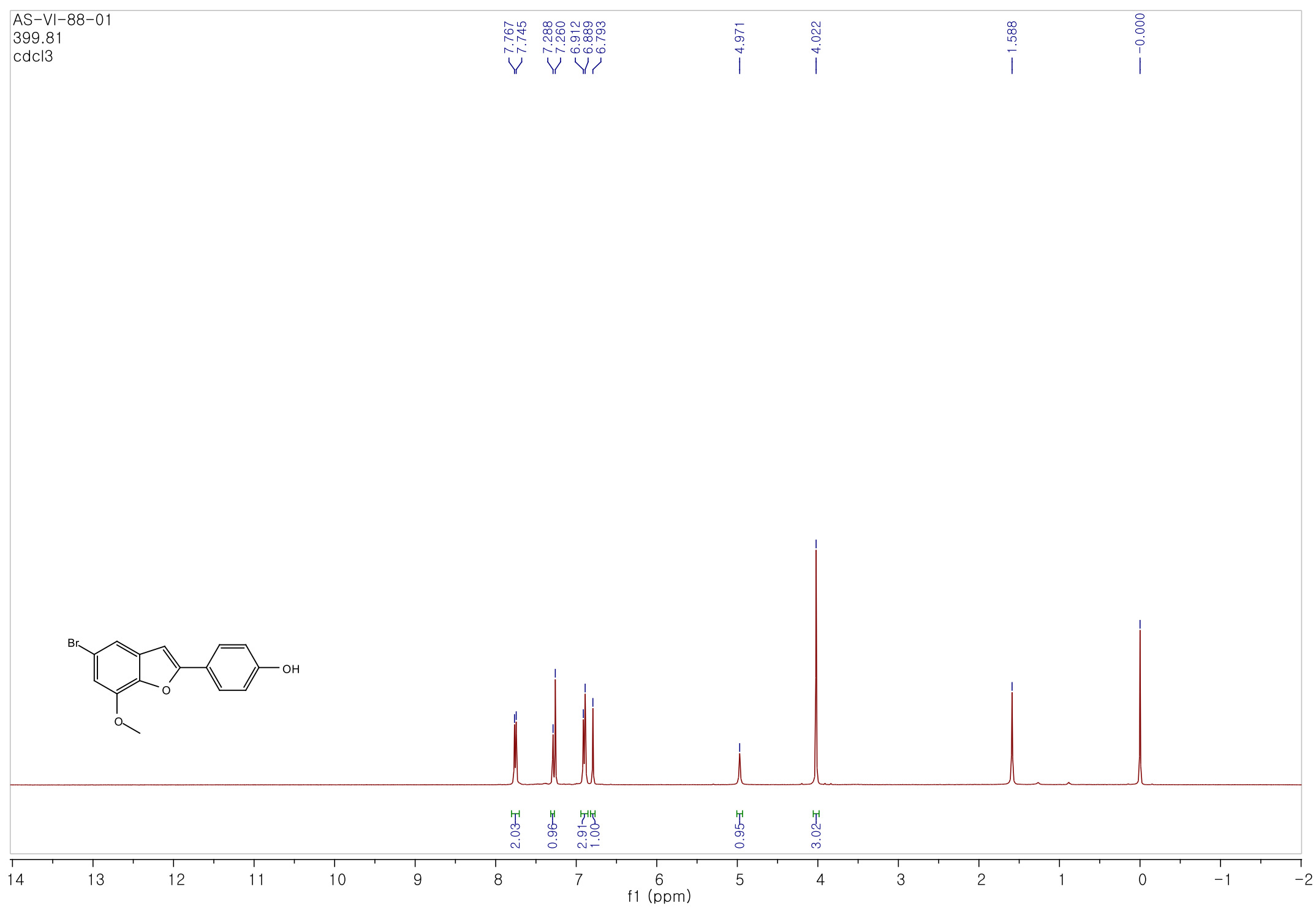


${ }^{13} \mathrm{C}$ NMR $\left(100 \mathrm{MHz}, \mathrm{CDCl}_{3}\right)$ spctrum of compound $\mathbf{1 8}$

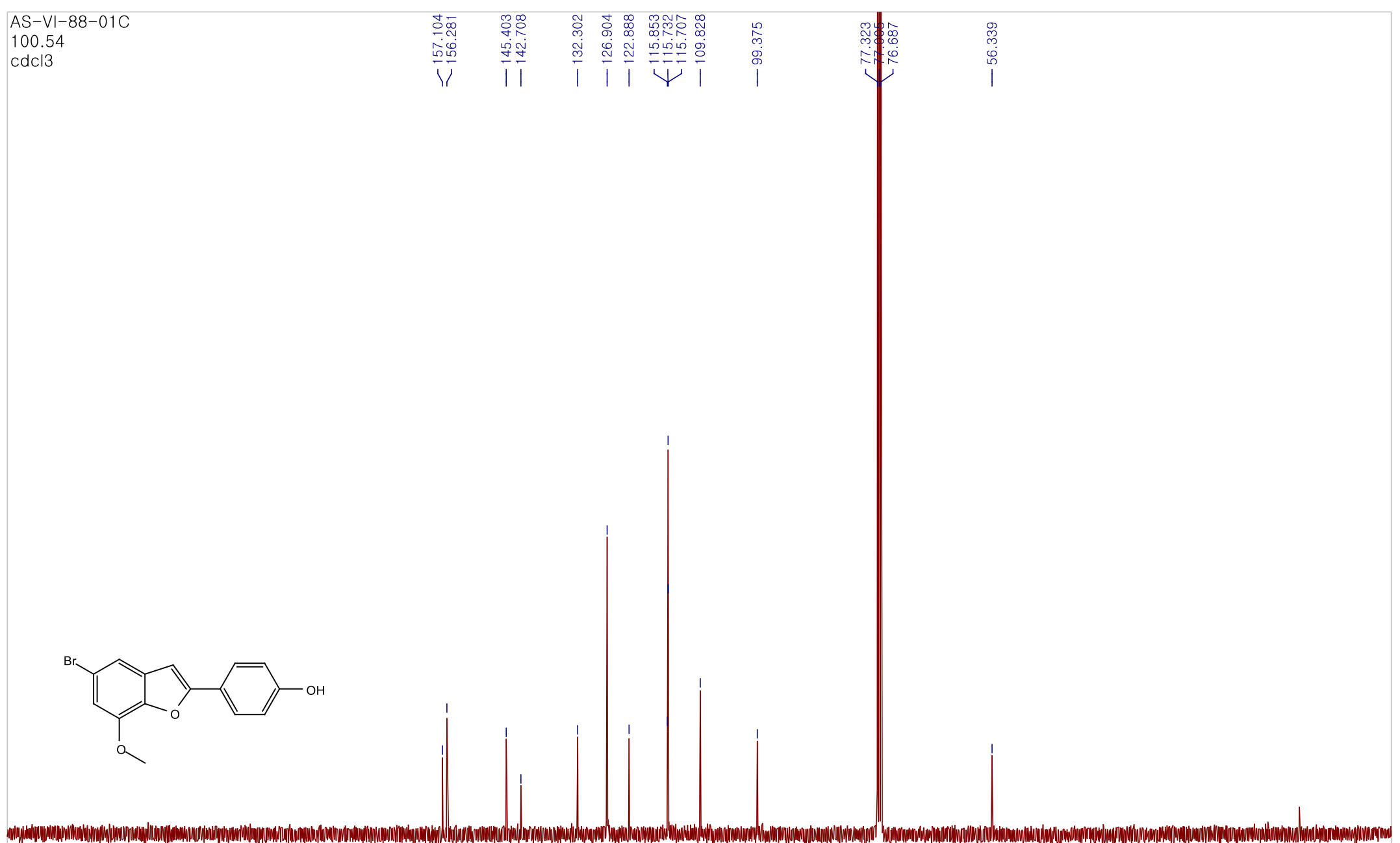

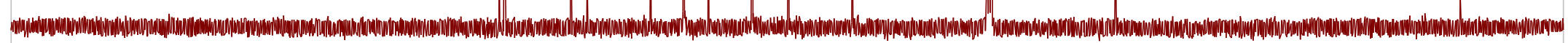

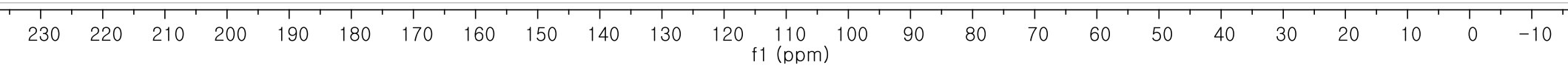


${ }^{1} \mathrm{H}$ NMR (400 MHz, $\mathrm{CDCl}_{3}$ ) spctrum of compound 19

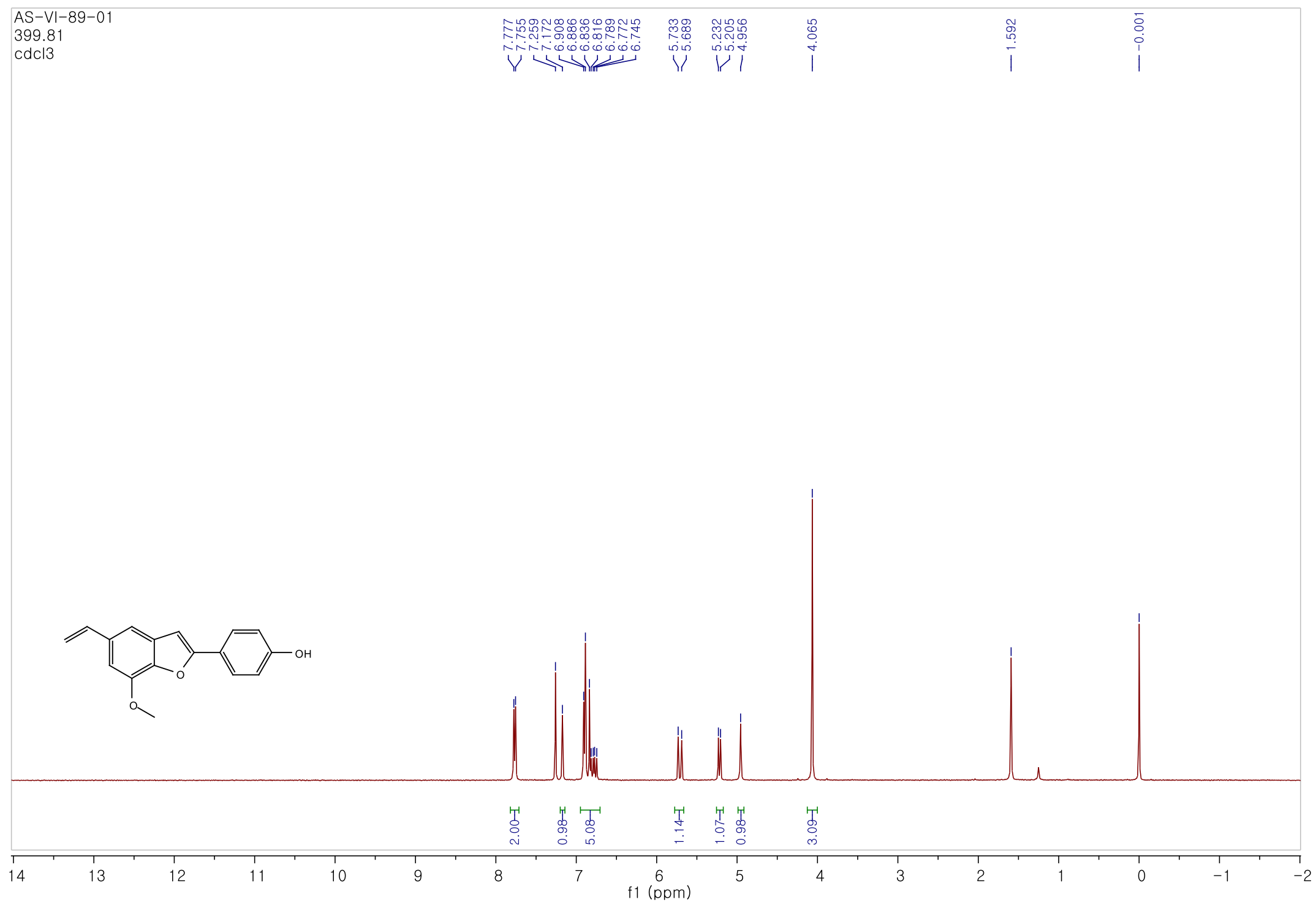


${ }^{13} \mathrm{C}$ NMR $\left(100 \mathrm{MHz}, \mathrm{CDCl}_{3}\right)$ spctrum of compound 19

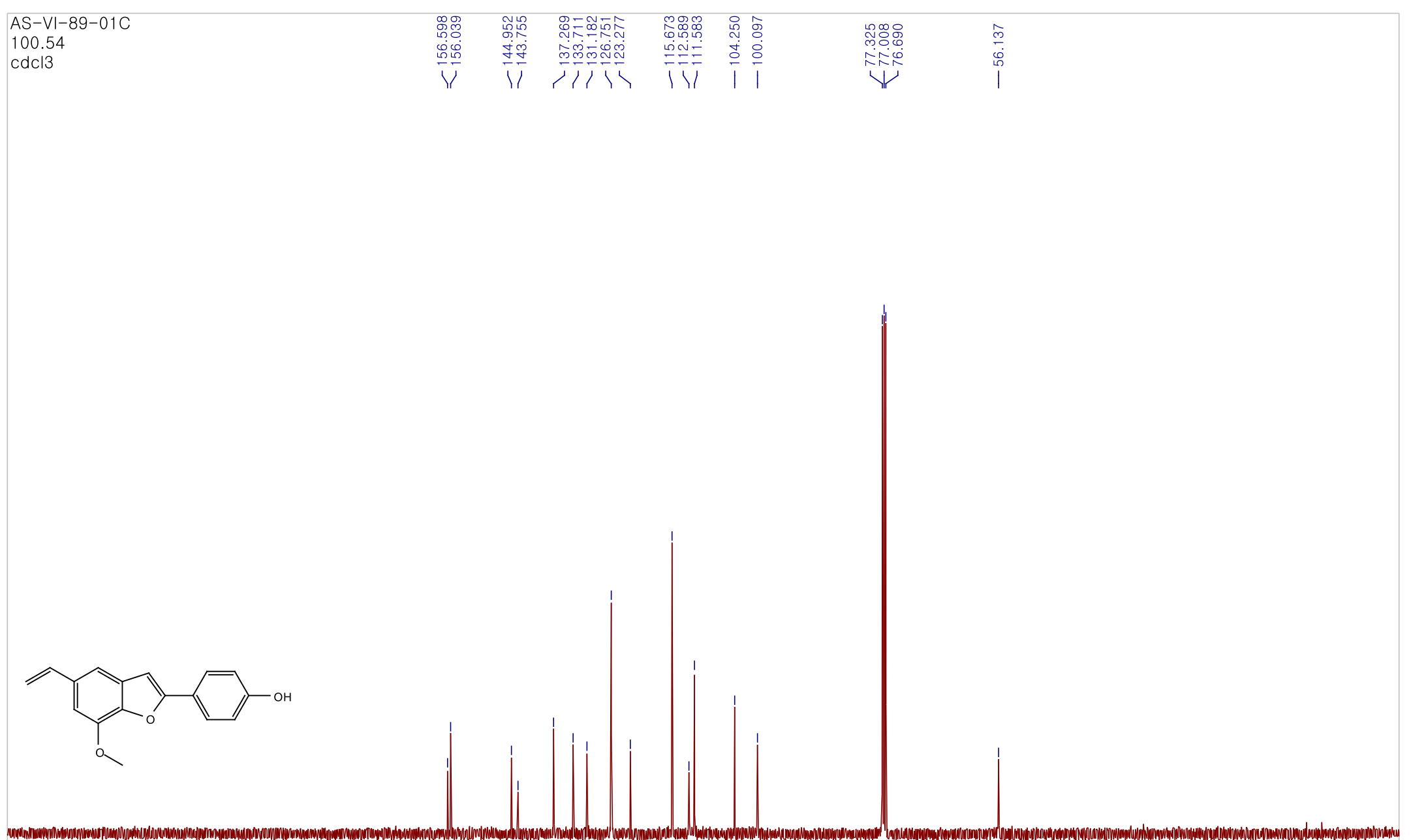

(1)

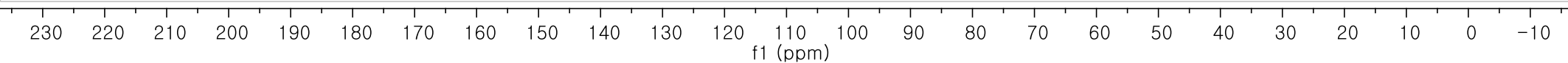


${ }^{1} \mathrm{H}$ NMR (400 MHz, $\mathrm{CDCl}_{3}$ ) spctrum of compound 20

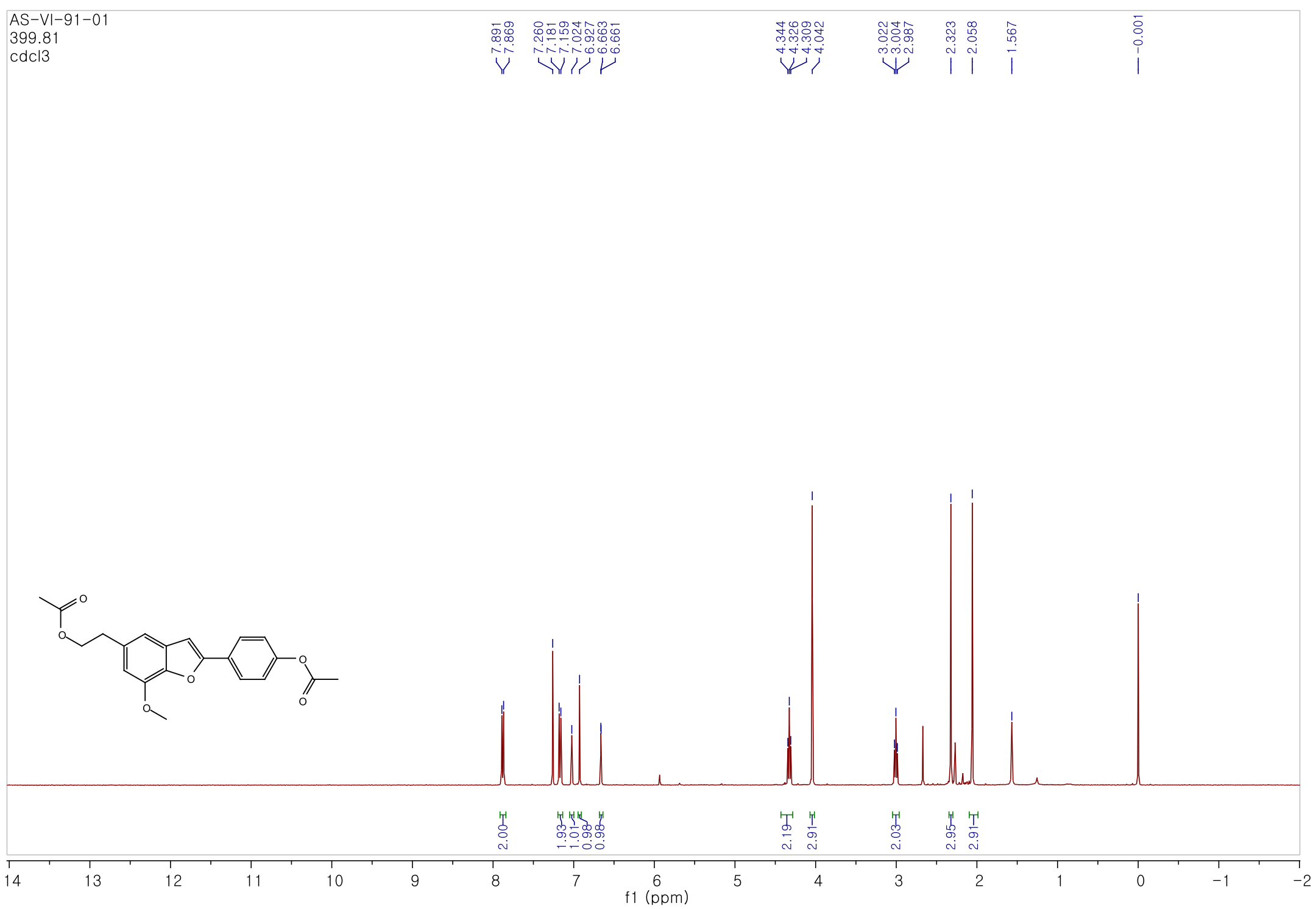


${ }^{13} \mathrm{C}$ NMR $\left(100 \mathrm{MHz}, \mathrm{CDCl}_{3}\right)$ spctrum of compound 20

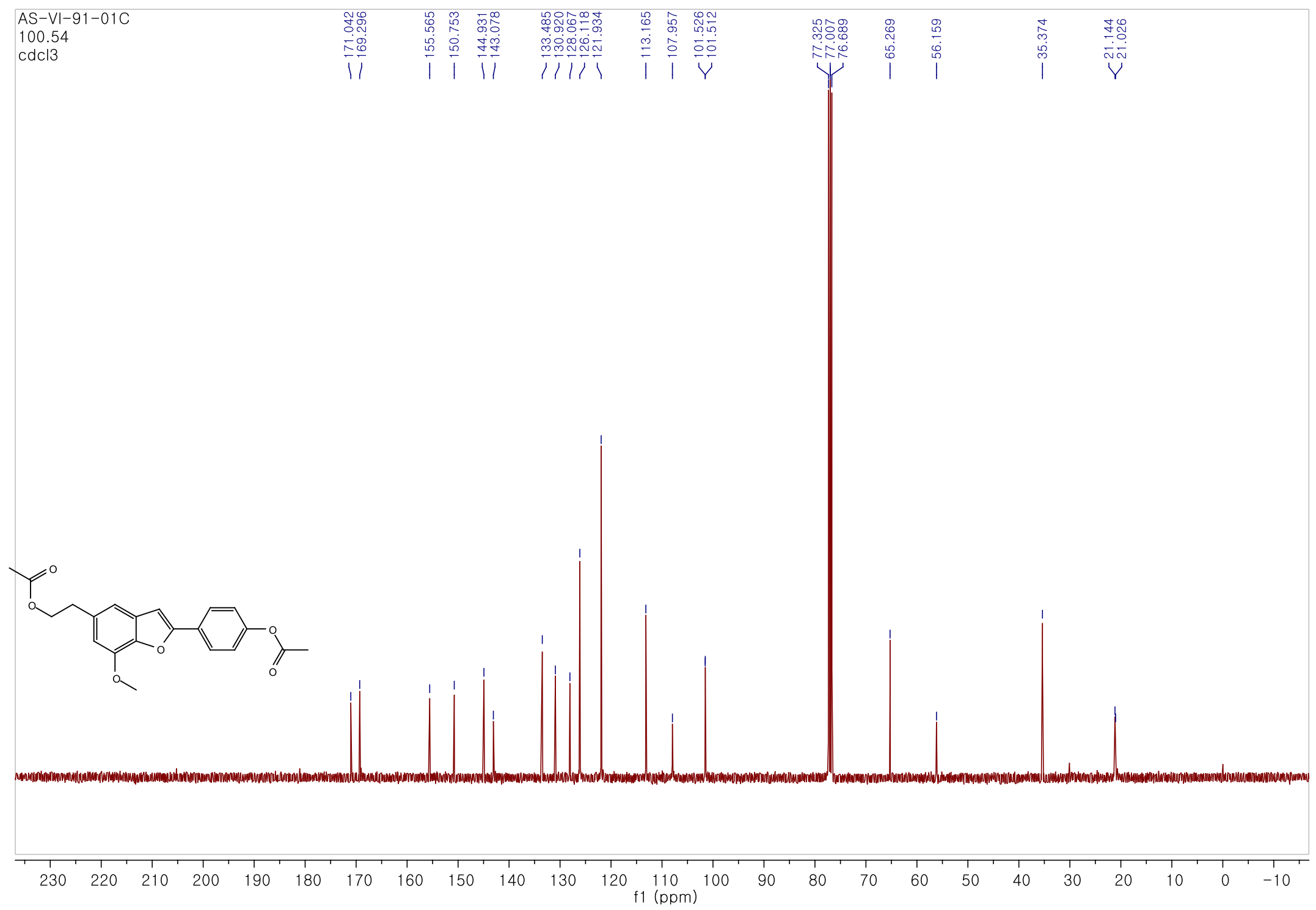

S49 
${ }^{1} \mathrm{H}$ NMR (400 MHz, $\mathrm{CDCl}_{3}$ ) spctrum of compound 21

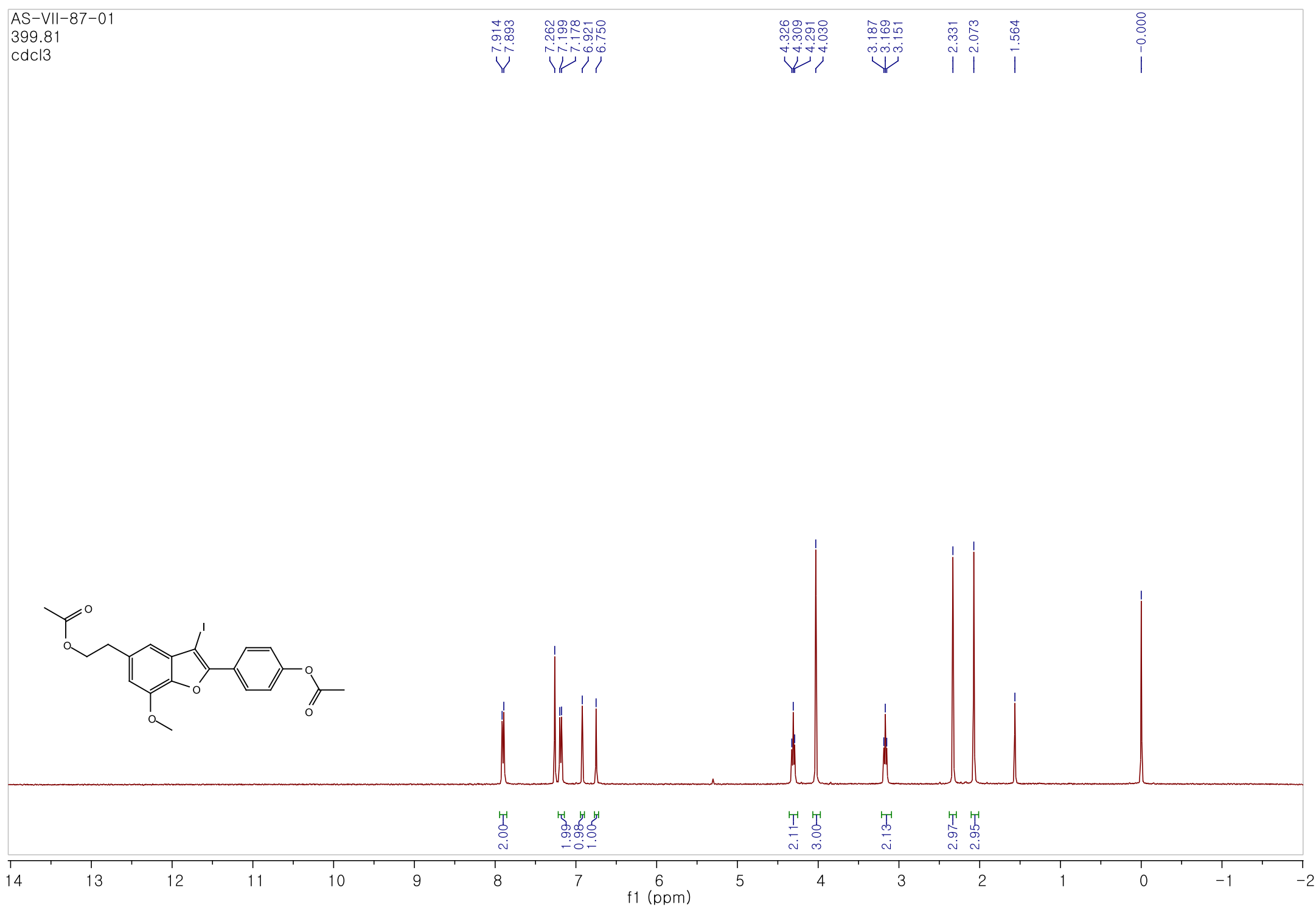


${ }^{13} \mathrm{C}$ NMR $\left(100 \mathrm{MHz}, \mathrm{CDCl}_{3}\right)$ spctrum of compound 21

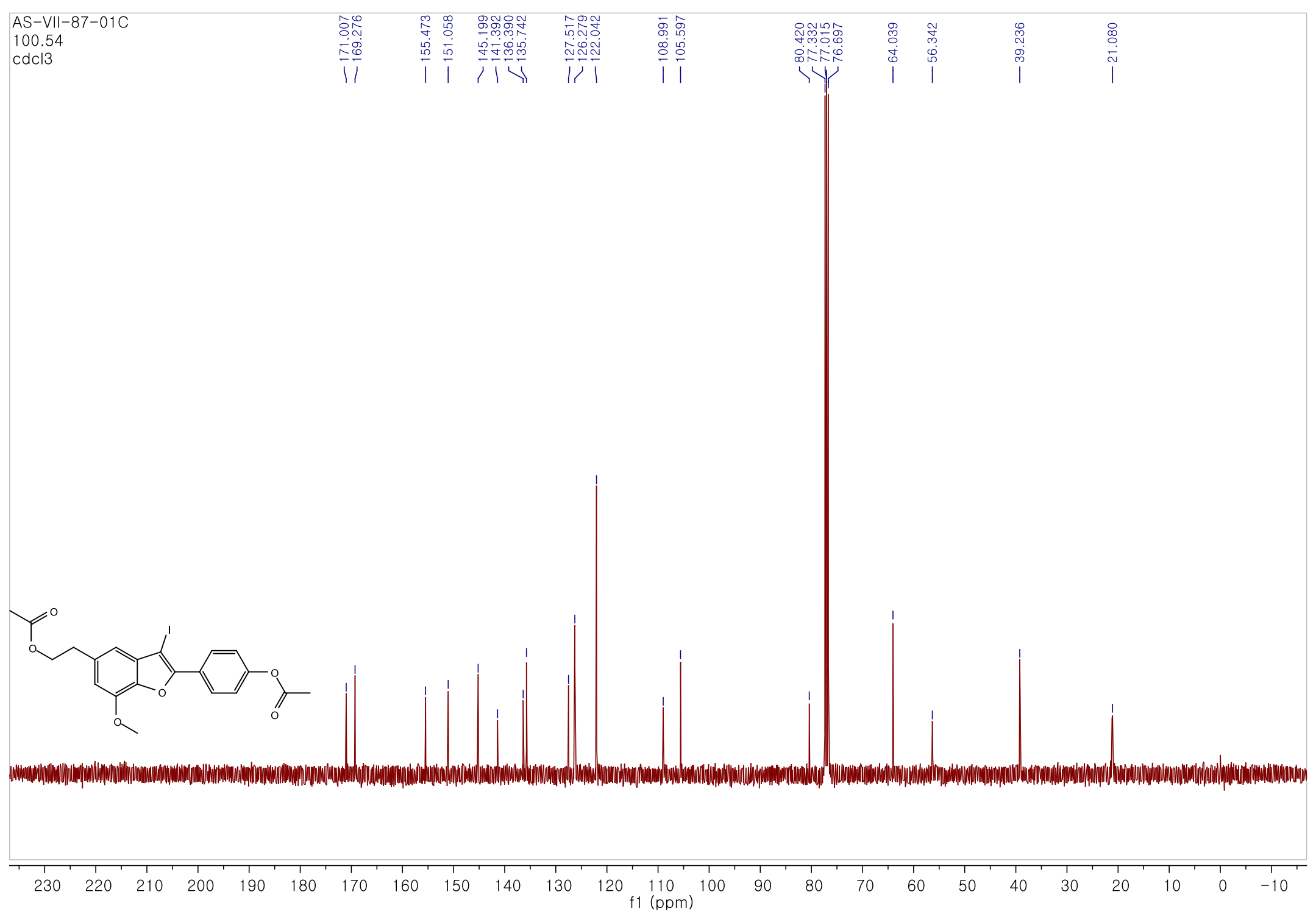


${ }^{1} \mathrm{H}$ NMR (400 MHz, $\mathrm{CDCl}_{3}$ ) spctrum of compound 22

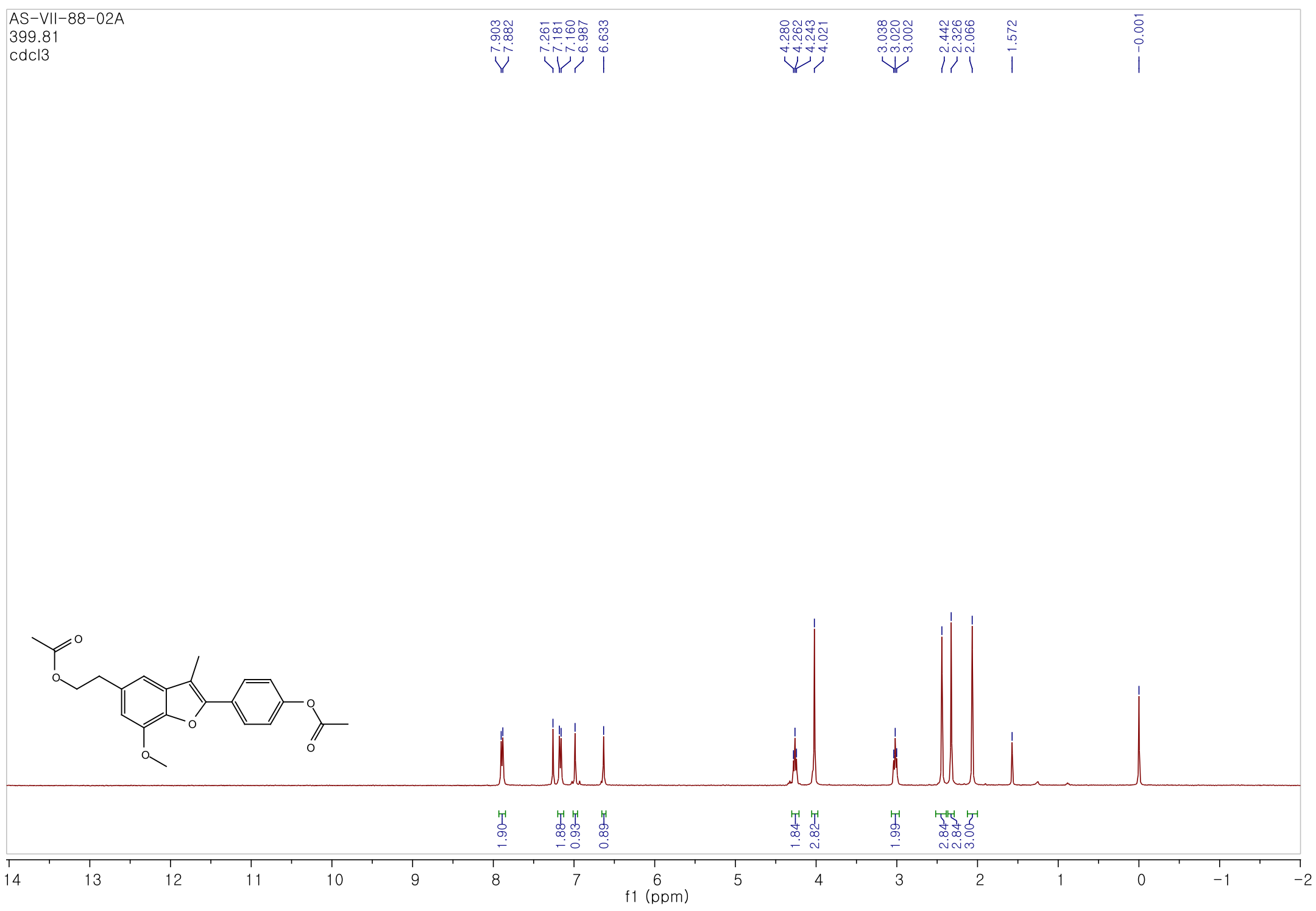


${ }^{13} \mathrm{C}$ NMR $\left(100 \mathrm{MHz}, \mathrm{CDCl}_{3}\right)$ spctrum of compound 22

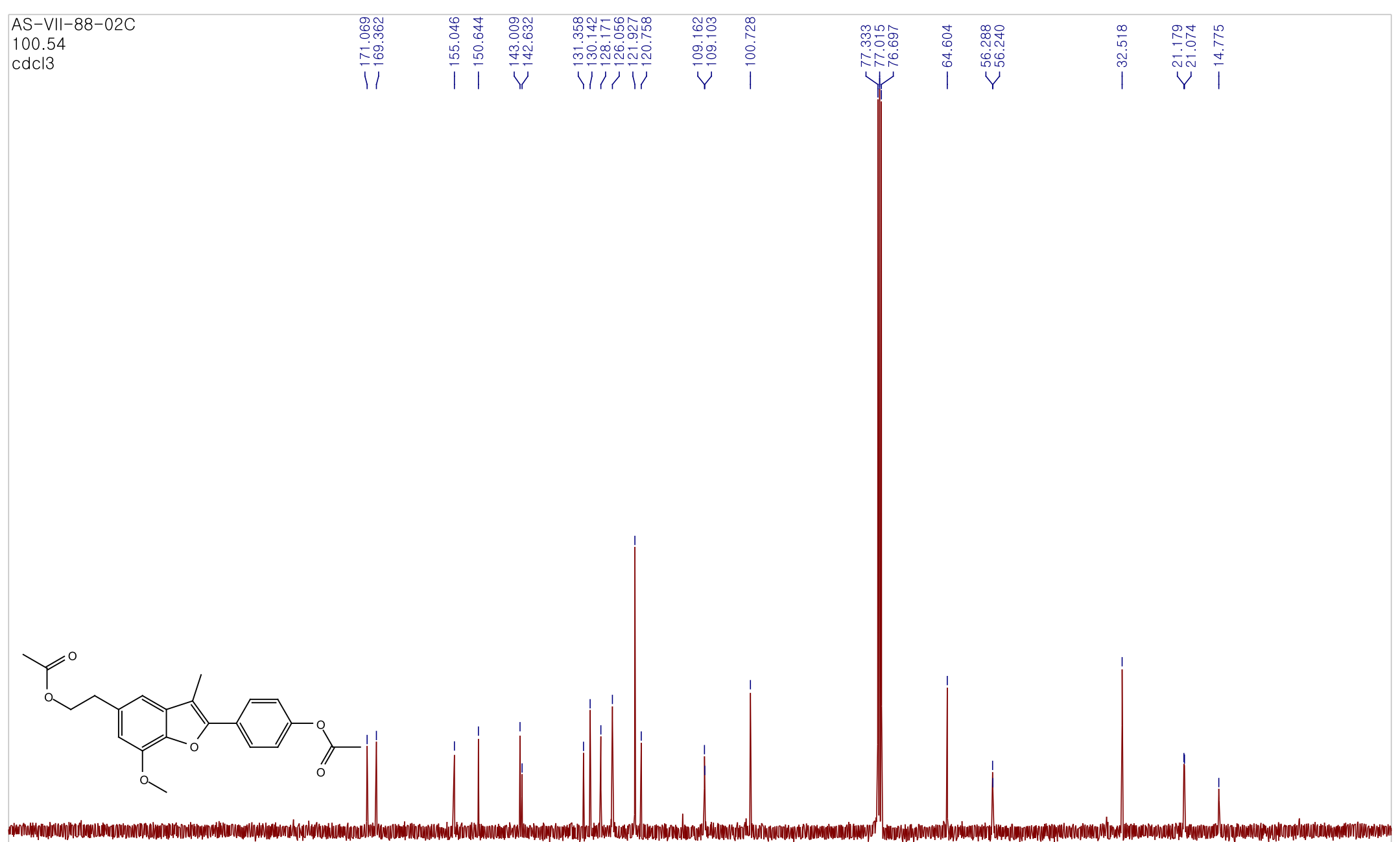

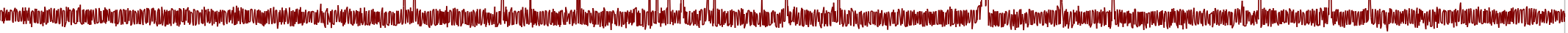

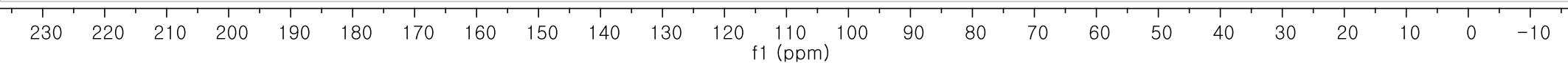


${ }^{1} \mathrm{H}$ NMR (400 MHz, $\mathrm{CDCl}_{3}$ ) spctrum of compound 25

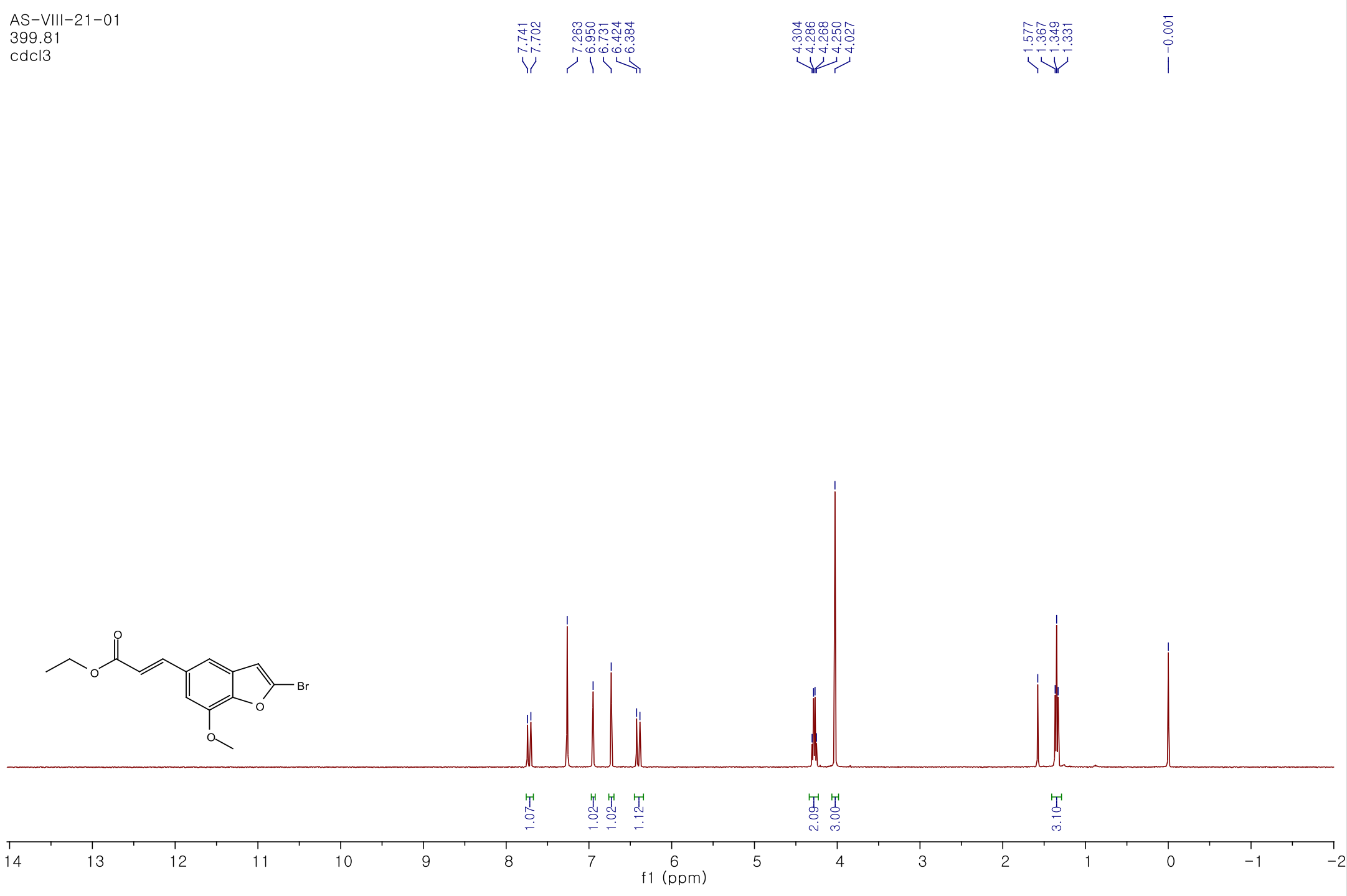


${ }^{13} \mathrm{C}$ NMR $\left(100 \mathrm{MHz}, \mathrm{CDCl}_{3}\right)$ spectrum of compound 25

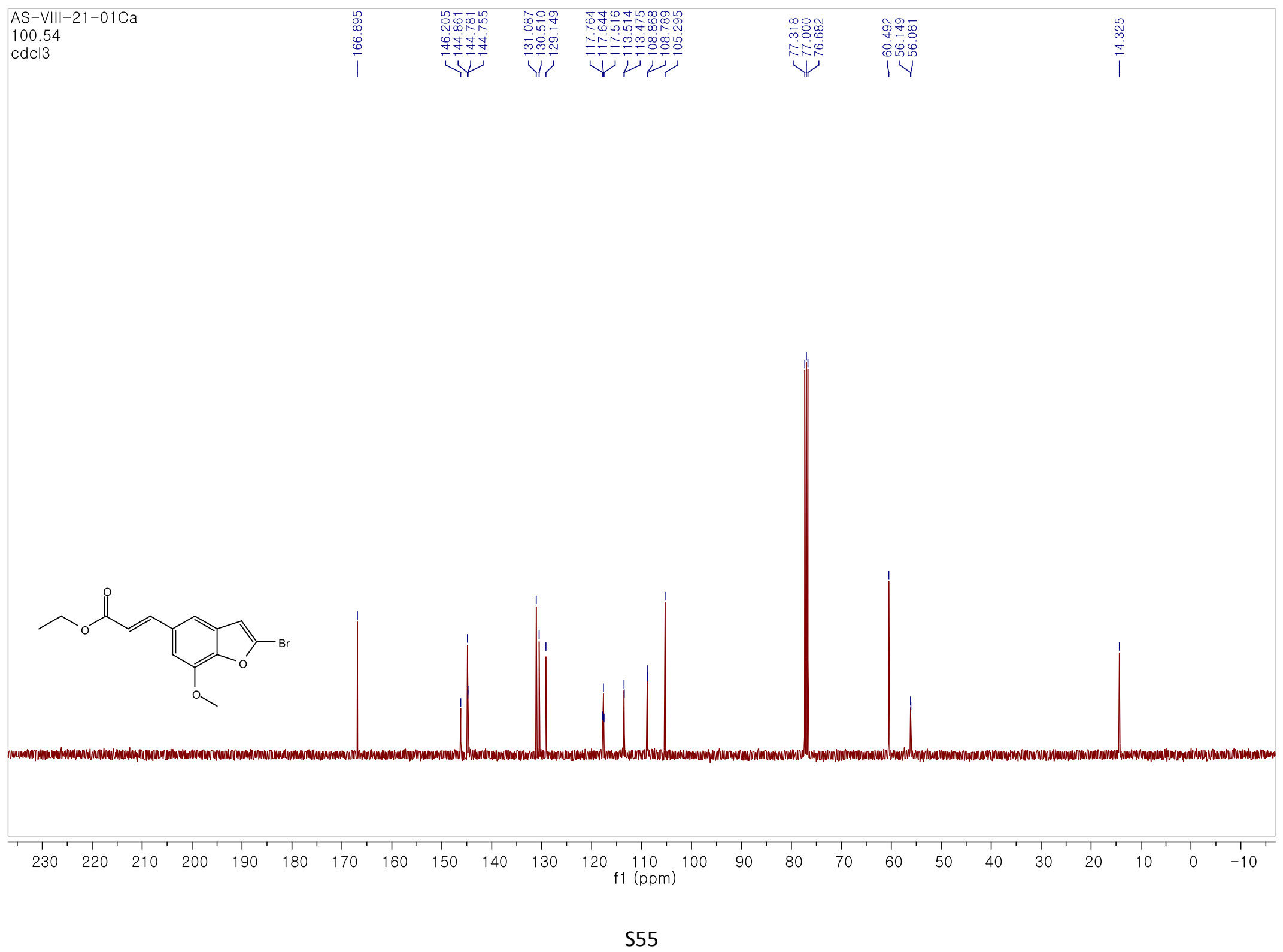


${ }^{1} \mathrm{H}$ NMR (400 MHz methanol- $d_{4}$ ) spctrum of compound 26

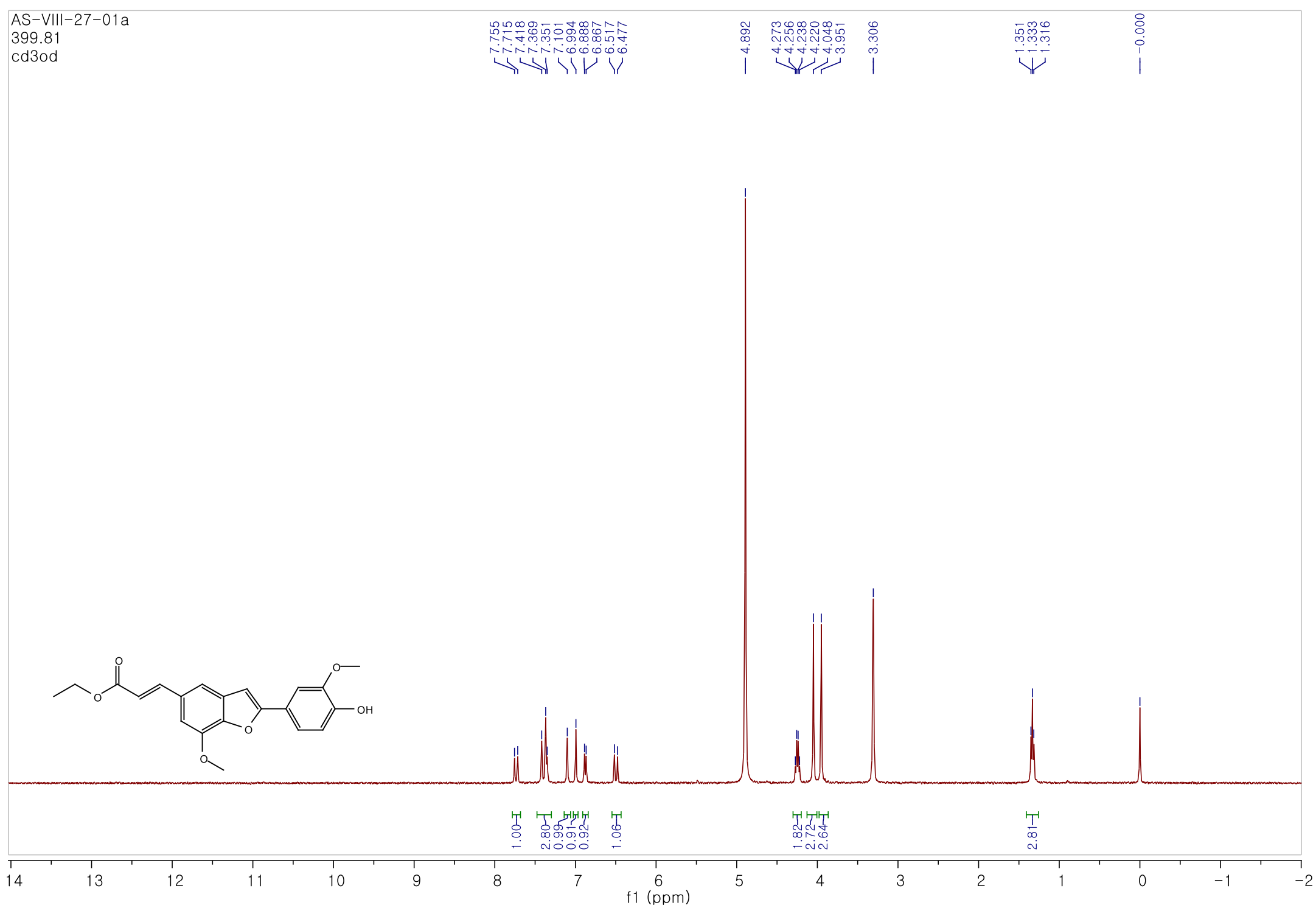


${ }^{13} \mathrm{C}$ NMR $\left(100 \mathrm{MHz}, \mathrm{CDCl}_{3}\right)$ spctrum of compound 26

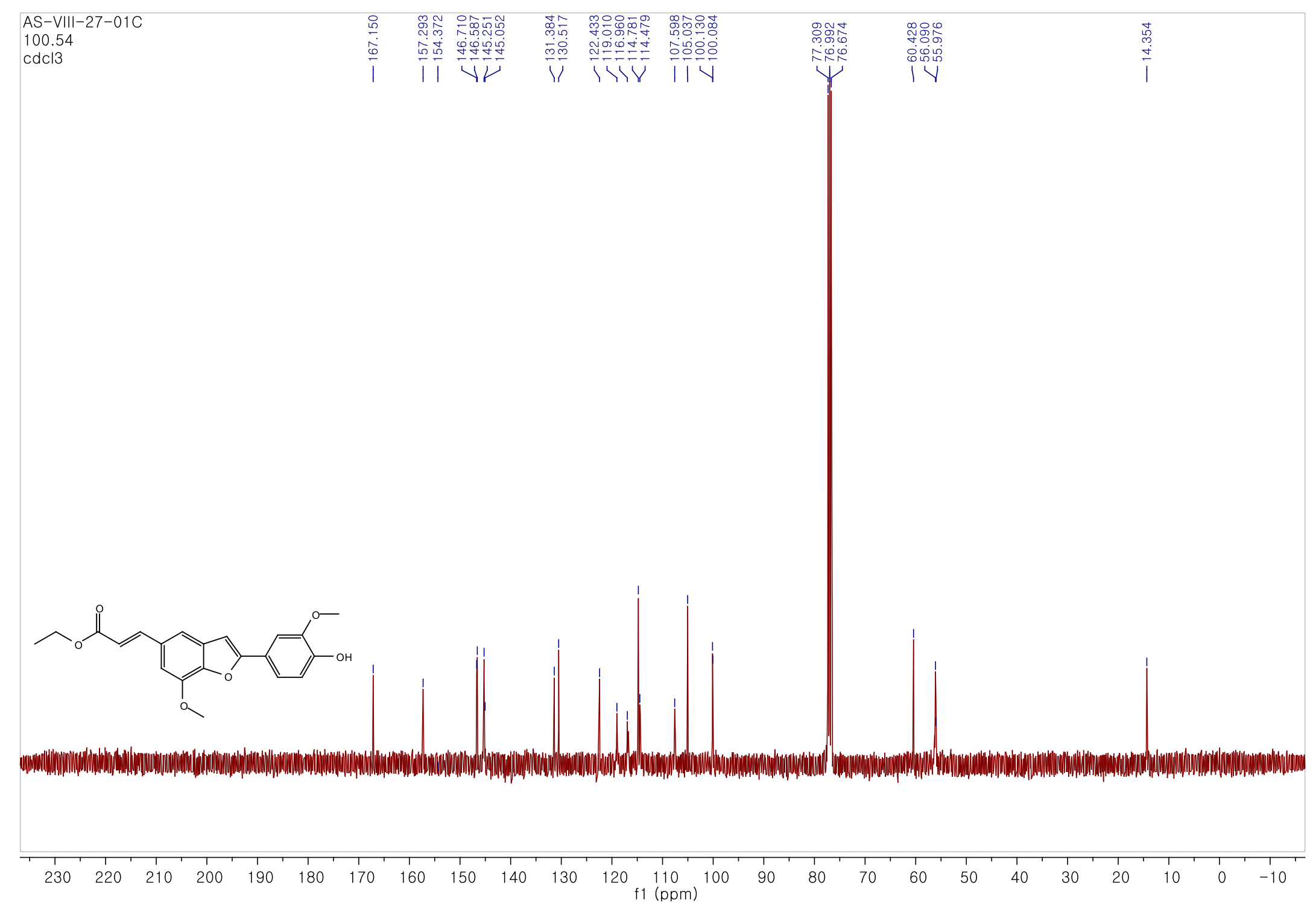


${ }^{1} \mathrm{H}$ NMR (400 MHz, $\mathrm{CDCl}_{3}$ ) spctrum of compound 27

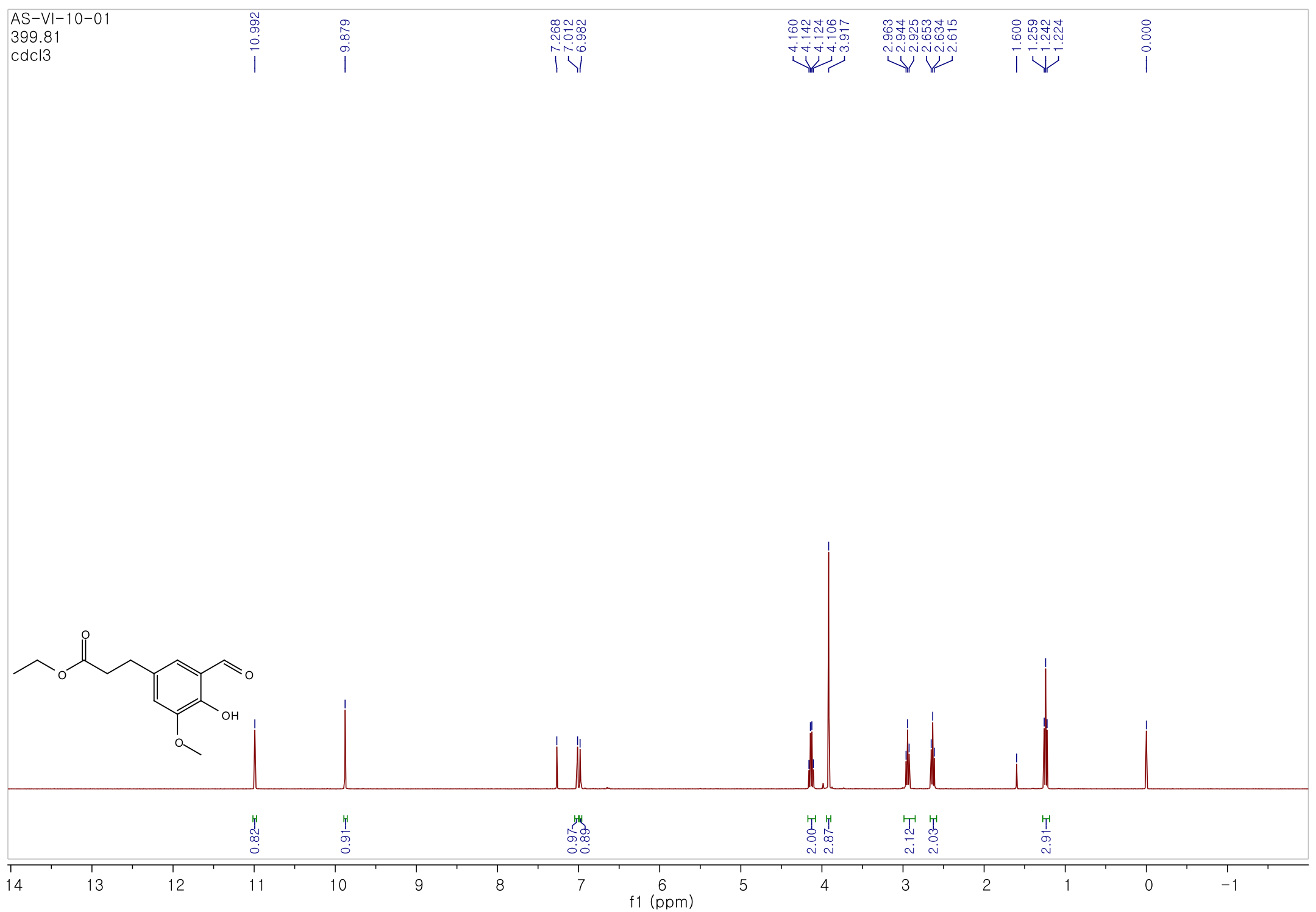


${ }^{13} \mathrm{C} \mathrm{NMR}\left(100 \mathrm{MHz}, \mathrm{CDCl}_{3}\right)$ spectrum of compound 27

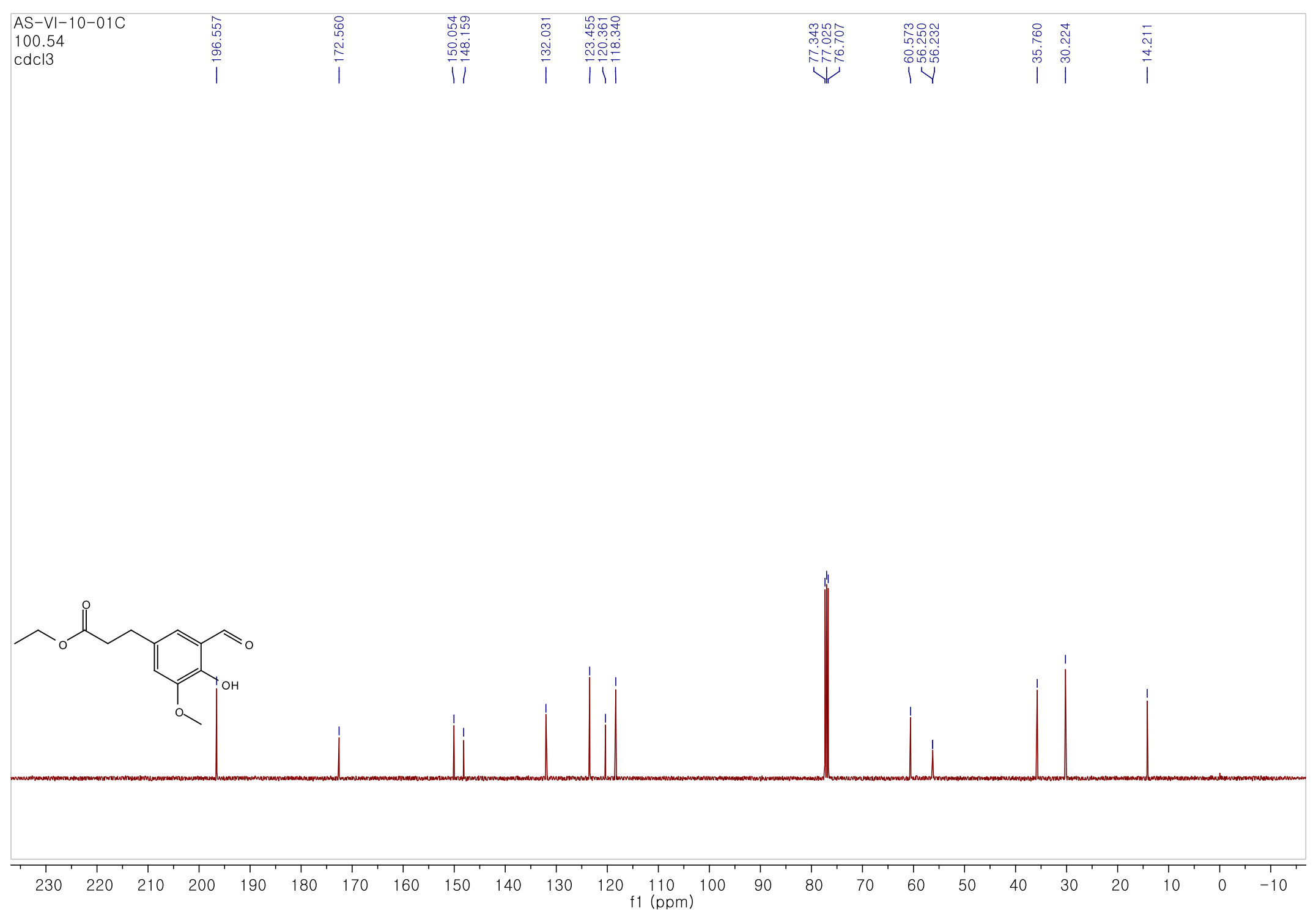


${ }^{1} \mathrm{H}$ NMR (400 MHz, $\mathrm{CDCl}_{3}$ ) spctrum of compound 28

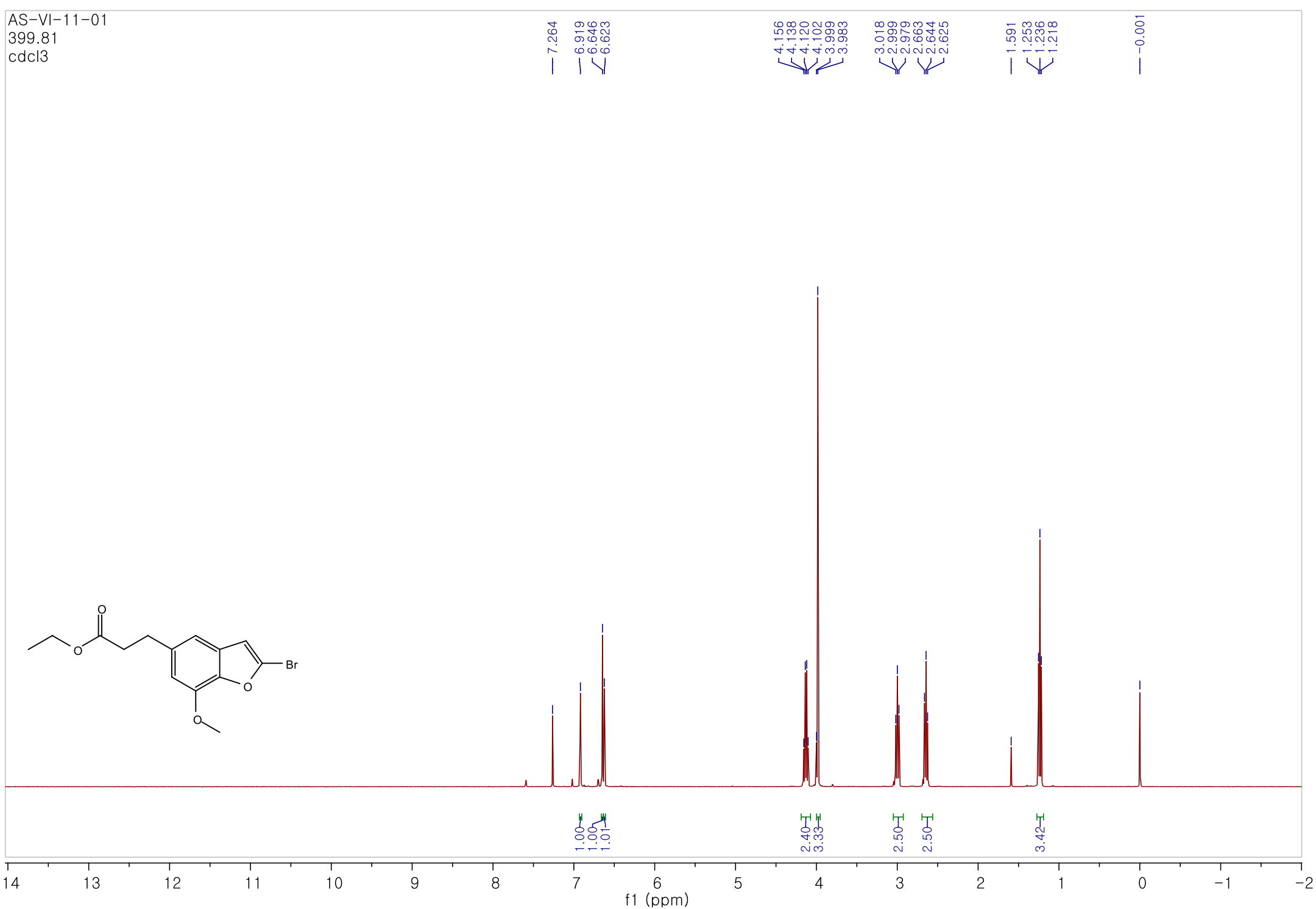


${ }^{13} \mathrm{C}$ NMR $\left(100 \mathrm{MHz}, \mathrm{CDCl}_{3}\right)$ spectrum of compound 28

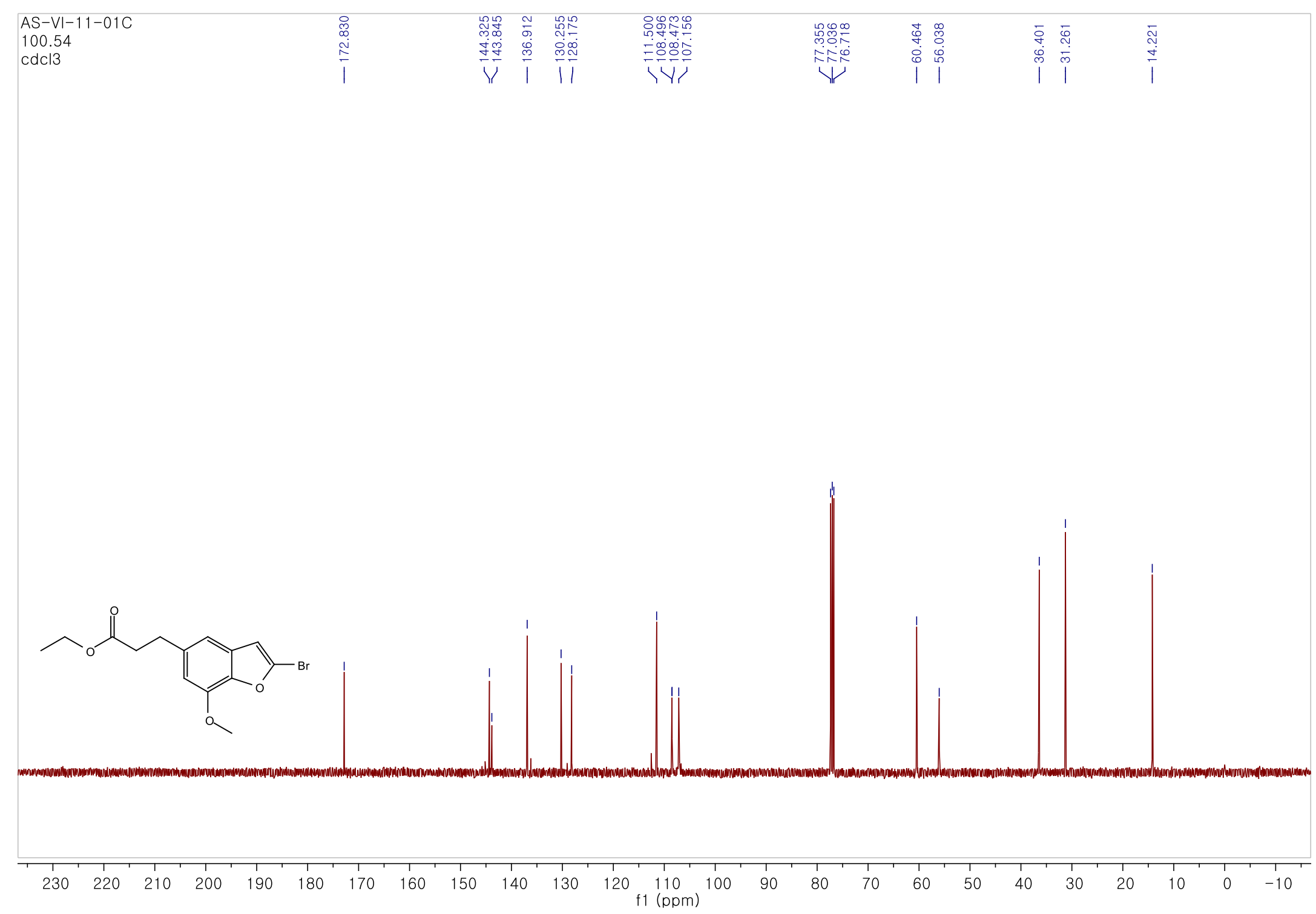


${ }^{1} \mathrm{H}$ NMR (400 MHz, $\mathrm{CDCl}_{3}$ ) spctrum of compound 29a

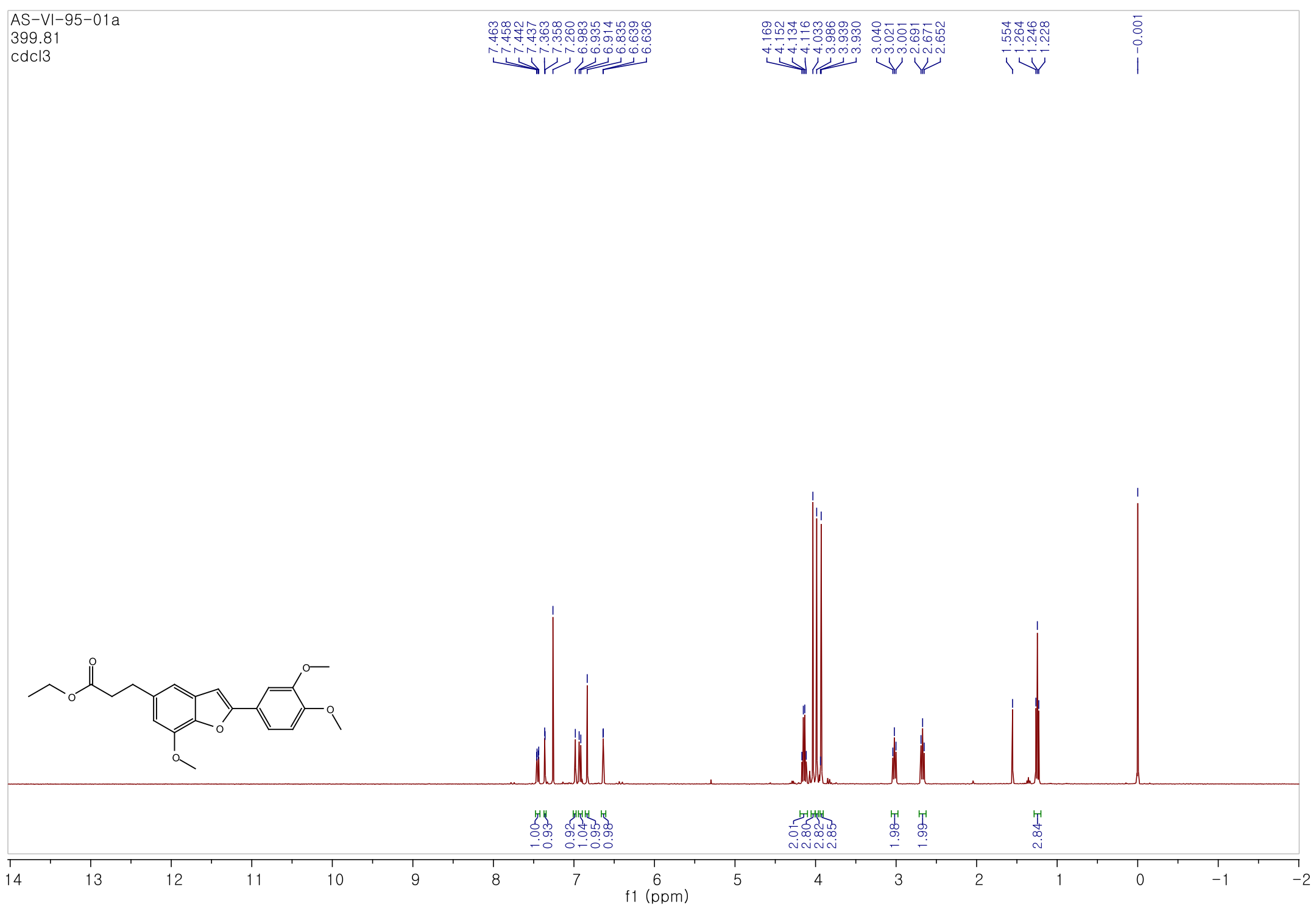


${ }^{13} \mathrm{C}$ NMR (100 MHz, $\mathrm{CDCl}_{3}$ ) spectrum of compound 29a
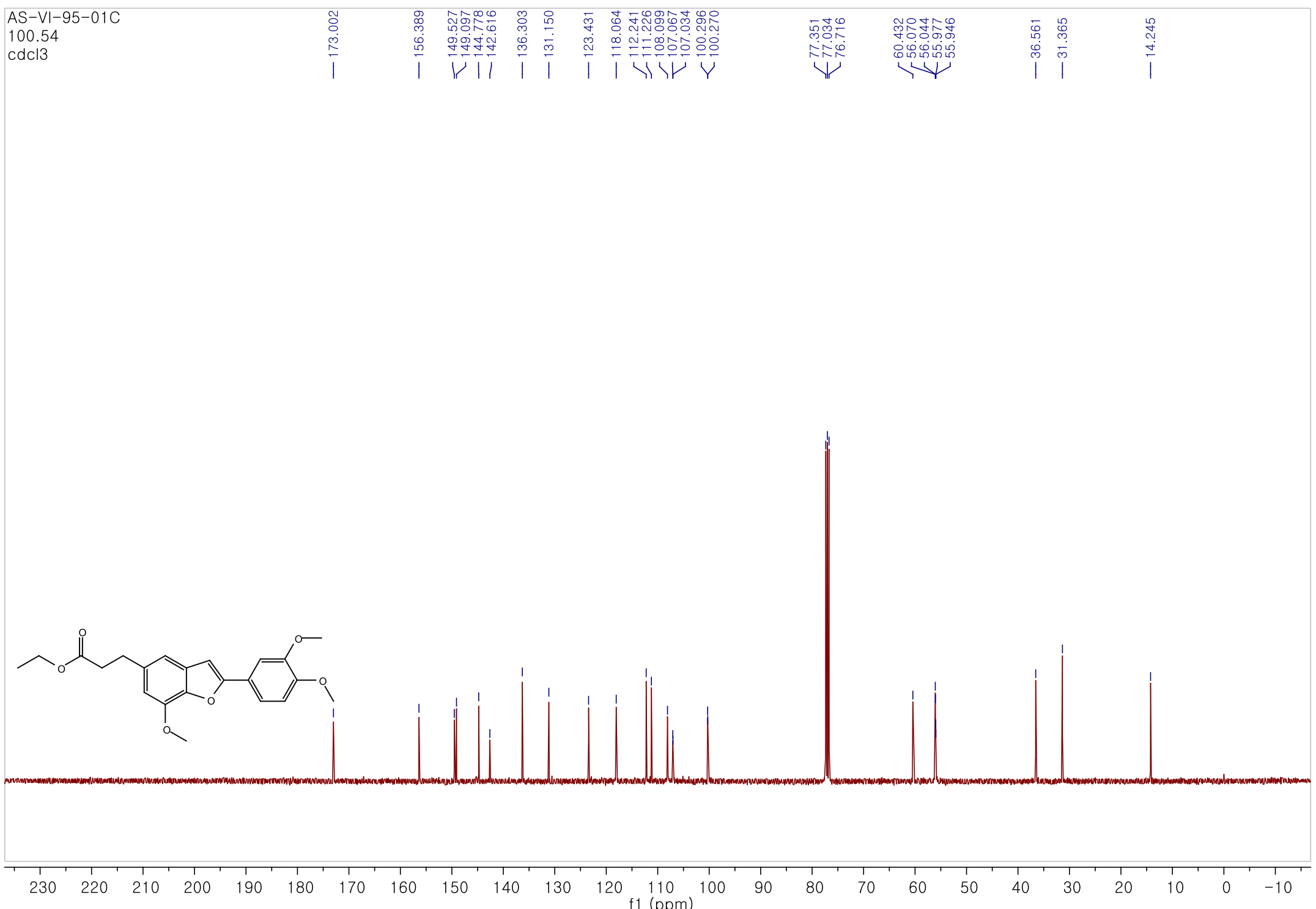
${ }^{1} \mathrm{H}$ NMR (400 MHz, $\mathrm{CDCl}_{3}$ ) spctrum of compound 29b

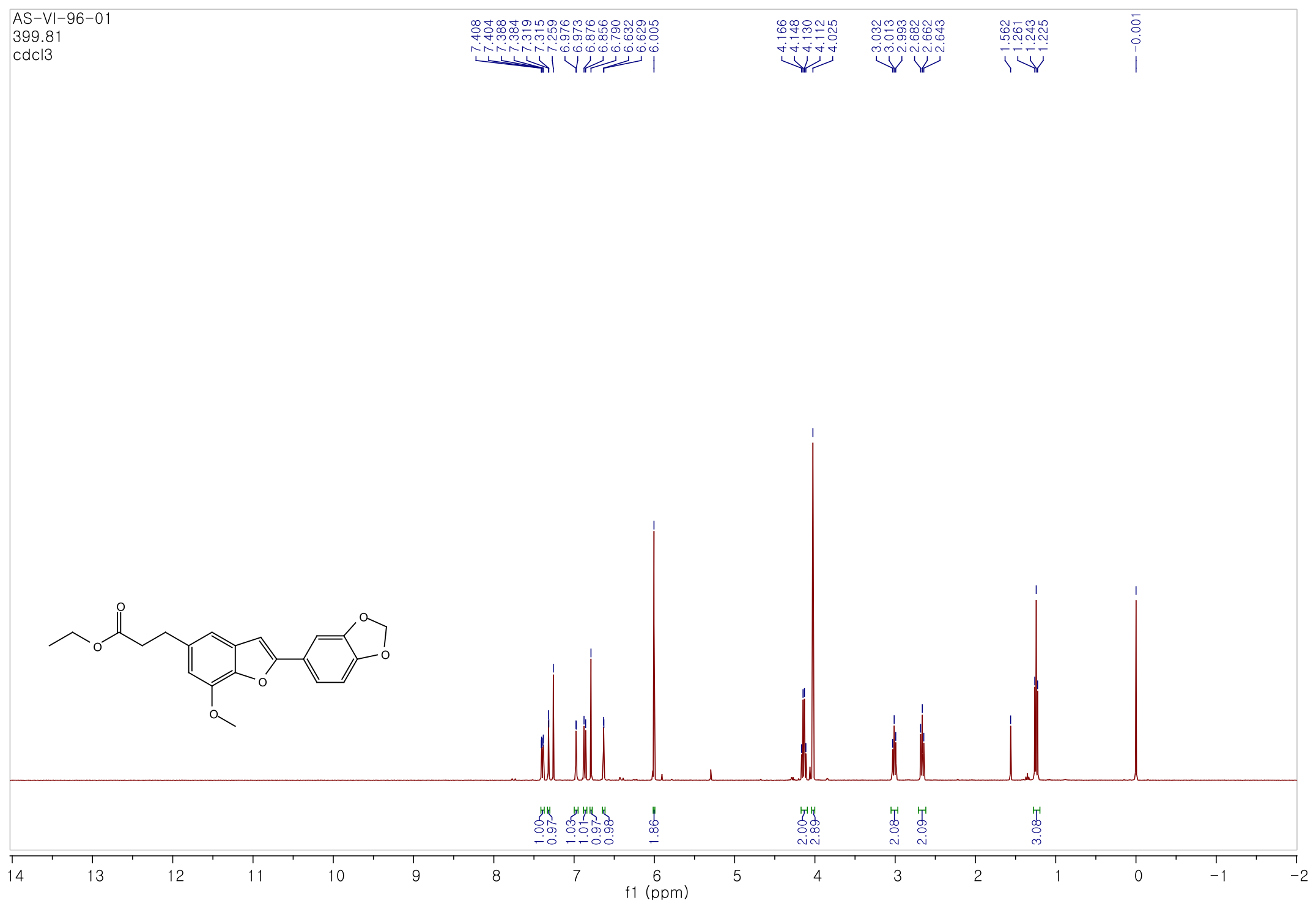


${ }^{13} \mathrm{C}$ NMR $\left(100 \mathrm{MHz}, \mathrm{CDCl}_{3}\right)$ spectrum of compound 29b
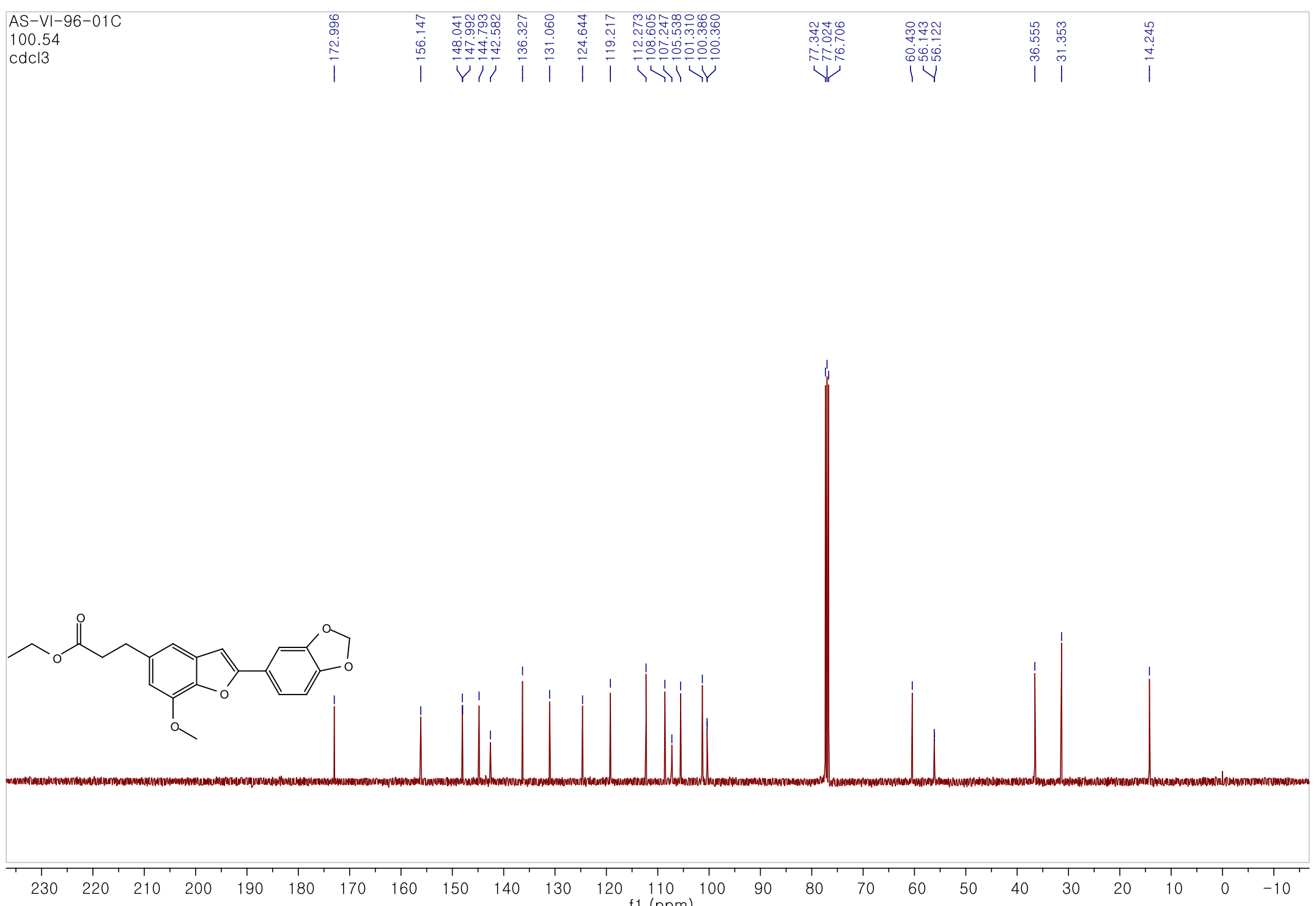


\section{HRMS Analysis}

\section{Compound 1}

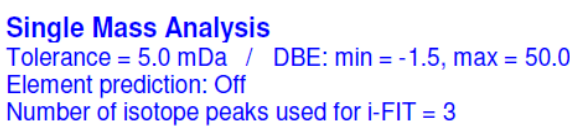

Number of isotope peaks used for $\mathrm{i}-\mathrm{FIT}=3$

Monoisotopic Mass, Even Electron lons

57 formula(e) evaluated with 1 results within limits (all results (up to 1000) for each mass)

Elements Used:

C: $0-500$ H: $0-1000$ O: $0-20$

AS-VIII-25-01 497 (8.528)

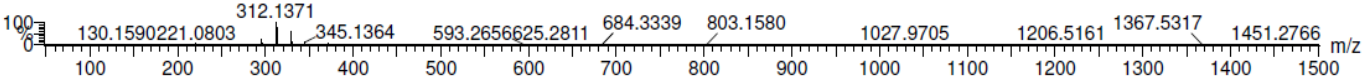

$.08 \mathrm{e}+004$ $\begin{array}{llll}\text { Minimum: } & & & \\ \text { Maximum: } & 5.0 & 10.0 & 50.0\end{array}$

Mass Calc. Mass mDa PPM DBE i-FIT Norm Conf $\left(\frac{2}{8}\right)$ Formula

$\begin{array}{llllllllll}313.1440 & 313.1440 & 0.0 & 0.0 & 9.5 & 382.5 & \mathrm{n} / \mathrm{a} & \mathrm{n} / \mathrm{a} & \mathrm{C} 19 \text { H21 }\end{array}$

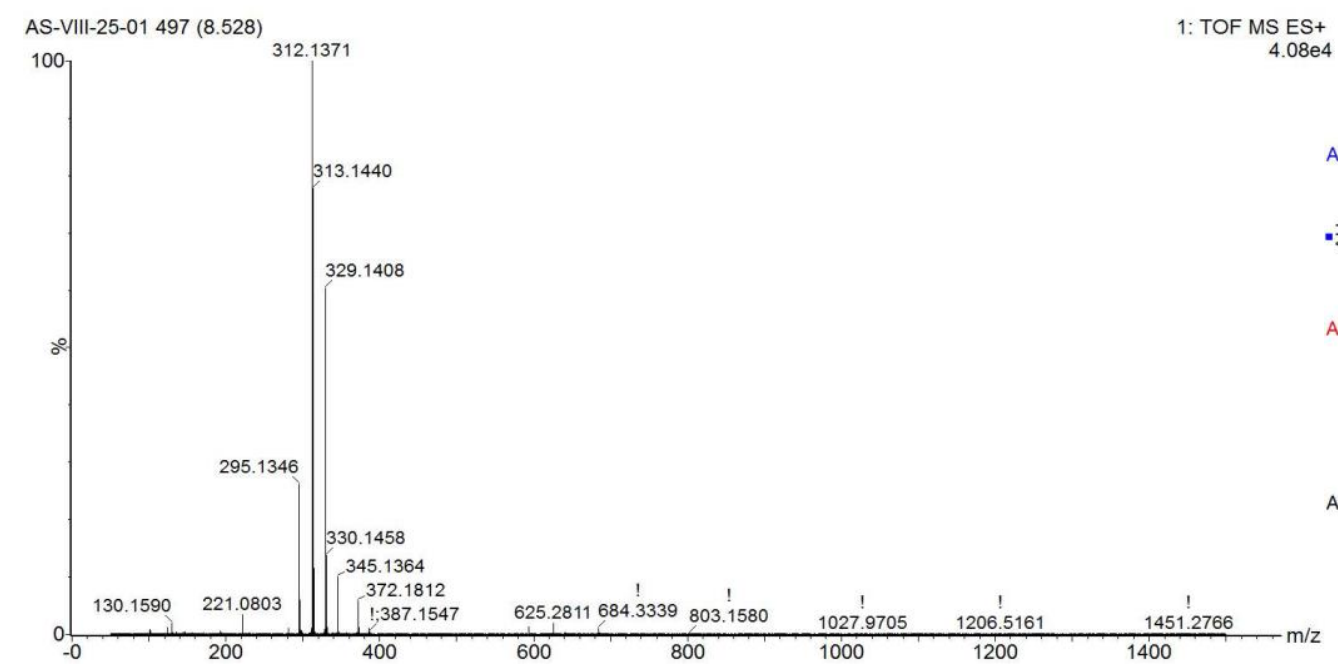

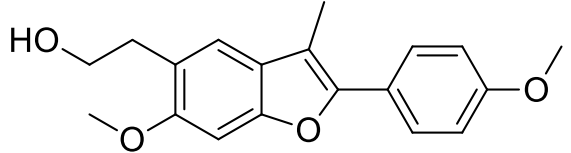

Chemical Formula: $\mathrm{C}_{19} \mathrm{H}_{20} \mathrm{O}_{4}$ Exact Mass: 312.1362

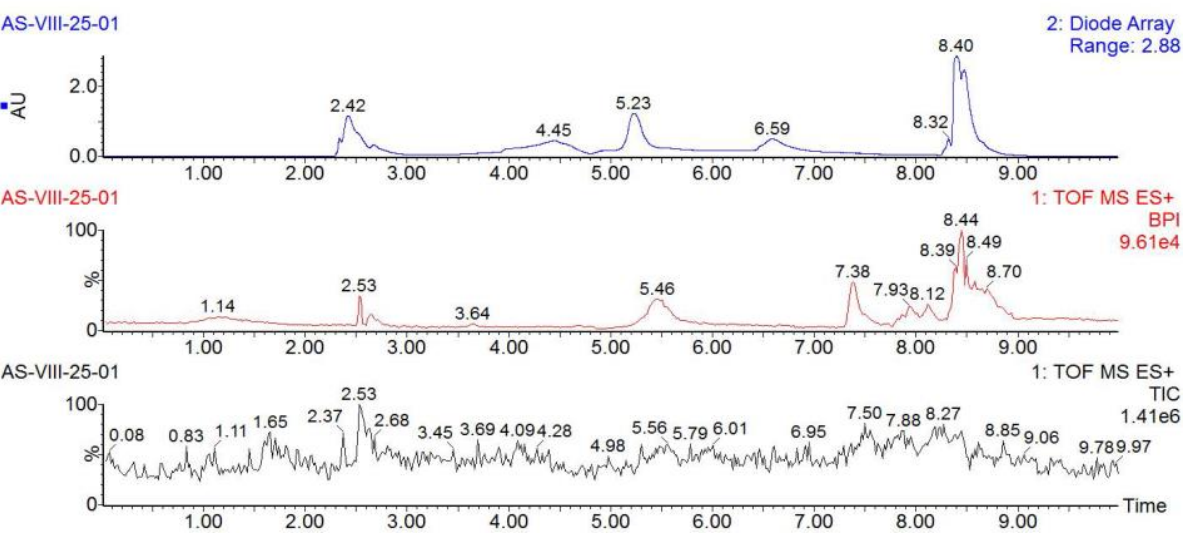




\section{Compound 2}

Single Mass Analysis

Tolerance $=5.0 \mathrm{mDa} /$ DBE: $\min =-1.5, \max =50.0$

Number of isotope peaks used for i-FIT $=3$

Monoisotopic Mass, Even Electron Ions

56 formula(e) evaluated with 1 results within limits (all results (up to 1000) for each mass)

$\begin{array}{ll}\text { Elements Used: } & \text { H: } 0-500 \\ \text { H: } 0-1000 & \text { O: } 0-20\end{array}$

AS-VIII-91-01 461 (7.911)

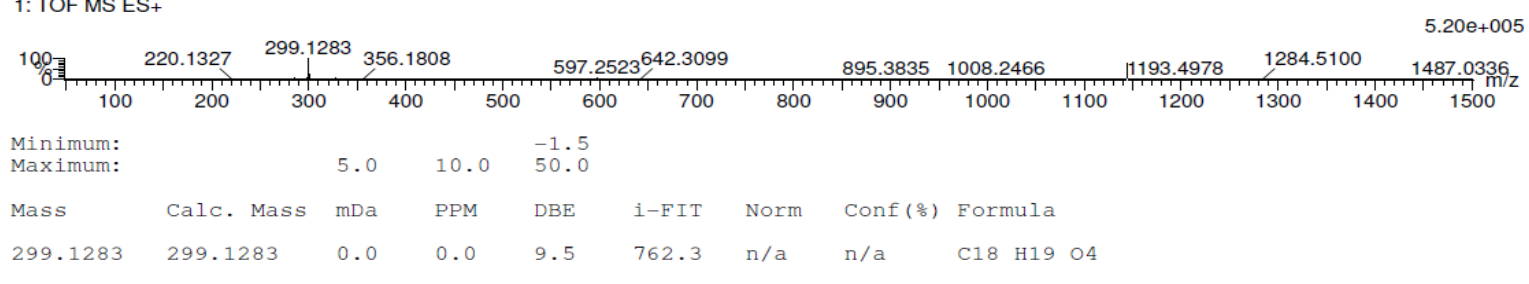

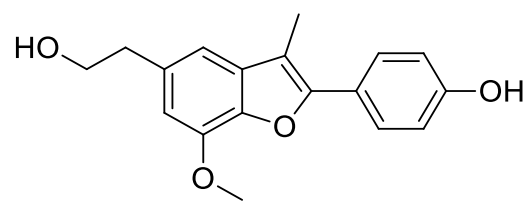

Chemical Formula: $\mathrm{C}_{18} \mathrm{H}_{18} \mathrm{O}_{4}$ Exact Mass: 298.1205
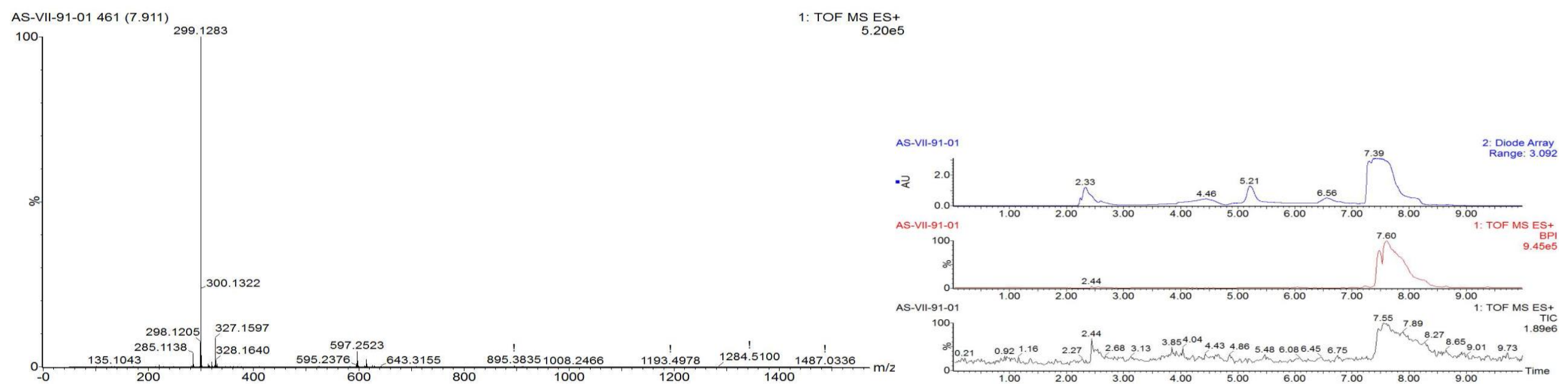


\section{Compound 3}

Single Mass Analysis

olerance $=5.0 \mathrm{mDa} /$ DBE: $\min =-1.5, \max =50.0$

Tolerance $=5.0 \mathrm{mDa}$ :

Number of isotope peaks used for $\mathrm{i}-\mathrm{FIT}=3$

Monoisotopic Mass, Even Electron Ions

(a)

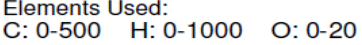

AS-VIII-92-01 $483(8.288)$

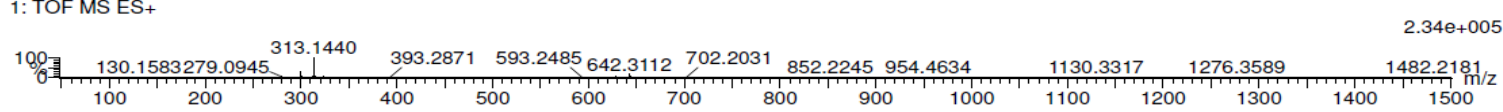

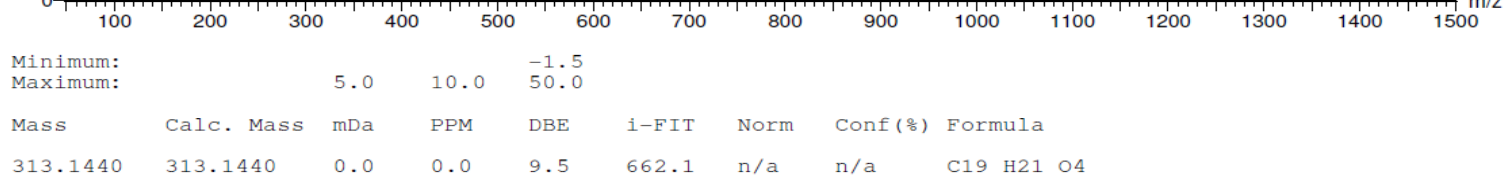

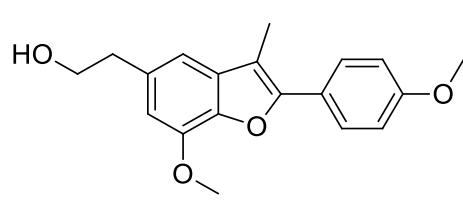

Chemical Formula: $\mathrm{C}_{19} \mathrm{H}_{20} \mathrm{O}_{4}$ Exact Mass: 312.1362

\footnotetext{
$\begin{array}{ll}\text { AS-VII-92-01 } 483(8.288) \\ 313.1440 & 1: \text { TOF MS ES+ } \\ 2.34 \mathrm{e}^{-} & \end{array}$
}
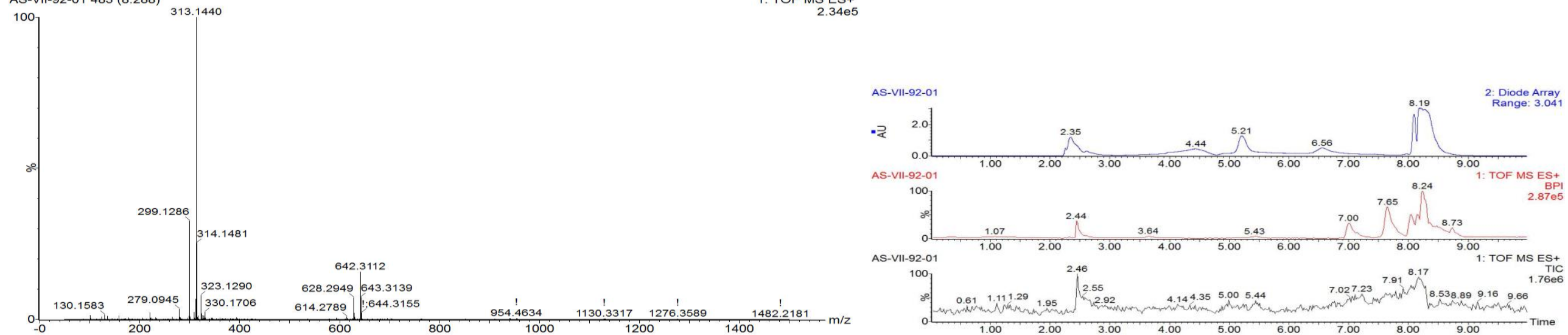


\section{Compound 4}

\section{Single Mass Analysis}

Tolerance $=5.0 \mathrm{mDa} /$ DBE: $\min =-1.5, \max =50.0$

Element prediction: Off

Number of isotope peaks used for i-FIT $=3$

Monoisotopic Mass, Even Electron lons

56 formula(e) evaluated with 1 results within limits (all results (up to 1000) for each mass)

Elements Used:

C: $0-500 \quad \mathrm{H}: 0-1000 \quad$ O: 0-20

AS-VIII-23-01 $463(7.946)$

1: TOF MS ES+

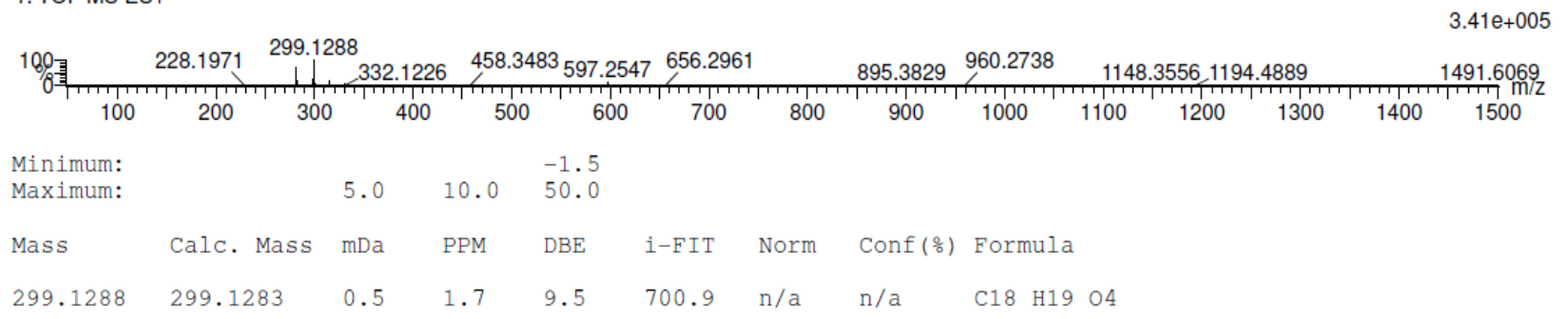

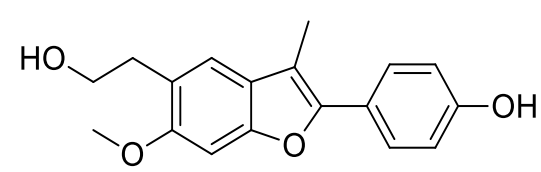

Chemical Formula: $\mathrm{C}_{18} \mathrm{H}_{18} \mathrm{O}_{4}$ Exact Mass: 298.1205
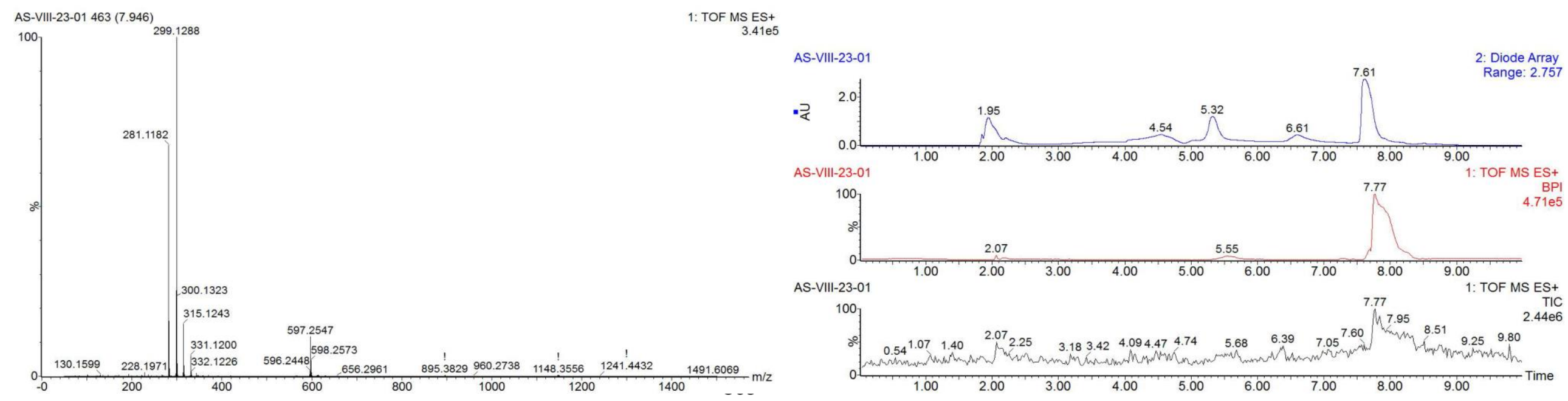


\section{Compound 5}

Single Mass Analysis

Tolerance $=5.0 \mathrm{mDa} /$ DBE: $\min =-1.5, \max =50.0$

Element prediction: Off

Number of isotope peaks used for i-FIT $=3$

Monoisotopic Mass, Even Electron lons

48 formula(e) evaluated with 1 results within limits (all results (up to 1000) for each mass)

Elements Used:

C: $0-500$ H: $0-1000$ O: $0-20$

AS-VIII-24-01 454 (7.791)

1: TOF MS ES+

$4.50 \mathrm{e}+005$

180 $207.0641 \quad 285.1129$

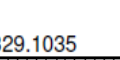

569.22246022327

835.3113869.3541

1147.3396 $\frac{1422.4806}{m / 2}$

Minimum:

Maximum:

$5.0-1.5$

Mass Calc. Mass mDa PPM DBE

285.1129

mDa PPM DB

i-FIT Norm Conf (\%) Formula

$708.6 \mathrm{n} / \mathrm{a} \quad \mathrm{n} / \mathrm{a} \quad \mathrm{C} 17 \mathrm{H} 17 \mathrm{O}$
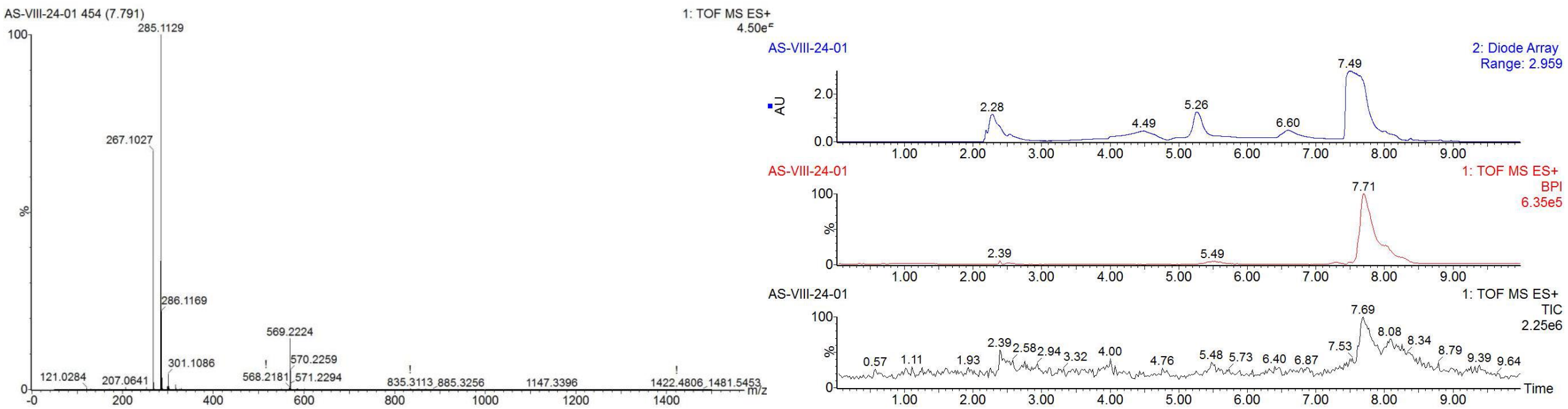


\section{Compound 6}

\section{Single Mass Analysis}

Tolerance $=5.0 \mathrm{mDa}$ / DBE: $\min =-1.5, \max =50.0$

Element prediction: Of

Number of isotope peaks used for i-FIT $=3$

Monoisotopic Mass, Even Electron lons

56 formula(e) evaluated with 1 results within limits (all results (up to 1000) for each mass)

$\begin{array}{lll}\text { C: } 0-500 & \text { H: } 0-1000 & \text { O: } 0-20\end{array}$

AS-VIII-26-01-2 491 (8.426)
1: TOF MS ES+

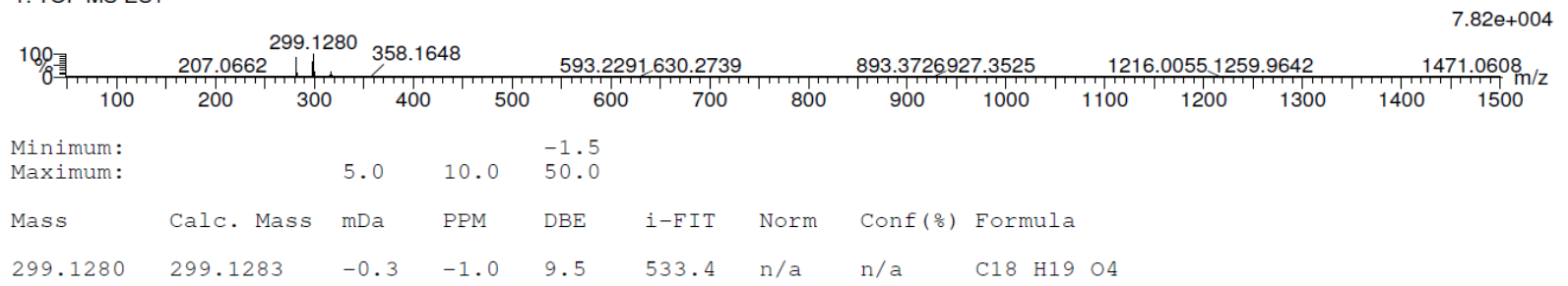

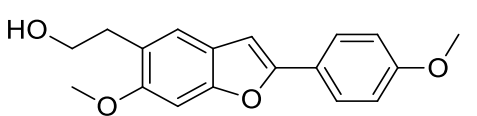

Chemical Formula: $\mathrm{C}_{18} \mathrm{H}_{18} \mathrm{O}_{4}$ Exact Mass: 298.1205
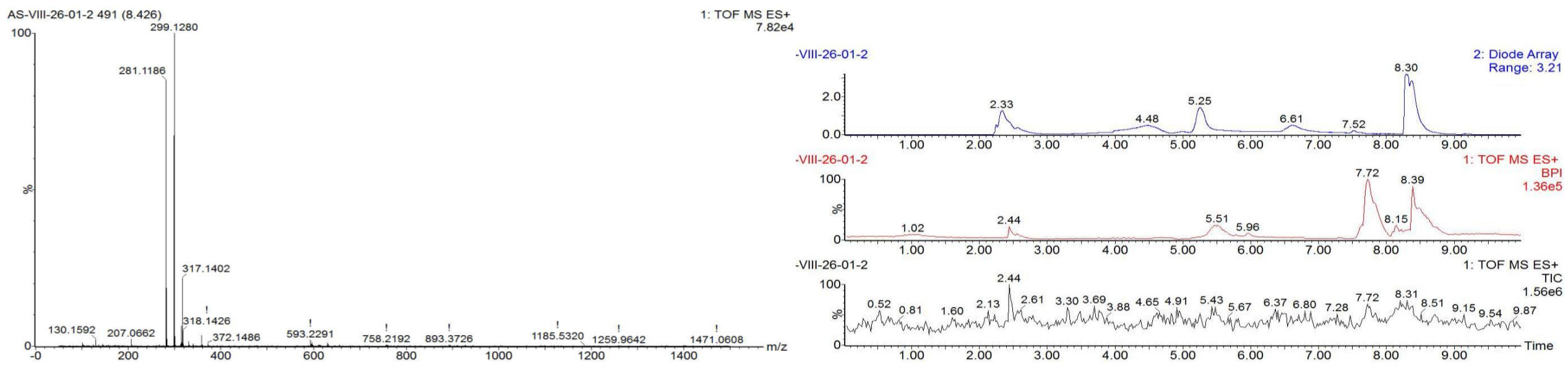


\section{Compound 7}

Single Mass Analysis

DBE: $\min =-1.5, \max =50.0$

Element prediction: Of

Number of isotope peaks used for $\mathrm{i}$-FIT $=3$

Monoisotopic Mass, Even Electron Ions

(all results (up to 1000) for each mass)

Elements Used: $0-500 \quad$ H: $0-1000$ O: 0-20
C.

AS-VI-90-01-2 $451(7.740$

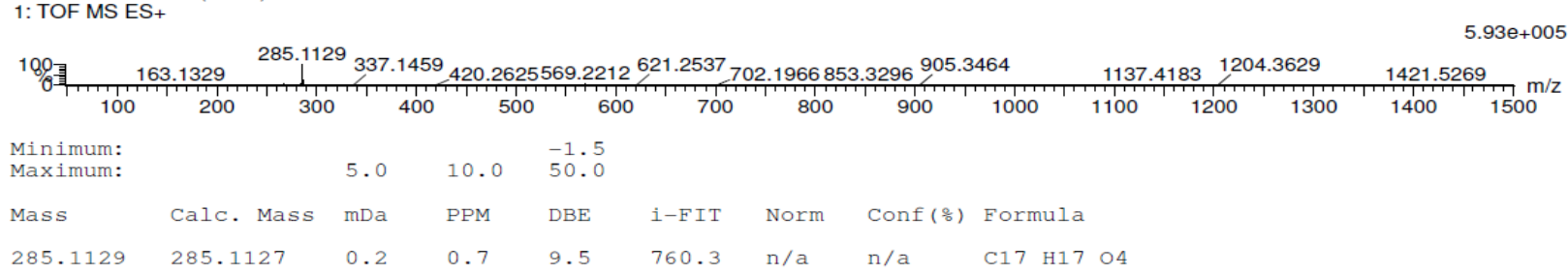

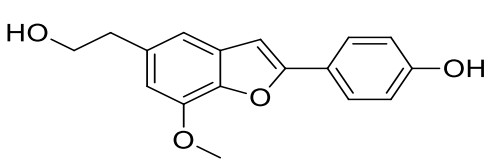

Chemical Formula: $\mathrm{C}_{17} \mathrm{H}_{16} \mathrm{O}_{4}$ Exact Mass: 284.1049
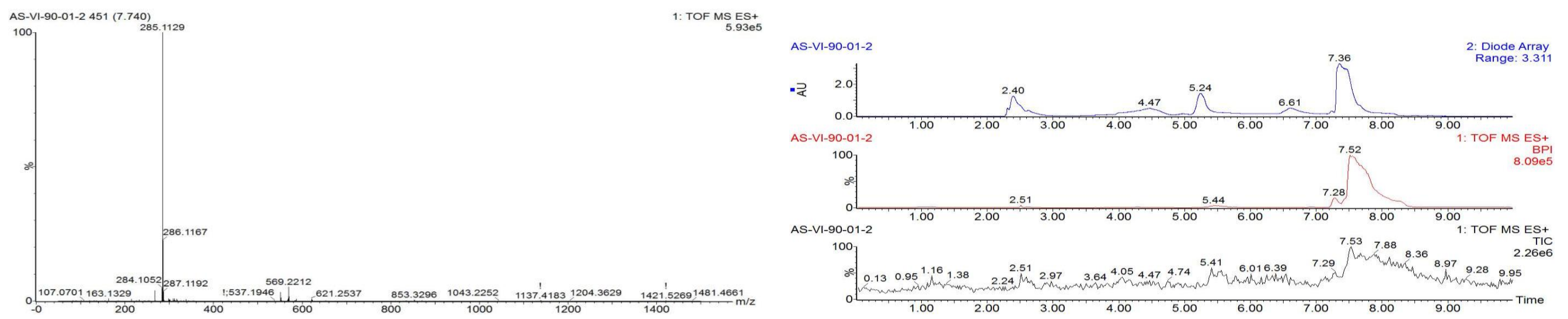


\section{Compound 8}

Single Mass Analysis

Tolerance $=5.0 \mathrm{mDa} /$ DBE: $\min =-1.5, \max =50.0$

Element prediction: Off

Number of isotope peaks used for $\mathrm{i}-\mathrm{FIT}=3$

\section{Monoisotopic Mass, Even Electron lons}

56 formula(e) evaluated with 2 results within limits (all results (up to 1000) for each mass)

Elements Used:

C: $0-500 \quad$ H: 0-1000 O: 0-20

AS-VIII-03-01 445 (7.637)

1: TOF MS ES+

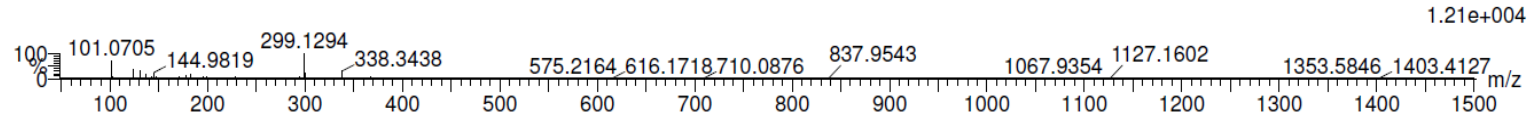

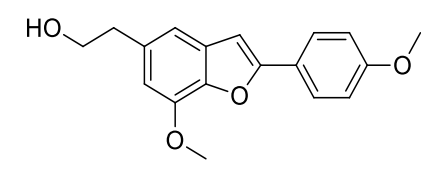

Chemical Formula: $\mathrm{C}_{18} \mathrm{H}_{18} \mathrm{O}_{4}$ Exact Mass: 298.1205

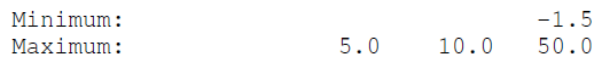$$
\text { Mass Calc. Mass mDa PPM DBE i-FIT Norm Conf }(\%) \text { Formula }
$$

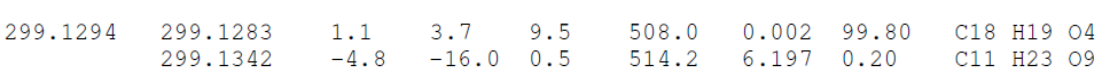
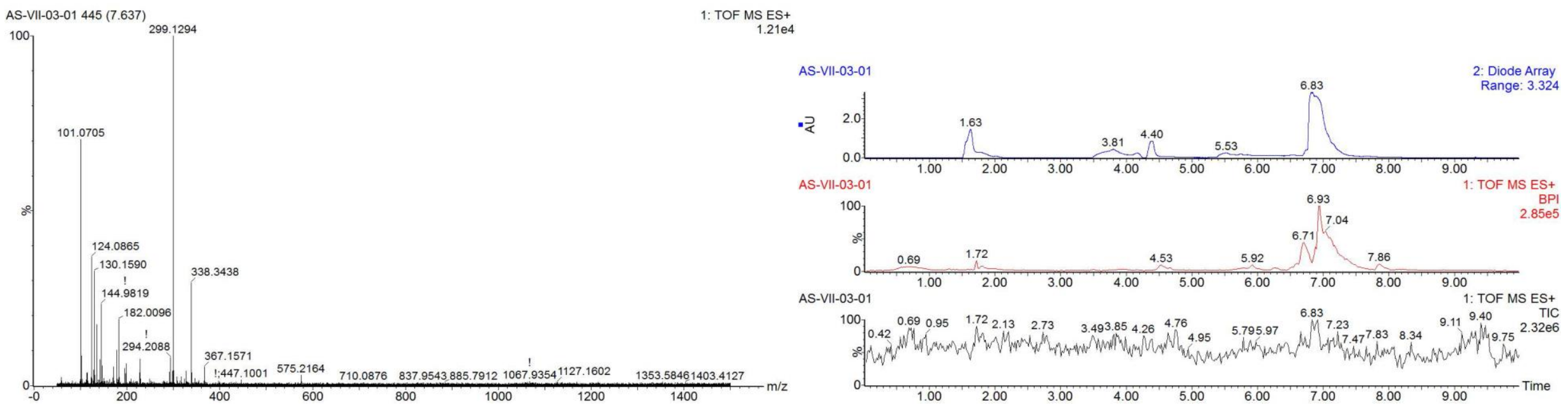
HPLC Analysis

Compound 1

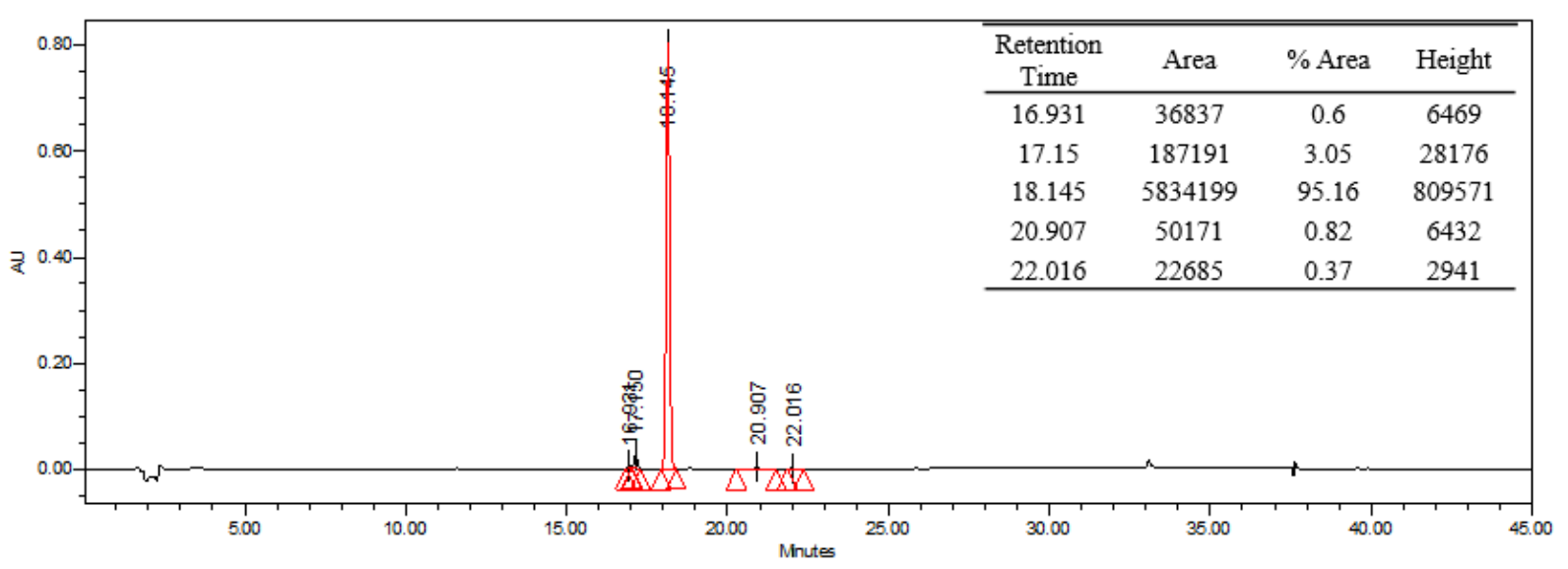

\section{Compound 2}

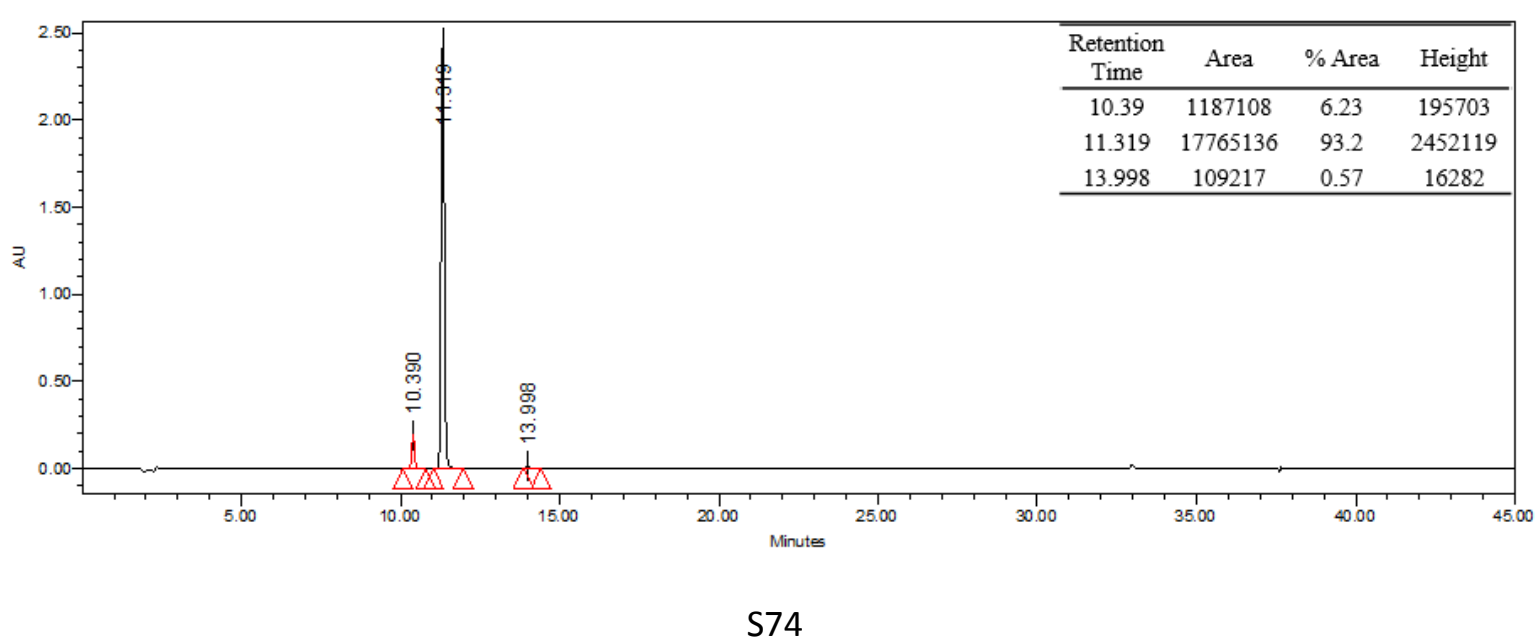




\section{Compound 3}

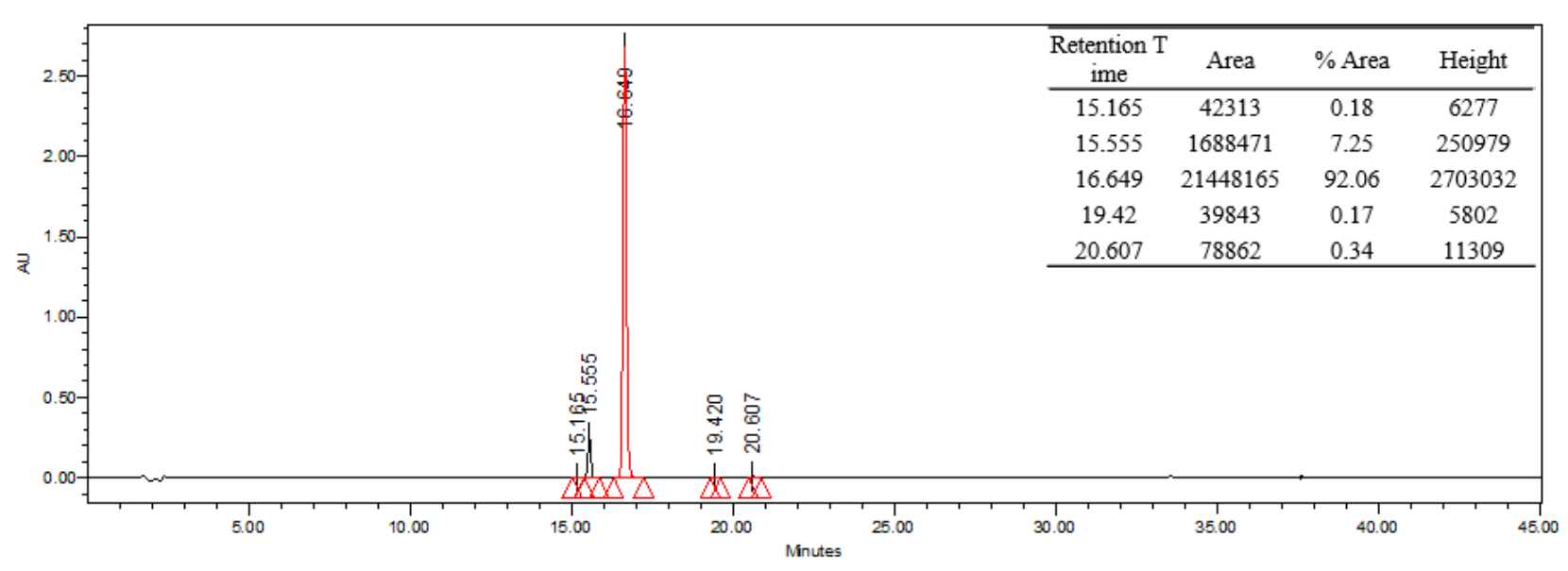

\section{Compound 4}

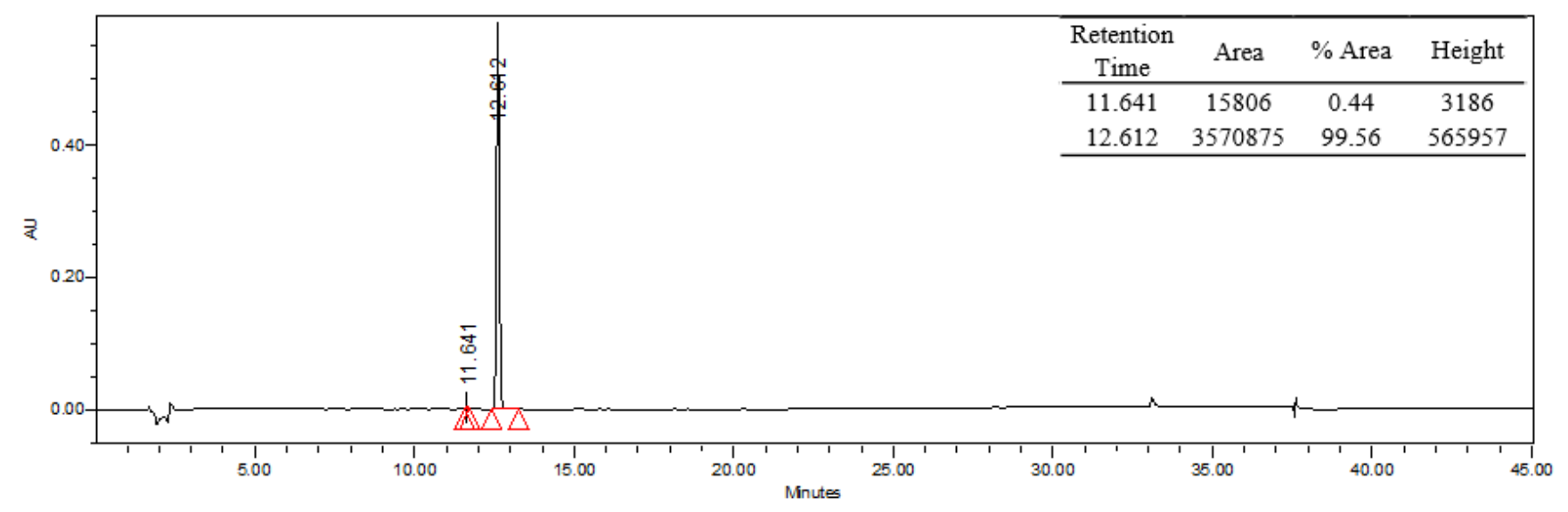


Compound 5

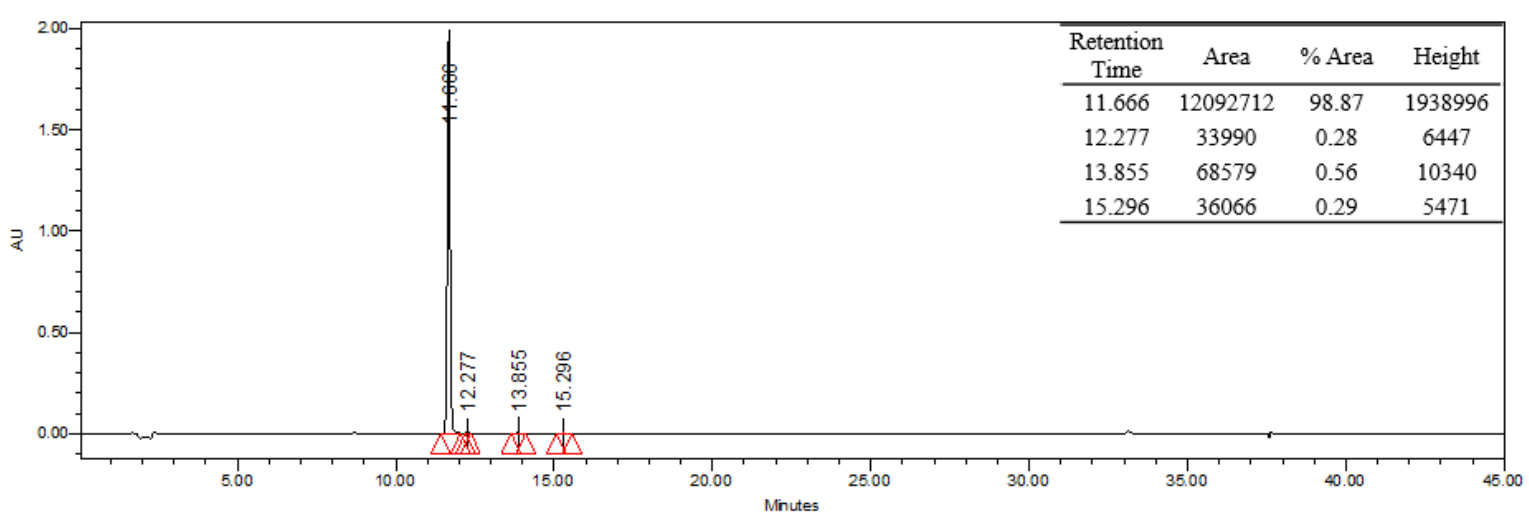

\section{Compound 6}

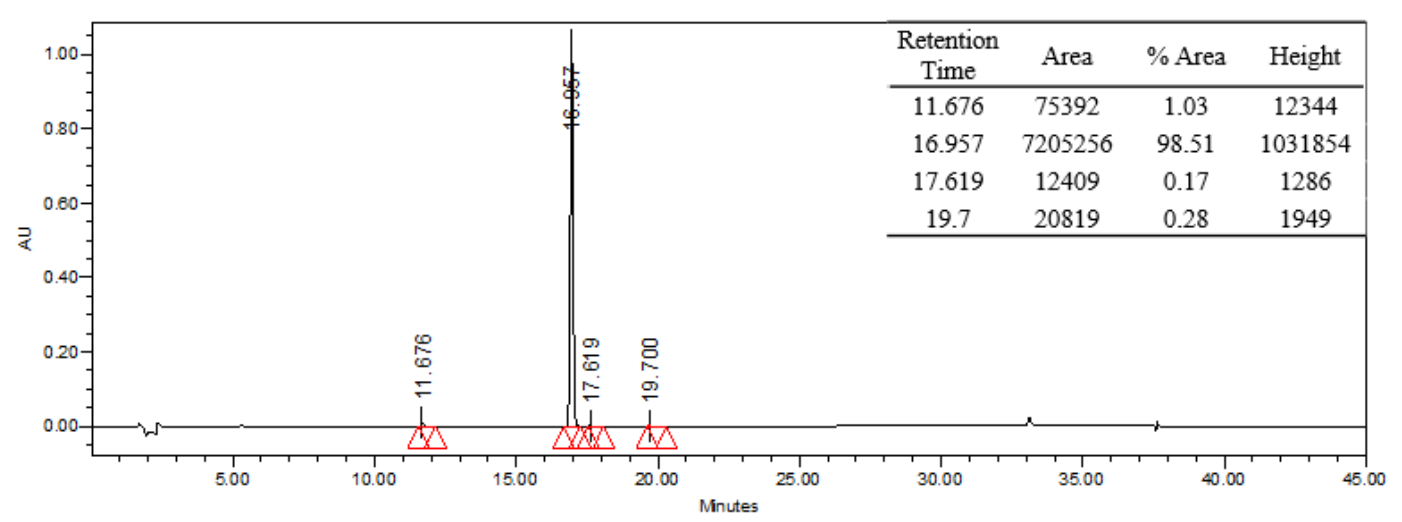




\section{Compound 7}

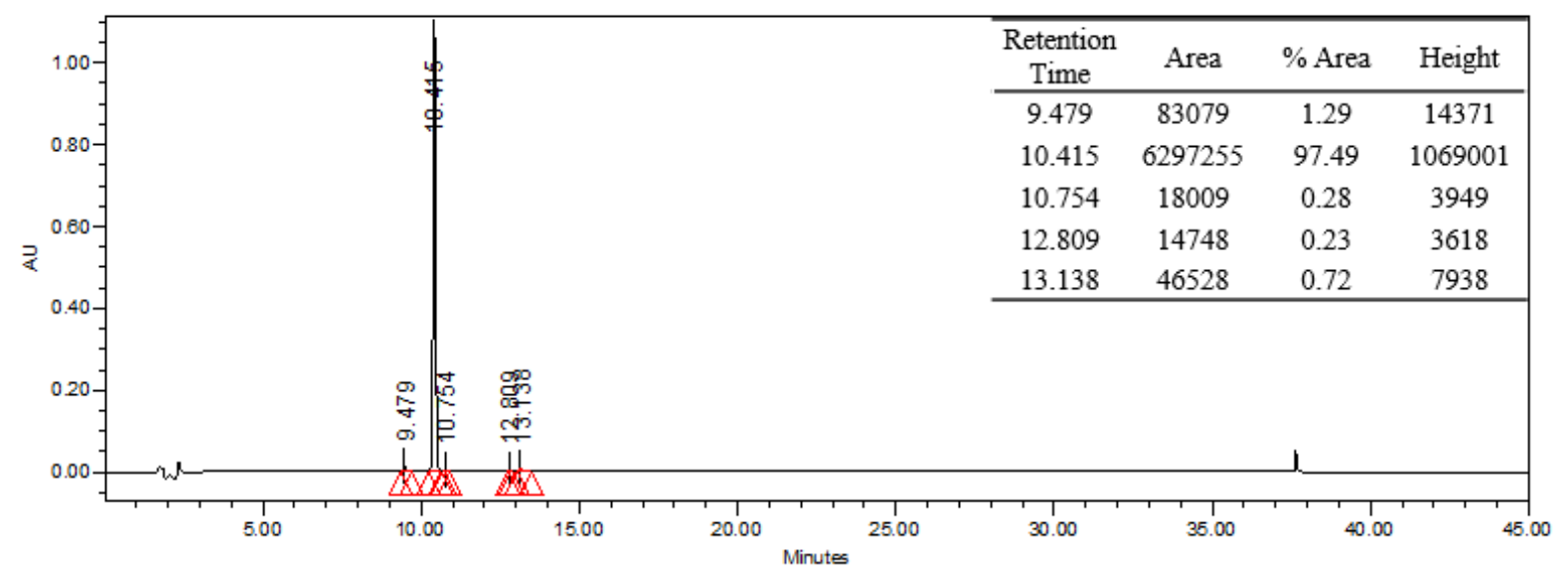

\section{Compound 8}

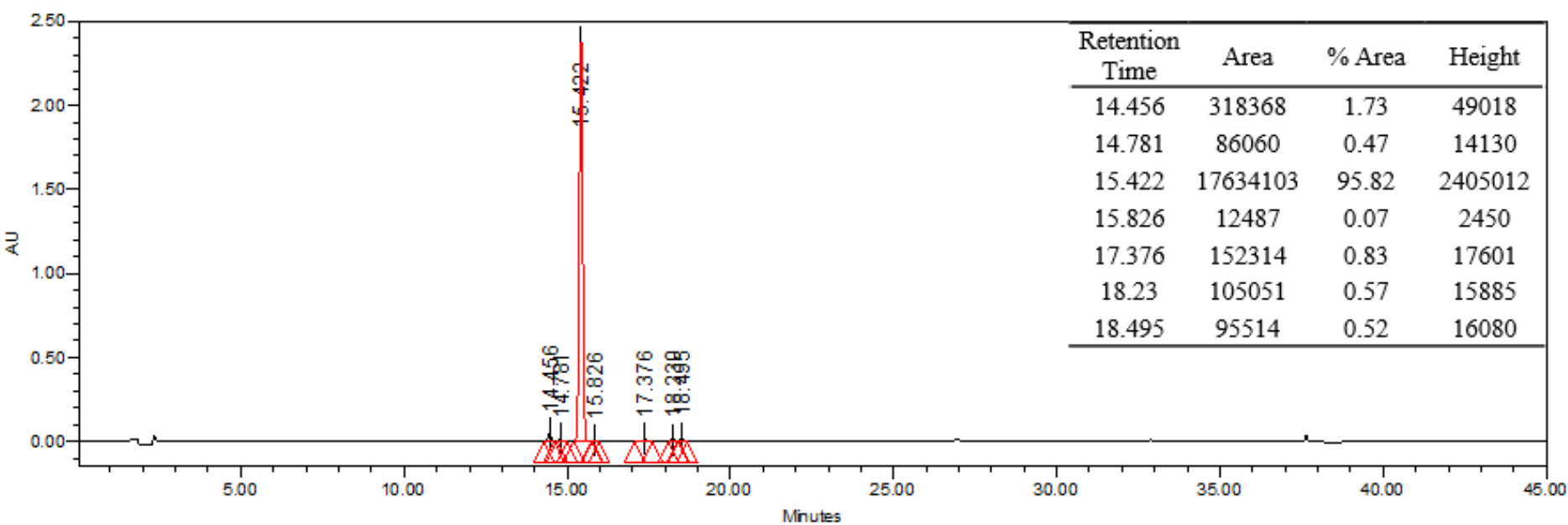

